Chapman University

Chapman University Digital Commons

Winter 12-2021

\title{
Special Education Parent Perceptions of Involvement and Parent-Educator Relationships During IEP Meetings at Nonpublic Schools
}

\author{
Alex Huynen \\ Chapman University, huynen@chapman.edu
}

Follow this and additional works at: https://digitalcommons.chapman.edu/education_dissertations

Part of the Disability and Equity in Education Commons

\section{Recommended Citation}

Huynen, A. M. (2021). Special education parent perceptions of involvement and parent-educator relationships during IEP meetings at nonpublic schools [Doctoral dissertation, Chapman University]. Chapman University Digital Commons. https://doi.org/10.36837/chapman.000331

This Dissertation is brought to you for free and open access by the Dissertations and Theses at Chapman University Digital Commons. It has been accepted for inclusion in Education (PhD) Dissertations by an authorized administrator of Chapman University Digital Commons. For more information, please contact laughtin@chapman.edu. 


\title{
Special Education Parent Perceptions of Involvement and Parent-Educator Relationships During IEP Meetings at Nonpublic Schools
}

\author{
A Dissertation by \\ Alex M. Huynen \\ Chapman University \\ Orange, CA \\ Attallah College of Educational Studies \\ Submitted in partial fulfillment of the requirements for the degree of Doctor \\ of Philosophy in Educational Studies
}

December 2021

Committee in charge:

Meghan Cosier, $\mathrm{PhD}$, Chair

Amy Jane Griffiths, PhD

Kelly Kennedy, PhD

John Brady, PhD 
The dissertation of Alex M. Huynen is approved.

\section{Meghan Cosier}

Meghan Cosier, PhD, Chair

Amy J Griffiths

Amy Griffiths, PhD

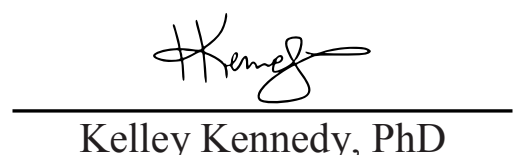

Kelley Kennedy, PhD

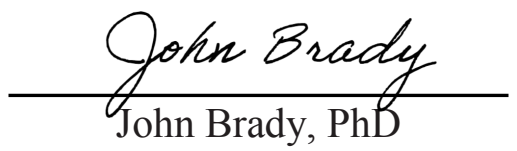

August 2021 
Special Education Parent Perceptions of Involvement and ParentEducator Relationships During IEP Meetings at Nonpublic Schools

Copyright $\odot 2021$

by Alex M. Huynen 


\section{ACKNOWLEDGEMENTS}

I am so thankful for all the support and guidance provided to me throughout the process of writing this dissertation and during my time at Chapman. There are many people I would like to thank for their help during this journey. To all my committee members, thank you for all your time and energy. You helped me meet tough deadlines while continuing to push me to submit my best work. I would like to thank my two committee chairs, Dr. Amy Griffiths and Dr. Meghan Cosier. This past year threw a lot of challenges at all of us.

Dr. Amy Griffiths, thank you for your guidance when I was starting my dissertation and your continued advice to help me improve. Reading your feedback, which always included praise, help me understand my strengths and areas of growth throughout the writing process.

Dr. Meghan Cosier, thank you for being open to taking on the job of being my committee chair, even when I was halfway through the process. I am so grateful for your time and the much-needed advice on qualitative research methods and structure.

To Dr. Kelly Kennedy thank you for your positivity and constructive feedback. Your knowledge of quantitative research methods and statistics has been immensely helpful. Every time we have talked, I was always amazed by your knowledge, ideas, and professionalism.

I would like to thank Dr. John Brady for his work as a professor and as a member of my dissertation committee. Your funny, yet helpful comments during meetings always provided a much-needed laugh and helped me remember your advice.

To my Chapman cohort of 2017, I consider you all close friends. The last 4 years with all of you have been filled with sarcasm, fun, and a wealth of useful and some not-so-useful information. Thank you for your support and willingness to answer text messages at any hour of 
the day or night. Thank you to all the Chapman professors and faculty for having a love for education and willingness to go the extra mile for your students. To my friends, thanks for understanding when I canceled plans or continuously talked about my dissertation.

I would like to thank all the educators who helped me get access to participants for this study. You are all amazing at what you do, and your students are lucky to have educators who are dedicated to research and improvement. I would also like to thank all the guardians who participated in my study. Without all of you, I could never have completed this dissertation.

To my family, your unwavering support through all my education has been empowering. Your love and limitless expectations have pushed me to continue my education to help others. Grandma and Poppy, you have taught me to be brave and work hard, thank you, I love you all the way to the moon and back. To Evelyn, you have changed my life and your perseverance has driven me to do more. Thank you for understanding when I would sit for hours and write and for getting me out of the house after those hours of writing.

Lastly, to my amazing mom, Dr. Kim. You taught me how to be a woman, educator, and professional. Thank you for always answering the phone when I had questions or needed to brainstorm ideas. Thank you for being a resource and an advocate to me, my siblings, and all the students you work with. Your dedication to students with differences is what motivated me to select this topic and what pushes me to try and make a difference for students and families. I love you! 


\begin{abstract}
Special Education Parent Perceptions of Involvement and Parent-Educator Relationships During IEP Meetings at Nonpublic Schools

by Alex M. Huynen
\end{abstract}

The Individuals with Disabilities Education Improvement Act (IDEIA) requires parents to be involved in all parts of the education decision-making process, including the IEP meeting. Although there is a vast body of research about parents of students receiving special education services and their perspectives of the IEP meeting, little is known about parents' perspectives of the IEP meeting while students are at a nonpublic school. Understanding the perspectives of parents whose students attend nonpublic schools will allow for more collaboration and more effective IEP for their students attending nonpublic schools. The current study explored parent perspectives of involvement and parent-educator relationships during IEP meetings held at nonpublic schools. A convergent mixed method design combined survey and interview results to build a reliable understanding of parent perspectives at IEP meetings in this environment. A selfadministered survey was created and pilot-tested for the study. Forty-one guardians of students who attended a nonpublic school in Orange, San Diego, and Los Angeles Counties volunteered to complete the survey after being contacted through their nonpublic student school, a school district representative, or a parent Facebook group post. A semistructured interview protocol was developed based on the survey and conducted with eight guardians who completed the survey and volunteered to participate in an interview. Descriptive statistics were used to analyze survey data to understand participant perspectives of involvement and parent-educator relationships. Structural, descriptive, and value coding was used to analyze interview data. Between-group 
analysis of variance was used to compare perspectives across demographic groups (e.g., parent race and ethnicity, parent education level, student number of years receiving special education services). Survey and interview results identified high positive ratings for involvement and parent-educator relationships. The participants' race had a significant impact on parent perspectives of communication during IEP meetings at nonpublic schools; however, due to small group sizes, further research should be conducted to verify the results. No other demographic characteristics analyzed had a significant impact on involvement, communication, or parenteducator relationships. 


\section{TABLE OF CONTENTS}

$\underline{\text { Page }}$

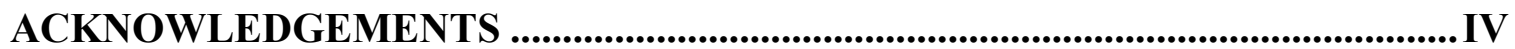

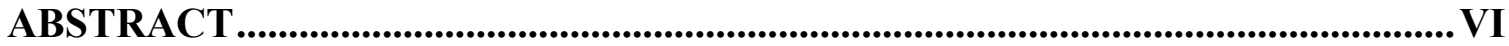

LIST OF TABLES ........................................................................................................ XII

LIST OF FIGURES .................................................................................................... XIV

LIST OF ABBREVIATIONS ...............................................................................

CHAPTER 1: INTRODUCTION...................................................................... 1

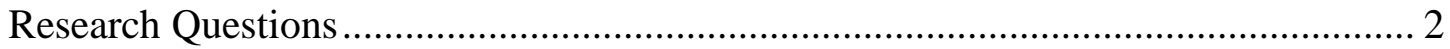

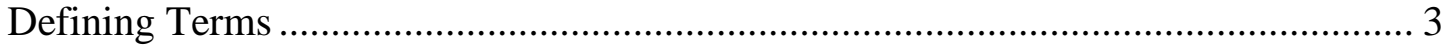

Parent Involvement ........................................................................ 3

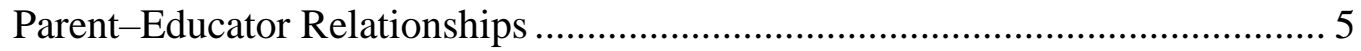

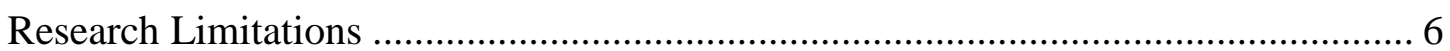

CHAPTER 2: LITERATURE REVIEW .................................................................. 7

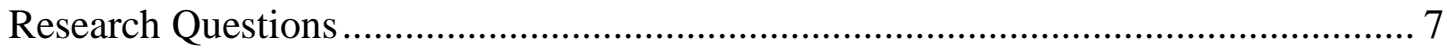

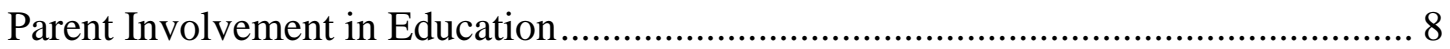

Parent Involvement and Academic Achievement.......................................... 9

Parent Involvement Programs ...................................................................... 9

Parent-School Partnership ..................................................................... 10

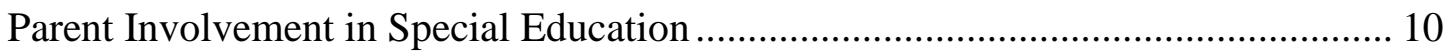

The Legality of Parent Participation in IEP Meetings .................................. 11

Why Involve Parents in Educational Decisions? ........................................... 11

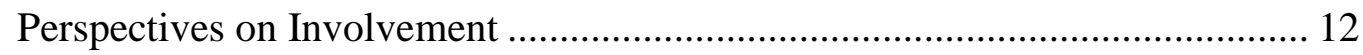

Perceptions of Parent-Educator Relationships .............................................. 15

Perception Differences Based on Demographics............................................ 20

Parent Perceptions During NPS Placement .......................................................... 23

Research in NPSs ................................................................................... 24

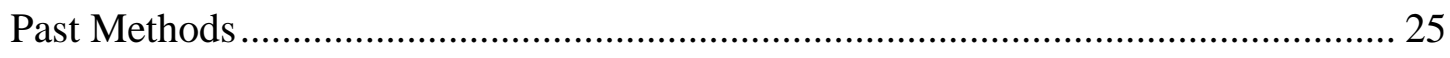

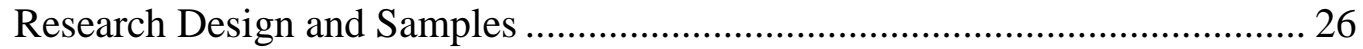

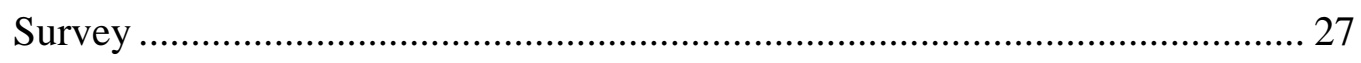

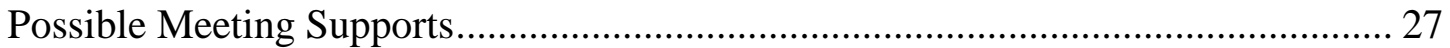

Effectiveness of Teams .......................................................................... 28

Conflict Resolution and Facilitation ...................................................... 31

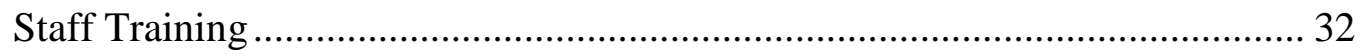




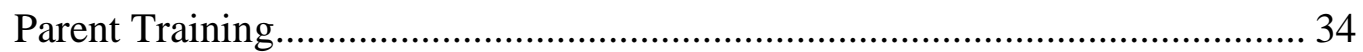

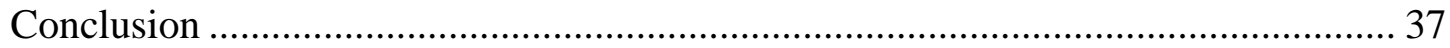

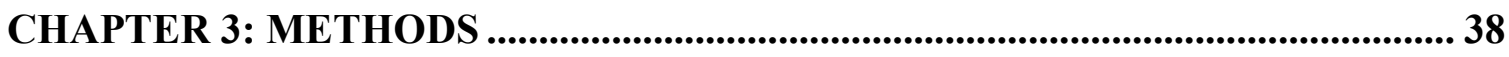

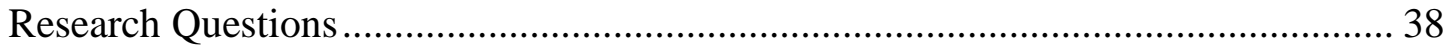

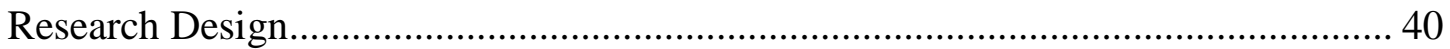

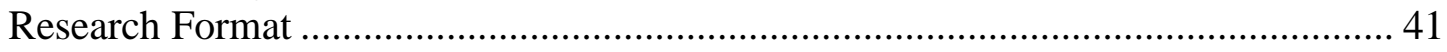

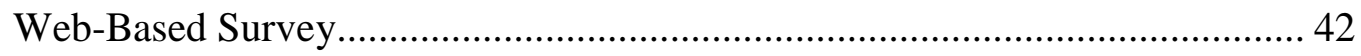

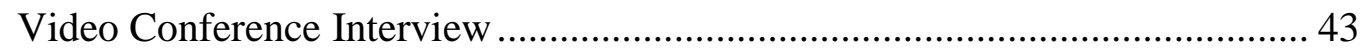

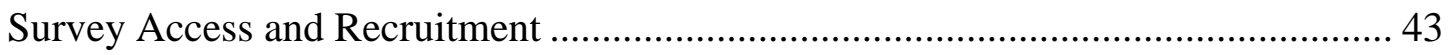

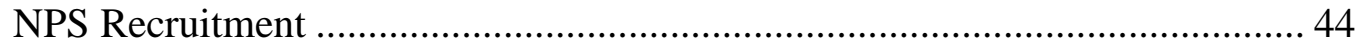

School District Representative Recruitment ....................................................... 45

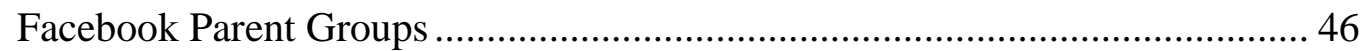

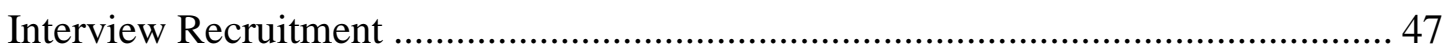

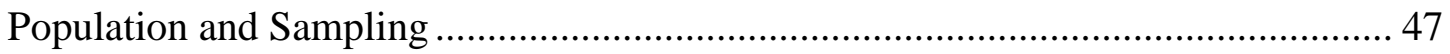

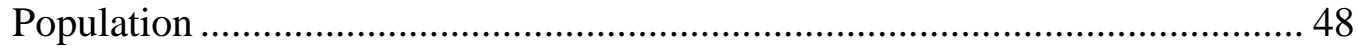

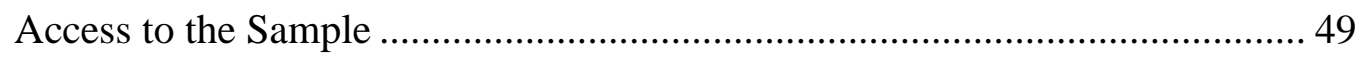

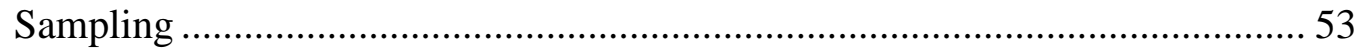

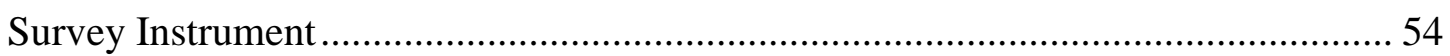

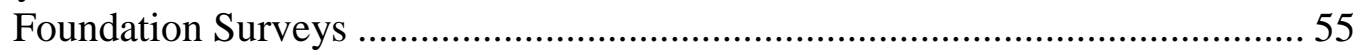

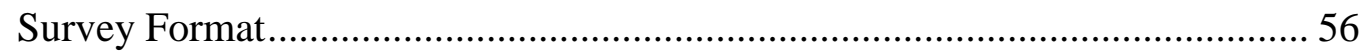

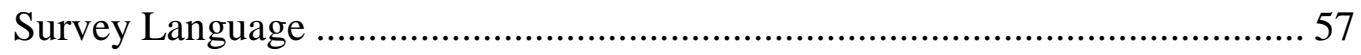

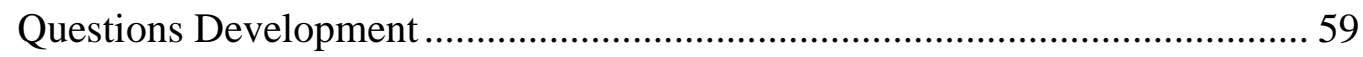

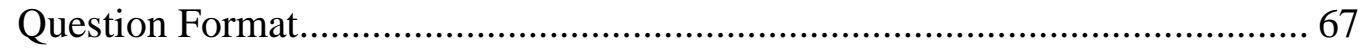

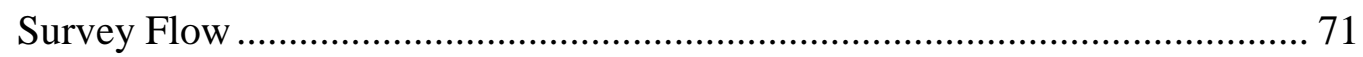

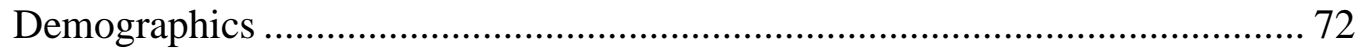

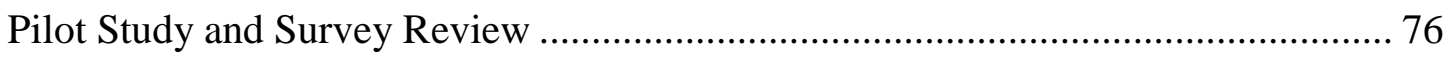

A Review by Experts in the Field ................................................................. 76

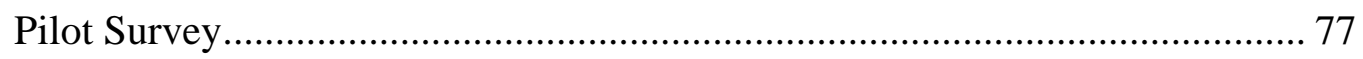

A Final Review by Experts in the Field........................................................... 79

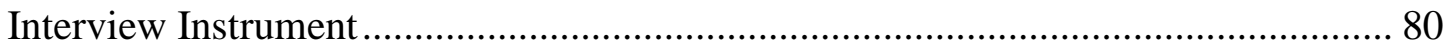

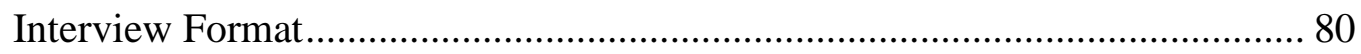

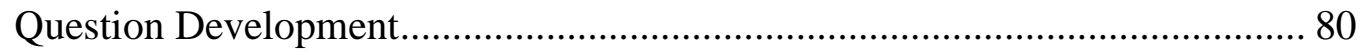

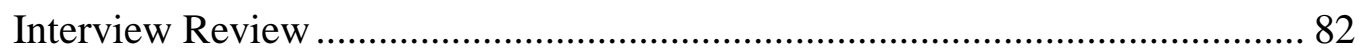

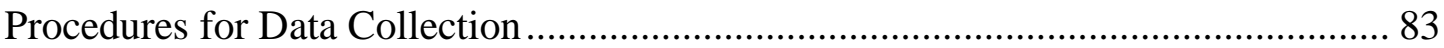

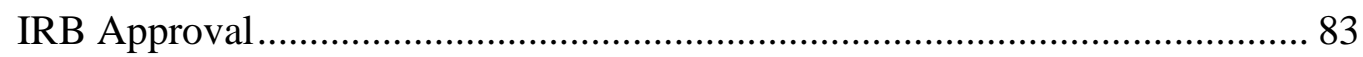

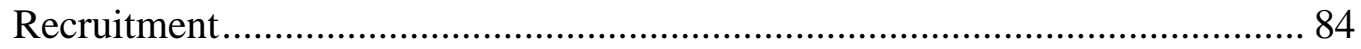

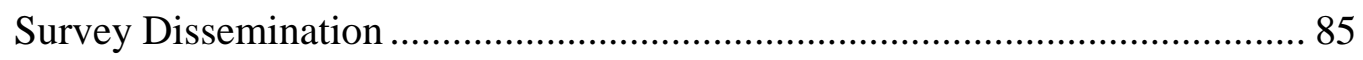

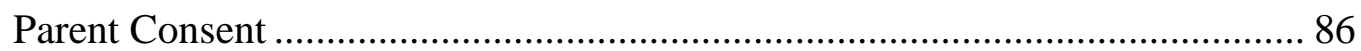

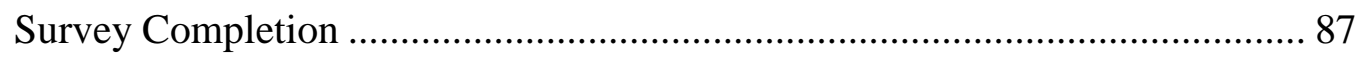

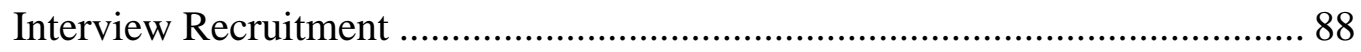

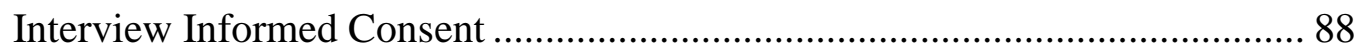




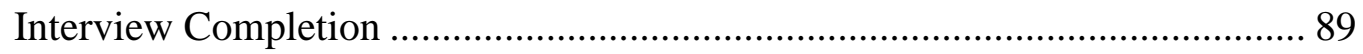

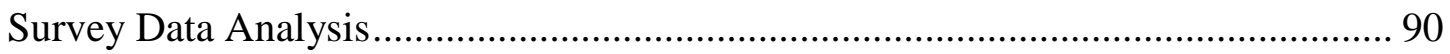

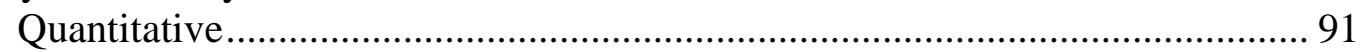

Nonresponse Bias................................................................................... 92

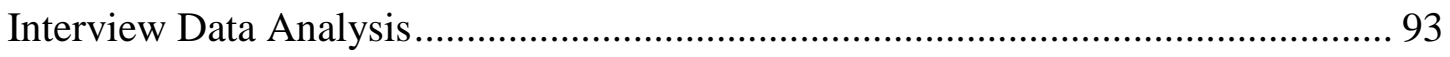

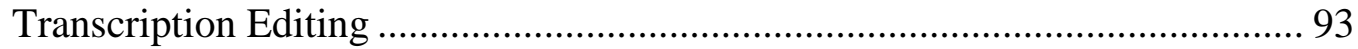

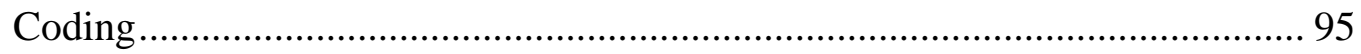

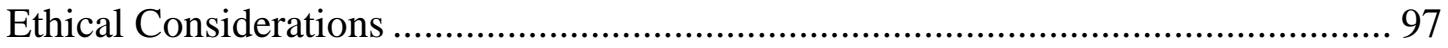

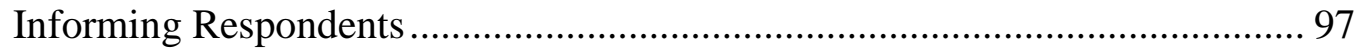

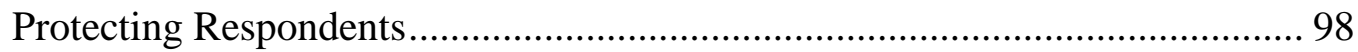

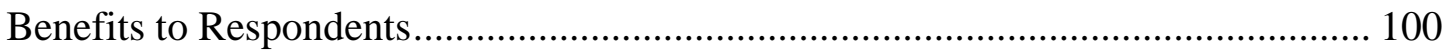

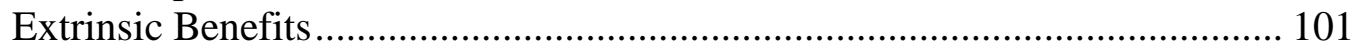

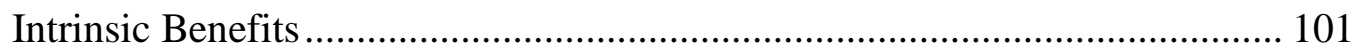

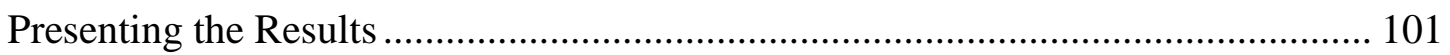

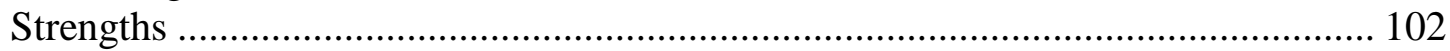

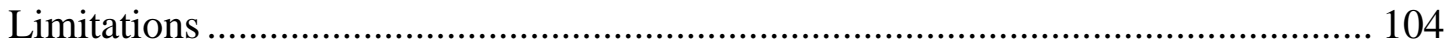

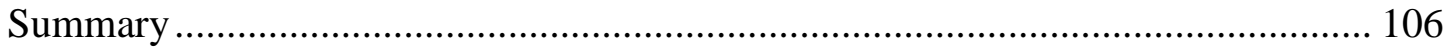

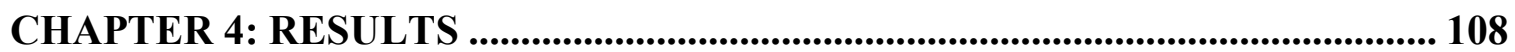

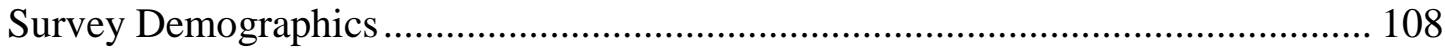

Participant Demographic .......................................................................... 108

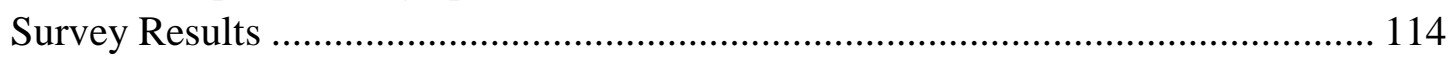

Total Rating of Involvement, Communication, and Relationships................... 115

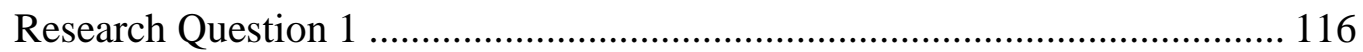

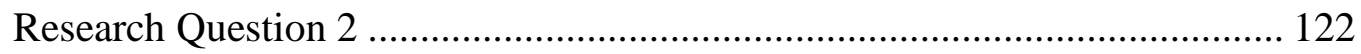

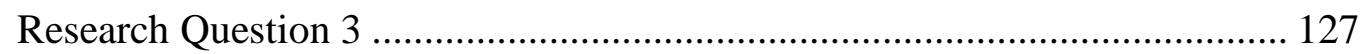

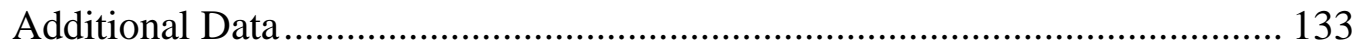

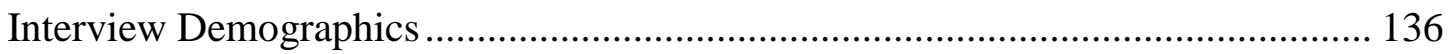

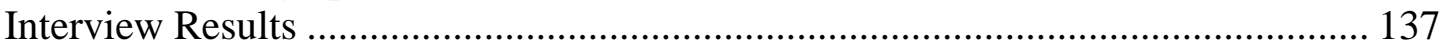

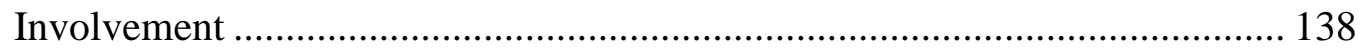

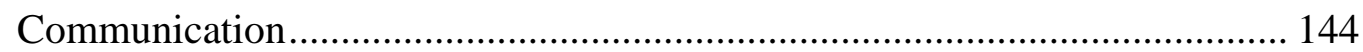

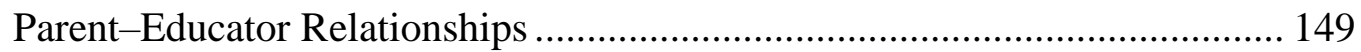

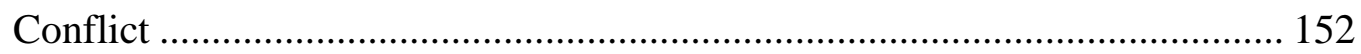

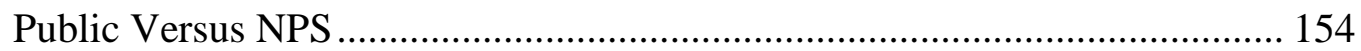

Value Coding - Positive and Negative Comments ......................................... 155

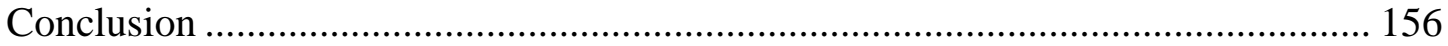

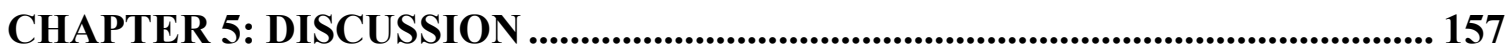

Research Question 1 Findings ......................................................................... 157

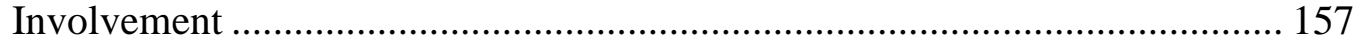

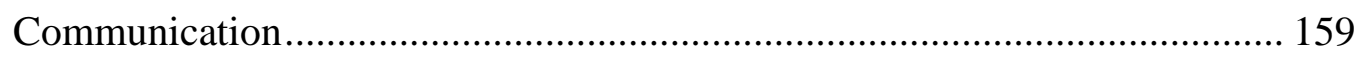

Research Question 2 Findings .......................................................................... 161

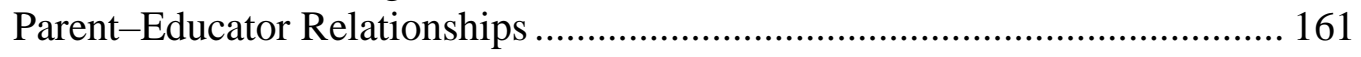




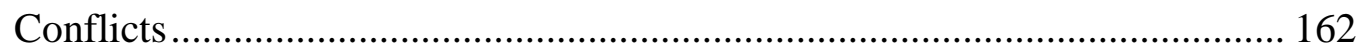

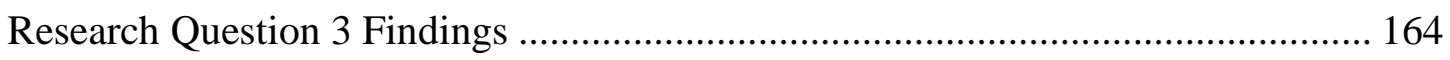

Additional Demographic Findings............................................................... 166

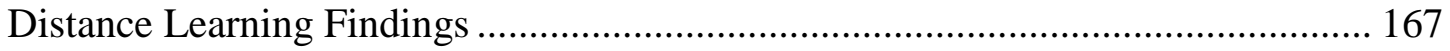

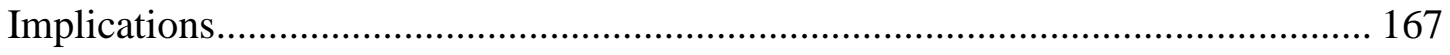

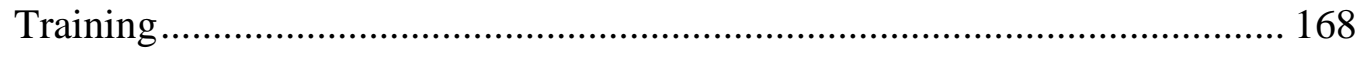

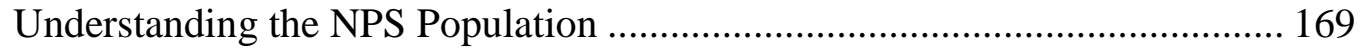

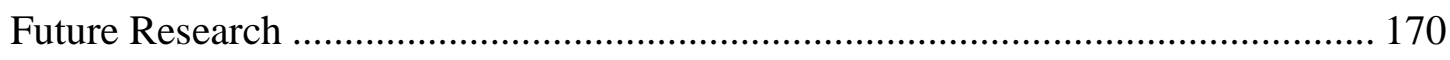

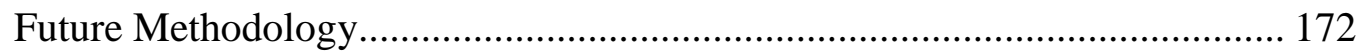

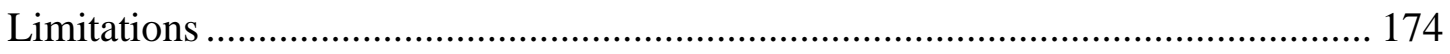

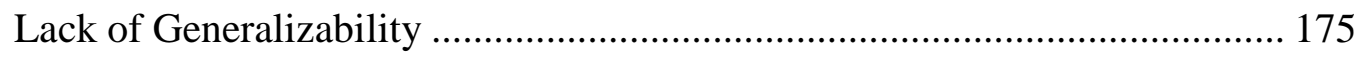

Accurate Representation of the Population...................................................... 175

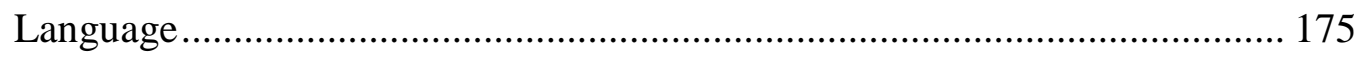

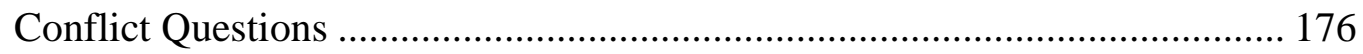

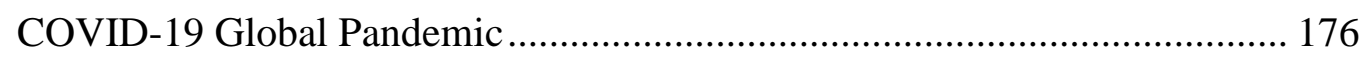

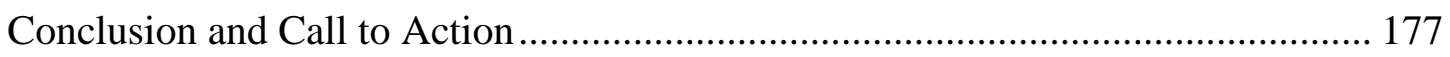

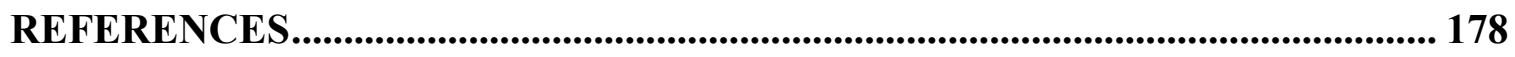

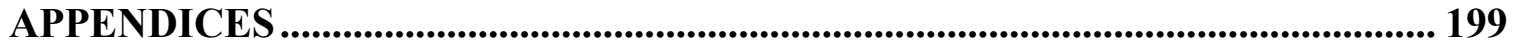




\section{LIST OF TABLES}

$\underline{\text { Page }}$

Table 3.1 Total Possible Survey Recipients by School or Representative ..................... 50

Table 3.2 SARC Population Grade Tools ............................................................... 51

Table 3.3 SARC Population Race and Ethnicity …............................................... 52

Table 3.5 Survey Question Topics by Section and Subsection ................................... 56

Table 3.6 Survey Questions Based on Section and Initial Source ............................... 59

Table 3.7 Survey Question Format by Section and Subsection .................................. 67

Table 3.8 Survey Path Based on Question Answers ............................................. 72

Table 4.1 Parent Demographic Information ........................................................... 109

Table 4.2 Student Demographic Information ..................................................... 111

Table 4.3 NPS and IEP Attendance Information ............................................... 112

Table 4.4 Ratings for Overall Involvement, Communication, and Relationships .......... 115

Table 4.5 Ratings for Participant Ratings on Involvement Questions ......................... 117

Table 4.6 Ratings of How the IEP Team Collaborates with Guardians ....................... 118

Table 4.7 Techniques to Include Guardians in the IEP Process ................................ 118

Table 4.8 Reason's Participants Felt They Were Not Involved in the IEP Process ....... 119

Table 4.9 Satisfaction Regarding NPS Communication........................................ 121

Table 4.10 NPS Communication: How Often, Methods, and Topics.......................... 121

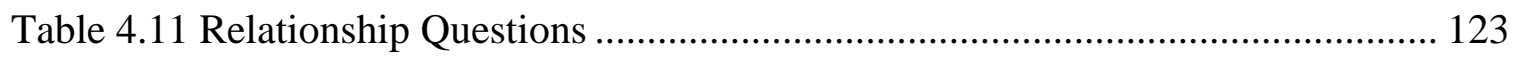

Table 4.12 Positive Relationships With Staff ........................................................ 124

Table 4.13 Conflict With Nonpublic and District Educators.................................... 125

Table 4.14 Type of Conflict With Nonpublic and District Educators .......................... 126 
Table 4.15 Descriptive Analysis - Race and Ethnicity........................................ 128

Table 4.16 Descriptive Analysis - Qualification for Free or Reduced-Price Lunch ..... 129

Table 4.17 Descriptive Analysis - Highest Level of Education ................................ 130

Table 4.18 Descriptive Analysis - Number of Years Receiving Special Education Services ............................................................................... 131

Table 4.19 Descriptive Analysis - Number of Years Attending an NPS .................... 132

Table 4.20 Descriptive Analysis - Primary Language …...................................... 133

Table 4.21 Participant Overall Ratings During Virtual Learning ............................... 135

Table 4.22 Meetings During Virtual Learning ....................................................... 135

Table 4.23 Structural and Descriptive Codes and Categories................................... 137

Table 4.24 Parent Comments About NPSs During Interviews.................................. 155 


\section{LIST OF FIGURES}

\section{Page}

Figure 3.1 Study Design: Convergent Mixed Method Design ................................... 41 


\section{LIST OF ABBREVIATIONS}

$\underline{\text { Abbreviation Meaning }}$

ASD Autism Spectrum Disorder

ASL American Sign Language

CAPSES California Association of Private Special Education Schools

CDE California Department of Education

IDEIA Individuals with Disabilities Education Improvement Act

IEP Individual Education Plan

IRB Institutional Review Board

LEA Local Education Agency

NPS Nonpublic School

PEP Parent Engagement and Empowerment Program

POC People of Color

SARC School Accountability Report Card

SELPA Special Education Local Plan Area

SPSS Statistical Package for Social Science 


\section{Chapter 1: Introduction}

Since the initial passage of the Education for All Handicapped Children Act in 1975, now called the Individuals with Disabilities Education Improvement Act (IDEIA), there have been rights that protect parents of children in special education. IDEIA expressly indicates parents are equal partners in special education and should be included in all educational decision-making processes. For students with disabilities, the IEP meeting is arguably one of the most crucial educational planning steps. All students receiving special education services have an IEP document that specifies their disability and details their individualized education plan to help them access their education. These plans are reviewed at least once every year (IDEIA, 2004). IDEIA states parents are to be directly involved in the IEP meeting. Despite legal mandates that require parent involvement in IEP meetings, past research indicated parents are not always included as equal members of the team (Cavendish \& Conner, 2018; Fish, 2006; Garriott et al., 2000; Lovitt \& Cushing, 1999; Tucker \& Schwartz, 2013; Zeitlin \& Curcic, 2014). Parents reported difficulty participating due to their perceived difficulties with communication, conflict, and relationships with educators (Fish, 2006, 2008; Stanley, 2015; Tucker \& Schwartz, 2013; Turnbull et al., 2011; Wagner et al., 2012; Zeitlin \& Curcic, 2014). Research on parent participation has mostly been conducted at traditional public schools. The following section provides details on the special education populations at traditional public schools versus the populations at nonpublic schools (NPSs).

As of December 2018, California had 795,047 students receiving special education services. Most students receiving special education services attended their traditional public school (California Department of Education, n.d.); however, approximately 10,549 students attended NPSs in California. NPSs are private schools that enroll students receiving special 
education services based on recommendations documented in their IEP and the student's level of need (California Department of Education, 2020a).

Although there is a vast body of research about parents of students receiving special education services and perspectives of the IEP meeting (e.g., Cavendish \& Conner, 2018; Fish, 2008; Garriott et al., 2000; Tucker \& Schwartz, 2013), little is known about parents' perspectives of the IEP meeting while their students are at an NPS. Parent perspectives of IEP meetings at NPSs are needed to ensure students can achieve their highest academic performance (Castro et al., 2015). Currently, there is no research on parent perspectives in NPSs to support the IEP process and training. The purpose of this study was to investigate parent perspectives about IEP involvement and parent-educator relationships during the IEP meeting for students attending an NPS. This study used a convergent mixed method design, using a survey and interviews to answer the following research questions.

\section{Research Questions}

Based on the purpose of this study, data were collected from parents of students who attended an NPS to gather parent perspectives about IEP meetings at NPSs. Research questions addressed perspectives about parent involvement and relationships with IEP team members. Additionally, perspectives on involvement and relationships were compared across subgroups. The following research questions were selected for this study:

- Question 1: How do parents of students receiving special education services perceive their level of involvement during the IEP meeting process at nonpublic schools?

- Question 2: How do parents of students receiving special education services perceive their relationships with the IEP team during the IEP meeting process at nonpublic schools? 
- Question 3: Do parent perceptions of involvement in the IEP meeting process at a nonpublic school vary across demographic variables (e.g., age of the child, eligibility category, number of years in special education, race/ethnicity, parent educational level)?

- Question 3A: Is there a difference between perceptions of parent involvement among parents with different educational levels?

○ Questions 3B: Is there a difference between perceptions of parent involvement among parents who self-identify in different race/ethnicity categories?

○ Questions 3C: Is there a difference between perceptions of parent involvement among parents whose children have been in special education longer than 5 years and those with children in special education less than 5 years?

\section{Defining Terms}

The research questions called for the collection of data on parent perspectives of involvement and parent-educator relationships. Past research has defined involvement (Garriott et al., 2000; Goldstein et al., 1980; IDEIA, 2004; Spann et al., 2003; Yoshida et al., 1978) and parent-educator relationships (Fish, 2008; Garriott et al., 2000; Simpson, 1996) during the IEP meeting in many ways. The definitions in this section combine multiple definitions from the literature.

\section{Parent Involvement}

The Individuals with Disabilities Education Act requires parents to be included in the IEP meeting (IDEIA, 2004). Based on Education for All Handicapped Children Act, Public Law 94142, parents being included in the IEP meeting is not enough; parents must be allowed to play an active role and be equal members of the decision-making process. Garriott et al. (2000) suggested parents should not only be recipients of information, but "active participant(s) in the 
development, implementation, and evaluation of the child's or young adult's IEP plan" (p. 38). Parents should be treated as equal members of the IEP team and allowed direct input in the formation of IEP goals and objectives. Evidence from Goldstein et al. (1980) and Yoshida et al. (1978) suggested similar issues have occurred for over 30 years. Both studies indicated that parents attended their child's IEP meetings but were not typically involved in developing objectives, interventions, or evaluation methods (Goldstein et al., 1980; Yoshida et al., 1978).

For the current study, parent involvement was defined as attending and being an active and equal member of the IEP team (Garriott et al., 2000; Zeitlin \& Curcic, 2014). Being an active and equal member means providing input and helping the team assess the child's skills, develop educational goals, providing input on services and supports, and advocating for the student (Garriott et al., 2000). The process of being an active team member is now described.

When actively involved, parents provide direct input into the creation of the IEP (Garriott et al., 2000). The following is a sequential example of what a parent may add to an IEP meeting if they are actively involved. This example is based on the researcher's professional experience attending IEP meetings. At the start of the meeting, parents may share their concerns with the IEP team. Although educators share present levels, an actively engaged parent may provide examples of current progress at home, along with strengths and weaknesses they have noticed. After noting areas of concern, parents may help develop goals or make suggestions of goals for their students. During the discussions about accommodations, parents may provide helpful examples that have worked at home in the past. Parents should also feel comfortable stating previously used ineffective techniques, so the team can implement new strategies or remove existing accommodations. Lastly, an actively involved parent may suggest beneficial services. Many parents research IEP meetings to better understand what services may or may not help. 
Others ask questions of the IEP team to understand what services should be provided. Throughout the IEP meeting, actively involved parents often asked questions, provide clarification, and answered questions asked by the IEP team. IEP team members should encourage and foster active parent involvement during IEP meetings, and the legal expectation is that parents are fully involved in the IEP process.

\section{Parent-Educator Relationships}

Parent-educator relationships should be more developed than simply what is mandated by law because quality parent-educator relationships are necessary for developing an effective educational plan (Garriott et al., 2000; Simpson, 1996). Fish's (2008) study concluded that building positive relationships between parents and educators involves treating parents as equals during the IEP meeting, valuing parents as equal partners to increase cooperation, and encouraging parental input and collaboration during IEP meetings. Positive parent-educator relationships included educators maintaining positive relationships with parents, providing a welcoming atmosphere, and treating parents as equal partners in IEP meetings (Fish, 2008). Garriott et al. (2000) suggested positive parent-educator relationships occur when parents and teachers assume equal responsibility to meet the student's needs. For the current study, parenteducator relationships were determined by the perspectives and feelings parents had while interacting and engaging with educators and the connections they created with those educators. Survey questions about relationships included educators' attempts to collaborate, understand parents, involve parents, and communicate during IEP meetings (Fish, 2008; Garriott et al., 2000; Stanley, 2015; Tucker \& Schwartz, 2013; Underwood, 2010). Based on the literature, these question topics impact whether parents feel like equal members of the IEP team. 


\section{Research Limitations}

This study may allow educators from districts and NPSs to understand parent perspectives during IEP meetings at NPS; however, due to the specificity of the sample, there were several research limitations. The most significant limitation is the lack of generalizability. Results of the current study may generalize to parents in the NPSs included in this study and may generalize to NPSs in the surrounding area, with similar demographics. The results cannot be generalized to all parents with students in an NPS, especially schools located outside of California. The term NPS differs by state, so results from California NPSs may not generalize to other states.

Another research limitation was the use of a survey design. If possible, using an experimental design would help control for other variables; however, it would be unethical to place students in an NPS setting for this study. A mixed-method design using a survey and interview allowed for the collection of as much data as possible from the current populations of parents in NPSs without altering student placements. Mixed method designs can have their limitations. There can be challenges comparing results from two forms of data collection, and when results do not overlap clearly, it can be hard to resolve the discrepancies. The current study attempted to foresee as many limitations as possible and alter the study design and methods when possible. 


\section{Chapter 2: Literature Review}

The previous chapter provided an introduction to this research study. This chapter includes previous research related to the current study. As stated previously, the purpose of this study was to investigate parent perspectives about IEP involvement and parent-educator relationships during the IEP meeting for students attending a nonpublic school (NPS). When deconstructing the past research, it was important to break up the research into focus areas so that each topic flows into the next. For this study, the first topic of focus was parent involvement in education and its impact on students. The second topic of interest was parent involvement in special education and IEP meeting. The third topic was research on parent perspectives of involvement in traditional schools. Finally, the last topic of interest would be all research directly connected to parent perspectives while their students attend NPSs. The research discussed in this chapter will be separated into the following sections: (a) parent involvement in education, (b) parent involvement in IEP special education and IEP meetings, (c) parent perspectives during IEP meetings in the traditional school setting, (d) research conducted with parents whose students attend NPSs, and (e) research surrounding effective meetings and training. After providing an overview of past research, the gap in the research will be discussed.

\section{Research Questions}

As stated in Chapter 1, the questions listed here were used as research questions for this study. The past research included in this chapter attempted to provide relevant information related to the topic of parent perspectives of involvement and relationships during the IEP process at NPSs.

- Question 1: How do parents of students receiving special education services perceive their level of involvement during the IEP meeting process at nonpublic schools? 
- Question 2: How do parents of students receiving special education services perceive their relationships with the IEP team during the IEP meeting process at nonpublic schools?

- Question 3: Do parent perceptions of involvement in the IEP meeting process at a nonpublic school vary across demographic variables (e.g., age of the child, eligibility category, number of years in special education, race/ethnicity, parent educational level)?

- Question 3A: Is there a difference between perceptions of parent involvement among parents with different educational levels?

○ Questions 3B: Is there a difference between perceptions of parent involvement among parents who self-identify in different race/ethnicity categories?

○ Questions 3C: Is there a difference between perceptions of parent involvement among parents whose children have been in special education longer than 5 years and those with children in special education less than 5 years?

\section{Parent Involvement in Education}

To understand the importance of parent involvement in special education and IEP meetings, it is important to understand the impact of parent involvement within education. Past research has established a relationship between parent involvement and academic achievement (Anthony \& Ogg, 2019; Fan \& Chen, 2001; Garbacz et al., 2017; Jeynes, 2005, 2012). Epstein $(1987,1992,1996)$ suggested a theoretical framework to understand the different levels of parent involvement. Epstein $(1992,1996)$ suggested the use of six levels of parent involvement as they relate to school. These levels include: (a) assisting parents in child-rearing skills, (b) schoolparent communication, (c) involving parents in school volunteer opportunities, (d) involving 
parents in home-based learning, (e) involving parents in school decision making, and (f) involving parents in school-community collaborations (Epstein, 1992, 1994). This model has been used in the research to define levels of parent involvement and help understand what teachers can do to increase involvement (Anthony \& Ogg, 2019; Fan \& Chen, 2001; Fantuzzo et al., 2000; Garbacz et al., 2017; Jeynes, 2005, 2010, 2012). The following information provides research about the link between parent involvement and student achievement, if parent involvement can be increased, and seeing parent involvement as a partnership.

\section{Parent Involvement and Academic Achievement}

Using 41 previous studies, Jeynes (2005) conducted a meta-analysis to examine the relationship between parental involvement and academic achievement in urban elementary students. Results of this study found a "considerable and consistent relationship between parent involvement and academic achievement among urban students" (Jeynes, 2005, p. 258). According to Jeynes (2005), results from his study indicated the influence of parental involvement might "largely transcend differences in SES, race, and other factors" (p. 259).

\section{Parent Involvement Programs}

After understanding that there is a connection between parent involvement and student achievement, educators need to know if parent involvement can be used as an intervention to positively impact student achievement. One way to use parent involvement as an intervention is to create programs to increase parent involvement. Research has found that programs designed to encourage parent involvement have a positive effect on student achievement (Jeynes, 2005). The meta-analysis by Jeynes (2005) discovered that creating programs to increase parent involvement can help reduce the achievement gap between struggling students and those who are more advanced. To create programs to increase parent involvement, research must first show that 
parents can be effectively taught to be more involved in their student's education (Epstein, 2001;

Henderson \& Mapp, 2002; Jeynes, 2010; Mapp et al., 2008). There is a debate among researchers that parents will either not be involved and cannot be forced to become involved (Barber, 2004; Batson et al., 2004) or parents can be taught to become more engaged and involved in their child's education (Epstein, 2001; Henderson \& Mapp, 2002; Jeynes, 2010; Mapp et al., 2008).

\section{Parent-School Partnership}

Traditionally, parent or family involvement has been considered "unidirectional" (Fantuzzo et al., 2000, p. 368). Methods to measure parent involvement had parents provide the number of hours they volunteered at school, attended school events, helped students with homework, or communicated with teachers (Fantuzzo et al., 2000; Garbacz et al., 2017). Using a developmental-ecological model allows researchers to understand the nature of family involvement on a multidimensional level (Brofenbrenner, 1986). Understanding families using a developmental-ecological model means understanding that "family is the most important influence on the development of young children" (Fantuzzo et al., 2000, p. 368). Referring to parent involvement as a parent-school partnership emphasizes the "co-equal" (Garbacz et al., 2017, p. 2) partners with joint planning and work.

\section{Parent Involvement in Special Education}

The following sections discuss parent involvement within special education. Specific tops include (a) the legality of parent participation within IEP meetings, (b) why parents should be involved in educational decisions, (c) parent perspectives of their involvement, and (d) parent perspectives of the parent-educator relationships. 


\section{The Legality of Parent Participation in IEP Meetings}

All students receiving special education services have an IEP that lays out the plan to help them succeed in their educational setting. The school of attendance is required to hold a meeting, at least once a year, to discuss the students' (a) present levels, (b) old goals, (c) new goals, (d) possible services, (e) accommodations and modifications, and (f) educational placement (Individual with Disabilities Education Improvement Act [IDEIA], 2004). Parents are required to participate in the development of the IEP based on the IDEIA of 1997 (IDEIA, 2004; Individual with Disabilities Education Act Amendments, 1997). More specifically, IDEIA requires parents to be involved in all parts of the education decision-making process, including the IEP meeting.

During the IEP meeting, educators must ask parents to help make critical educational decisions to help develop an IEP for their student(s). IDEIA (2004) requires making critical decisions during the IEP meeting to be a team process where parents work collaboratively with educators. The parent perspectives vary during these meetings, and understanding these perspectives is crucial for schools and districts to ensure a successful IEP meeting and positive educational outcomes. Two areas of parent perspectives of interest include their involvement in the IEP meeting and perspectives of parent-education relationships during the IEP meeting.

\section{Why Involve Parents in Educational Decisions?}

Besides being legally required to include parents in the IEP meeting and decision-making process, there are other reasons to include parents in the educational decision-making process. When looking at the general education population, many researchers have encouraged parent involvement as a strategy to increase achievement outcomes within diverse general education students (Bouffard \& Weiss, 2008; Epstein, 2001a, 2001b; Pushor \& Murphy, 2004; Underwood, 
2010). Many studies have been conducted on the effects of parent involvement on students' educational outcomes and achievement. Although not all types of parent involvement have been found to positively affect achievement (Crossnoe et al., 2002; Domina, 2005; Jeynes, 2007; Williams et al., 2005), overall, parent involvement has been linked to positive student achievement (Jeynes, 2007). Like those in general education, parents of students receiving special education services are also important. Parent involvement in the IEP is critical for student success (Underwood, 2010).

\section{Perspectives on Involvement}

Parent perceptions of involvement during IEP meetings vary by area, district, and school (Lovitt \& Cushing, 1999). The following studies provide an example of how parent perceptions of involvement range from little involvement to high. Stanley (2015) conducted a qualitative interview study focusing on 12 mothers of students receiving special education services and their lived experiences during IEP meetings. Mothers in Stanley's study indicated the importance of being involved in the IEP, but each mother's level of participation varied. The mothers reported a range of involvement that included attending the IEP meeting, voicing their concerns, making requests, and participating in the discussions (Stanley, 2015). Despite the reports that IEP participation was important, $30 \%$ of parents in the study wanted to be more involved in the IEP meeting process, and $2 \%$ wanted to be less involved.

Two examples of high levels of involvement were seen in Tucker and Schwartz's (2013) and Wagner et al.'s (2012) studies. Tucker and Schwartz included a survey of 135 parents of children diagnosed with an autism spectrum disorder. Tucker and Schwartz found 71\% of parents rated their involvement as high. Wagner et al. (2012) used two longitudinal studies, Elementary Longitudinal Study and National Longitudinal Transition Study-2, to understand the 
involvement of approximately 11,000 parents of students receiving special education services. The longitudinal studies used surveys and interviews. Results indicated $70 \%$ of parents reported their level of involvement or participation as about right (Wagner et al., 2012). Each of these studies shows the extremes in parent involvement when they attend their students' IEP meetings. When participating in an IEP meeting, parent involvement can range from being an active participant to a recipient of information (Garriott et al., 2000).

During an IEP meeting, parents can either have active or passive involvement (Garriott et al., 2000). Parents who actively participate in an IEP ask questions, offer information and add to the discussion. Parents who see their role as the recipient of the information or who are treated as such would be considered passive participants. In the study by Garriott et al. (2000), half of the $89 \%$ of parents who always attended their students' IEP provided statements that referred to engaging in active participation, while the other half suggested passive involvement. Past research on parent engagement during IEP meetings suggests parents are either passively involved (Cavendish \& Conner, 2018; Childre \& Chambers, 2005; Garriott et al., 2000; Martin et al., 2004; Wagner et al., 2012; Zeitlin \& Curcic, 2014) or take a more active role in the IEP meeting (Garriott et al., 2000; Habel \& Persitz, 2015; Zeitlin \& Curcic, 2014). Passive and active involvement are now discussed.

\section{Passive Involvement}

Students, parents, and teachers all noted challenges in meaningful involvement by parents during the IEP development and meeting. Many parents reported having a passive role in the IEP process (Childre \& Chambers, 2005) and felt encouraged by educators to take that role based on the minimal time allotted for them to speak (Zeitlin \& Curcic, 2014). In the study by Garriott et al. (2000), most parents with passive involvement reported they attend IEP meetings to be 
informed about their child's academic progress and the educator's plan. This process of informing parents was noted in the study by Underwood (2010), where almost all parents who were interviewed reported at least one interaction where the teacher or team was updating them instead of having a more active interaction. In addition to attending meetings, parents reported receiving phone calls that would inform them of their student's progress. Of the 31 parents involved in the study, 13 (41.9\%) reported they "were not at all, rarely, or only somewhat involved in the development of the IEP" (Underwood, 2007, p. 27).

Mothers in the study by Cavendish and Conner (2018) expressed the process was passive rather than a partnership because educators did not allow parent thoughts to influence the IEP planning. Similarly, parents were not asked to contribute information during the IEP development (Underwood, 2010). In summary, many parents report they engaged in passive involvement within IEP meetings (Childre \& Chambers, 2005; Zeitlin \& Curcic, 2014), with parents reporting feelings of being reported to and a lack of partnership between the teachers and parents in the development of the IEP (Cavendish \& Conner, 2018; Garriott et al., 2000; Underwood, 2010).

\section{Active Involvement}

Despite the high rates of passive participation, research shows incidences of active participation during IEP meetings (Garriott et al., 2000; Habel \& Persitz, 2015; Zeitlin \& Curcic, 2014). Garriott et al. (2000) found $46 \%$ of parents agreed they were able to give "ample, direct input" (p. 39) by giving direct input for goals and objectives during the IEP meeting. Similarly, Zeitlin and Curcic (2014) found one third of parents who participated in the study felt they actively participated and were able to collaborate with the IEP team. An even higher rate of active participation was seen in an earlier study by Salembier and Furney (1997). Salembier and 
Furney (1997) investigated parent involvement and found that two-thirds of the 36 parents who participated in their interview protocol reported, "satisfaction with their level of participation" (as cited in Garriott et al., p. 38). They were able to ask and answer questions, talk, and listen to educators during the IEP meeting.

Many parents would like a more active role in the IEP meeting (Zeitlin \& Curcic, 2014). Zeitlin and Curcic (2014) found that some parents wanted encounters with educators to be more active, personal, and meaningful. The exact number of parents was not included. They wanted to be part of a team and not sit in the backseat (Zeitlin \& Curcic, 2014). Garriott et al. (2000) found that some of the positive experiences that increased active participation included: (a) teachers encouraging parents to participate actively, (b) asking for parent input, and (c) providing drafts before the IEP. When parents reported ways how educators involved them in the IEP meeting, $60 \%$ of parents indicated they were asked for their input, $46 \%$ were provided regular communication about student's progress, and 30\% were involved in planning and writing IEP goals (Tucker \& Schwartz, 2013).

\section{Perceptions of Parent-Educator Relationships}

When focusing on relationships between parents and educators, Fish (2008) found most parents perceived their relationships with educators during the IEP process as relatively positive. Trust was found to be a critical factor in building relationships between staff and families (Turnbull et al., 2006). Fish found $96 \%$ of parents in his study felt IEP team members "maintained positive relationships with parents" (p. 12). Positive relationships were perceived because parents felt educators respected and valued their input, treated parents as equal partners, and allowed parents to discuss their child's program freely during the meeting (Fish, 2008).

Garriott et al. (2000) found 45\% $(n=37)$ of parents indicated they were always treated fairly and 
equitably. Garriott et al. indicated the educators in IEP meetings showed a willingness to listen to parent input and ask for their opinion. Despite positive perceptions of parent-educator relationships, there are large groups of parents who have different perceptions of the parenteducator relationship (e.g., Lo, 2008; Stanley, 2015; Zeitlin \& Curcic, 2014).

The following sections provide information from past research about the areas parents have identified that impact their relationship with the educators on the IEP team during the IEP meeting. These areas include: (a) communication and planning, (b) role tension, (c) asymmetrical relationships, and (d) parent perceptions of the educator's knowledge.

\section{Communication and Planning}

According to Dabkowski (2004), a widely accepted and necessary practice in developing IEPs and working with families in special education is communication between parents and the school team. Problems with communication during IEP meetings have been reported as an issue in multiple studies (Lovitt \& Cushing, 1999; Stanley, 2015; Tucker \& Schwartz, 2013; Zeitlin \& Curcic, 2014). A survey of 135 parents with children who had a diagnosis of autism spectrum disorder revealed communication was a major theme when referring to their relationships with educators (Tucker \& Schwartz, 2013). Of the 135 parents, 66\% indicated Yes when asked if there was a time when they did not feel included in their child's educational collaboration and planning. Furthermore, some parents felt their ideas and suggestions were not included, there was no regular communication, the educator created the IEP without their input, and educators did not consider the information from outside providers (Tucker \& Schwartz, 2013). Stanley (2015) interviewed 12 mothers of students receiving special education services and found all 12 mothers felt frustrated when they perceived educators did not hear and validate their concerns. When Zeitlin and Curcic (2014) interviewed 20 parents of students receiving special education 
services, "most parents" were dissatisfied due to the level of communication and poor pre-IEP and post-IEP planning, and there was a high need for better communication to enhance one another's perceptions and values. Lovit and Cushing (1999) included that parent comments stated poor communication had detrimental effects on their children's educational success. In summary, past research shows parents feel communication with educators impacts their relationships and should be strengthened during the IEP meeting process.

\section{Role Tension}

Many of the parents who expressed concerns or challenges with the IEP process reported role tensions between parents and educators. Zeitlin and Curcic (2014) found only one third of participants noted positive role experience during the IEP meeting by using terms such as “collaborator," "liaison," or "relationship builder" (p. 9). Parents often found interactions were structured, so they played the role of a "token participant" (Zeitlin \& Curcic, 2014, p. 9). This idea of a token participant was echoed in research done by Valle and Aponte (2002), who noticed educators often feel they must convince parents of what is best for their children by being the professional who is disempowering and condescending. This role tension may be affected by asymmetrical relationships during IEP meetings.

\section{Asymmetrical Relationships}

IEP participants with asymmetrical relationships were identified as a major theme by parents who sensed a power difference between their claim to knowledge about their child and school experts who often dominated the decision-making process (Zeitlin \& Curcic, 2014). Parents described relationships as adversarial with an imbalance of knowledge, power, and authority. Zeitlin and Curcic (2014) found parents felt worried, frustrated, and angry due to educators' comments, gestures, and inflections. The setting of an IEP meeting can be 
overwhelming to parents. One parent described his experiences as "10 to 12 professionals sitting on the opposite side of the table who would go on to tell us a host of negative things about our young son" (Zeitlin \& Curcic, 2014, p. 7). Due to the "authoritative discourse of psychoeducational reports and behavior objectives" (Valle \& Aponte, 2002, p. 476), professionals in IEP meetings tend to dominate. Authoritative discourse is very different from parents' everyday language and can leave parents overwhelmed by the power difference (Zeitlin \& Curcic, 2014). To combat feelings of unequal relationships, parents shared they feel they must become experts in disability so they can assert power during the meeting. Viewing the professional as the expert and parents' perceptions of educators' knowledge are two reasons IEP meetings may feel asymmetrical to parents. These two concepts are now discussed.

\section{Professional as Expert}

A phenomenon that occurs during the IEP meeting that often affects the parent-educator relationship is parents feeling the professional is the expert. This idea is mentioned in multiple studies and often deters parents from being active participants in their child's IEP, which adds to the asymmetrical relationship between professionals and parents (e.g., Lo, 2008; Stanley, 2015; Turnbull \& Turnbull, 1997). Turnbull and Turnbull (1997) indicated that professionals' expertise with assessments holds more power because they are objective and scientific, while parents' knowledge of their students is dismissed because it is subjective. Additionally, parents perceive the educator or professional as the expert or most knowledgeable about special education, which prevents parents from questioning educators and leads to the educator making all educational decisions (Stanley, 2015). When studying culturally diverse or low socioeconomic parents and their involvement, Kalyanpur et al. (2000) reported that the problems of seeing the educator as the expert are heightened because "the child's culture itself is seen as somehow being at fault" 
(p. 124). Lo (2008) found that Chinese parents perceived educators as experts and had minimal interactions with the educators and were less likely to ask questions. These same parents reported they perceived the IEP meeting "as designed for professionals to report their child's progress, evaluation results, and any changes made in placement or services" (Lo, 2008, p. 24). The view of the professional as the expert stops parents from sharing their knowledge or experiences about their child.

\section{Parent Perceptions of Educators Knowledge}

Educators require extensive knowledge about special education and the student's disability to suggest appropriate goals, services, and accommodations. Parents' perceptions of educator knowledge can impact their relationship. Of those surveyed in the Fish (2008) study, $24 \%$ disagreed and 10\% strongly disagreed that school personnel conveyed sufficient knowledge. In the mixed-method survey by Tucker and Schwartz (2013), parents of students with autism spectrum disorder (ASD) indicated professionals being knowledgeable about their student's disability was an important quality to parents. When asked more specifically about their educators' level of knowledge regarding ASD, less than half of parents indicated the educators had very high or high levels of understanding. The fact that less than half of parents rated in the high or very high range suggests a professional's knowledge of disabilities, such as ASD, may not be at the level of understanding desired by parents. This theme continued with parents indicating they desired more training for school staff, more staffing support, and increased related services. During interviews, one parent felt it was difficult to advocate for her child because her son had a rare condition, and none of the educators had enough knowledge about his needs (Lo, 2008). Because of this lack of knowledge, this parent felt unable to advocate 
for her child's needs. The gap between the educator's knowledge and the parent's expectations created a dynamic of asymmetry and caused problems with communication during IEP meetings.

\section{Perception Differences Based on Demographics}

Parent perceptions of the IEP meeting could be affected by several other variables unrelated to the educator or process itself. Some variables that affect parent perception include language, race, and ethnicity. Policies in IDEIA indicate that educators must inform parents of their rights and any changes to the IEP and incorporate parent knowledge into the IEP decisionmaking process (Kalyanpur et al., 2000). Despite this requirement, a collaboration between parents and educators continues to be less than optional, especially with diverse families (Kalyanpur et al., 2000). Understanding and improving these differences can "build relationships that are reciprocal and mutually empowering - and ultimately beneficial to the students" (Kalyanpur et al., 2000, p.132).

\section{Language}

A demographic characteristic that has been researched concerning parents during the IEP process is parent primary language. Multiple studies support language differences are a significant barrier during the IEP process (Cavendish \& Conner, 2018; Cheatham \& LimMullins, 2018; Jung, 2011; Lo, 2008). Jung (2011) discussed how limited English proficiency puts culturally and linguistically diverse parents at a significant disadvantage when communicating with educators. Ortega (2014) added to this idea by indicating there tends to be a language hierarchy, where individuals who have limited English proficiency are viewed negatively compared to native English speakers. These views and disadvantages can cause shifts in parent perception of the IEP meeting. The following sections discuss how educators' views of 
bilingual parents and interpreters and how educators speak to bilingual parents impact the parents' perceptions during the IEP meeting.

During the IEP meeting, educators' views of bilingual parents can alter parent perspectives. When parents present with imperfect English, their input and expertise can be viewed as less valuable because educators focus on the linguistic skills and grammar of the parents instead of the child (Cook, 2012; Ortega, 2014). This lack of value pushes parents to allow the educator to make more decisions about the child's education. Due to this shift of following educator views and decisions, parents' perceptions of the IEP become deficit-focused, and they begin blaming themselves for their child's struggles (Correa-Torres \& Zebehazy, 2014).

Using interpreters is an additional issue related to bilingual or non-English speaking parent perceptions. Lo (2008) used observations of IEP meetings and interviews of Chinesespeaking parents to collect data on the participation and experiences of parents. Of the five Chinese-speaking parents who participated, four required an interpreter at the meeting. Many problems occurred due to the use of translators, which impacted parents' perceptions of the IEP process. Parents were aware they were missing information, had difficulty with the terminology, and felt they had an overall disadvantage during the meeting (Lo, 2009). Due to problems that may arise when using an interpreter, parents whose primary language differs from that of the meeting often have differing levels of participation. Lo (2009) observed minimal interaction between Chinese parents and professionals. The parents were less likely to ask questions and make comments during the meetings, and some shared they felt overwhelmed by the amount of information. Based on these studies, language significantly impacts parents' perceptions.

The way educators speak to parents whose primary language is not English asserts their expertise and results in marginalizing parents (Cheatham \& Ostrosky, 2011). Similar to using 
jargon, the use of English can reduce parents' ability to participate and leave parents feeling as though educators are not listening and allowing few opportunities for parents to give input (Lee \& Park, 2016).

\section{Race, Ethnicity, and Culture}

Race and ethnicity can impact parents' experiences during the IEP meeting and affect their perceptions. Similar to language, race and ethnicity can cause communication breakdowns between parents and educators. Culture has been shown to affect parents during IEP meetings in two ways, feeling as though they are to blame for their child's disability (Correa, 1992;

Kalyanpur, 1998; Kalyanpur et al., 2000; Kalyanpur \& Rao, 1991) and treating educators as unquestionable experts (Kalyanpur et al., 2000; Wong, 1989).

In past research, parents of children with disabilities expressed feeling as though their child's deficits were their fault; however, these feelings seem to be heightened in parents from a culturally diverse background (Kalyanpur et al., 2000). This conclusion was made based on previous research conducted with African Americans (Kalyanpur \& Rao, 1991), Hispanics (Correa, 1992), Native Americans (Kalyanpur, 1998), and Puerto Rican American parents (Harry, 1992). In these studies, professionals were quoted blaming students or family's culture for their deficits. In Kalyanpur's (1998) study, the professional stated "their culture was hurting them" (p. 322) when referring to why the student had language delays. These views from the educators impacted parents' perceptions of the IEP process and caused them to feel like the source of their child's difficulties.

Differing cultural views can impact parent participation in the IEP meeting process. For example, Chinese families assign people different levels of dominance based on status. The most common characteristics of dominance are age or education (Wong, 1989). Indian and Korean 
families have similar hierarchical orders (Wong, 1989). These hierarchical orders affect how parents perceive experts in the IEP meeting. Experts may be a "source of unquestionable knowledge" (Kalyanpur et al., 2000, p. 127), and therefore, parents will not speak up and disagree.

Parents' perceptions of the IEP process can vary based on their demographic characteristics or the characteristics of their children. Based on the research discussed previously, parent language and culture can affect their IEP meeting experiences. Other demographic characteristics that may affect their IEP meeting perceptions are age, educational level, socioeconomic status, and student disability.

\section{Parent Perceptions During NPS Placement}

According to the California Department of Education (n.d.), most students in California attend traditional public schools. This study used the California Department of Education's (2020a) definition of public school: "kindergarten through grade 12 and/or adult educational institution that: is supported with public funds" (Section 3) and provides education to all students in attendance. The needs of students in traditional public schools drive research on special education because most students receiving special education services are engaged in services in their local public schools. Because most special education students attend their local public school, understanding parent perspectives of IEP meetings in the traditional public-school environment is essential. The studies discussed so far have all taken place in the traditional public-school setting.

Another educational setting for research is NPSs. California Education Code Section 56034 defined an NPS “as a private, nonsectarian school that enrolled individuals with exceptional needs according to an individualized education plan and is certified by the state" 
(California Department of Education, 2020b, Section 10). The federal government uses the term NPS as a description for any private school, although California Educational Code includes only those schools that enroll students "with exceptional needs according to an individualized education plan" (California Department of Education, 2020b, Section 10). For this study, the California Educational Code description was used when referring to NPSs. NPSs meet the needs of students with disabilities whose needs cannot be met at their public school or local education agency (LEA). NPSs offer courses of study that range from graduation with a diploma to receiving a certificate of completion to primarily working on adaptive life skills (Parrish et al., 1998).

Being placed at an NPS would be a change of educational placement. Any change of placement is an IEP team decision and must be based on the needs of the student (IDEIA, 2004). Once at an NPS, students have IEP meetings every year where the parent is required to be a participant. This continues until the student transitions to another program or back to their LEA.

A student's placement at an NPS is funded by the LEA that the student is enrolled (Miyamoto, 1990). For example, a school district or special education local plan area (SELPA) may be responsible for paying for the student's placement. The LEA is responsible for paying for all services provided by the NPS, which are determined by the student's IEP. The state reimburses the LEA for the cost of services provided by the NPS; however, the LEA "receives at least 70 percent of the excess cost of the NPS or agency tuition" (Miyamoto, 1990, p. V-1).

\section{Research in NPSs}

Limited research has been conducted on the IEP processes in the NPS setting. During a literature review of NPS research, no articles were found on parent perceptions of the IEP processes in NPSs. Dissertations have been written about the job satisfaction of NPS 
administrators (Houpt, 2010) and perspectives of staff on the operation of NPSs (Shepard, 2015).

Neither of these dissertations included parent perspectives in their research. The only study found that included parent perspectives was a dissertation looking at student movement from public to NPSs by focusing on parent attitudes (Dee, 1981). None of these dissertations focused on parent perspectives in IEP meetings at NPSs. As a result, the summary of the research includes research on NPS enrollment.

\section{NPS Enrollment}

Based on the California Department of Education CalEdFacts (2020b) data, California had a total of 390 NPSs and 10,549 students attending those NPSs during the 2018-2019 school

year. During the same year, the state of California provided special education services to 795,047 individuals (California Department of Education, n.d.). Using this data, the percentage of students in NPSs makes up approximately $1.3 \%$ of students receiving special education services. Less than $2 \%$ may not seem like a large population; however, based on the funding required for students to attend an NPS, they are a unique and valuable population of students.

\section{Past Methods}

Research on parent perspectives is widespread in special education (e.g., Burke \& Sandman, 2015; Cavendish \& Conner, 2018; Fish, 2008; Garriott et al., 2000; Slade et al., 2018; Tucker \& Schwartz, 2013). When creating a new study, it is essential to consider how past research has successfully answered similar research questions. A few areas of focus include: (a) research designs, (b) sampling, and (c) survey design. Past research on parent perspectives of IEP meetings have included qualitative and quantitative methodology with a range of sampling techniques, with the most common being purposeful (e.g., Agran \& Hughes, 2008; Burke \& Sandman, 2015; Cavendish \& Conner, 2018; Fish, 2008; Garriott et al., 2000; Slade et al., 2018; 
Tucker \& Schwartz, 2013). The following section includes information about past research methods to inform the current study.

\section{Research Design and Samples}

Past literature has shown a variety of sample sizes, but most sample sizes are selected based on the method of data collection, such as surveys and interviews (e.g., Agran \& Hughes, 2008; Burke \& Sandman, 2015; Lo, 2008; Patel \& Stevens, 2010; Wagner et al., 2012; Zeitlin \& Curcic, 2013). The research can be separated into three groups: (a) small, (b) large, and (c) national studies. Studies that include a relatively small sample appear to gain information more thoroughly by using multiple data sources, such as surveys, interviews and records reviews (Lo, 2008; Zeitlin \& Curcic, 2013). The second group of research studies included large samples of 40 to 200 participants and usually a researcher created survey or a research-based questionnaire that was easily administered to many individuals (Agran \& Hughes, 2008; Burke \& Sandman, 2015; Cavendish \& Conner, 2018; Fish, 2008; Garriott et al., 2000; Slade et al., 2018; Tucker \& Schwartz, 2013). The last group of research studies included studies that relied on available national survey data. These researchers often used specific questions or selected a subgroup of respondents, and their sample size varied depending on the number of respondents who matched their criteria (Coots, 1998; Crosnoe, 2001; Johnson et al., 2002; Patel \& Stevens, 2010; Wagner et al., 2012).

Studies used school districts, public schools, family help agencies, nonprofit organizations, and parent advocacy groups as access points to the studies' target population. Nonprobability sampling was the most common sampling method when studying parent perspectives and the IEP process (Agran \& Hughes, 2008; Burke \& Sandman, 2015; Cavendish \& Conner, 2018; Fish, 2008; Garriott et al., 2000; Lo, 2008; Patel \& Stevens, 2010; Slade et al., 
2018). Four studies reviewed used data collected during a national survey or large sample survey (Coots, 1998; Crosnoe, 2001; Slade et al., 2018; Wagner et al., 2012). In two of the national studies or other extensive surveys, random stratified sampling was used (Coots, 1998; Wagner et al., 2012).

\section{Survey}

When designing surveys to collect parent perceptions, researchers often use a combination of both open and closed-ended questions in their surveys (Cavendish \& Conner, 2018; Coots, 1998; Fish, 2008; Slade et al., 2018; Wagner et al., 2012). Multiple-choice questions were often used. When collecting survey data about parents' perceptions, questions using Likert-scales were very common because they gain exact information and offer fewer answer choices than other question formats (Coots, 1998; Crosnoe, 2001; Fish, 2008; Garriott et al., 2000; Patel \& Steven, 2010; Slade et al., 2018). When asking questions that require multiple choices, using "other" may be an option. When Tucker and Schwartz (2013) created their survey, an other option was provided for all close-ended questions because they knew their options did not include all possible options for the parents.

\section{Possible Meeting Supports}

When focusing on parent perspectives, the goal is to understand. However, the secondary outcome would be to improve the IEP process for parents and staff. In the previous section, the gap in the research was discussed. This section reviews special education and outside of special education research to understand dynamics that can improve the IEP process once parent perspectives are clearly understood within the NPS setting. Topics discussed include the effectiveness of teams, conflict resolution, teacher training, and parent training. 


\section{Effectiveness of Teams}

Hackman's (2011) book was written to "improve collaboration and teamwork" (p. 26) to eventually improve the quality, speed, and agility of intelligence work throughout the community. The book was not written about teams in education, but the suggestions for teams can be applied to any team. The information from this book is tied into this section on the effectiveness of teams. The effectiveness of teams can be divided into who is involved and the nature of the interactions between team members.

\section{Who Is Involved?}

Part of creating an effective team is considering who should be included. Besides members legally required to attend IEP meetings, research both in education and outside of education shows that the following are important to consider when creating a team: (a) members should be from multiple disciplines, (b) members should have different knowledge and experiences, and (c) there should be parent and administrator involvement.

According to Hackman (2011), “any team must include members who have knowledge and skills that the task requires" (p. 15). This would include members from multiple disciplines. Education research has shown similar suggestions. For example, during prereferral meetings, having team members from multiple disciplines creates a complete understanding of the child, especially if each member has their knowledge of the student (Etscheidt \& Knesting, 2007). Martin et al.'s (2004) study found that participants had more positive views about the IEP meeting when general education teachers attended IEP meetings. They reported that they talked more at the meeting, talked more about student strengths, reported feeling more empowered to make decisions, reported increased knowledge of what to do next, and reported feeling better about the meeting (Martin et al., 2004). When related services providers attended the IEP 
meetings, participants rated that they knew the reason for the meeting better and talked more about student interests (Martin et al., 2004).

In addition to including individuals from multiple disciplines, teams should include members with the experience and expertise to help problem solve. Hackman (2011) indicated organizations commonly include people based on their organizational role instead of their experience or knowledge. Special education teams should consider both who is required to attend and who has the most valuable knowledge about the student. According to Etscheidt and Knesting (2007), the experience and expertise of team members were found to increase dialogue and increase effective problem-solving throughout the meeting. This was echoed by Mehan et al. (1986) when reporting that all IEP team members come to meetings with their knowledge about the student, expertise, and past experiences.

Due to this distribution of knowledge among team members, decisions should not be made by one person, but the knowledge of all individuals should be used to solve problems. Etscheidt and Knesting (2007) reported that the commitment of the team members included in each meeting was a "major contributor to the problem-solving process" (p. 274). It was important that the educators believed in the process and were there to support the student.

Parent involvement in IEP meetings has been discussed in previous sections, but administrator involvement is also important. During the study, multiple team members indicated that having the administrator involved in the meeting, both for logistics and as an active member, contributed to the interpersonal dynamic of the meeting. Administrators were viewed as “valuable partners" (Etscheidt \& Knesting, 2007, p. 276). Parent participation and administrator support and involvement created a stronger group dynamic (Etscheidt \& Knesting, 2007). 


\section{Nature of Interactions}

Along with having specific team members, the nature of the team's interactions is crucial to effective problem solving. The following research discusses: (a) having a clear purpose, (b) relying on data, (c) concerns should be addressed using multiple options, and (d) professionalism.

According to Hackman (2011), all teams must have a clear, challenging, and consequential team purpose. By challenging, Hackman suggested team members should "stretch" to accomplish their tasks. When using the word consequential, Hackman proposed that team purposes should have clear expectations for each team member. During research in education, Etscheidt and Knesting (2007) reported that teams found it hard to target one clear concern, but when they were able to do so, the problem-solving process was more effective and structured. The effectiveness increased when teams clearly stated the concern and developed a plan to help support the student. Additionally, team members openly discussed multiple options for solving the problem and a clear plan to solve the problem (Etscheidt \& Knesting, 2007).

The use of data and documentation was linked to creating conversation and problem solving among team members (Etscheidt \& Knesting, 2007). When there was little data, the team had nothing to discuss and nothing to use as past success or weaknesses. During prereferral meetings, all members appreciated the importance of professionalism throughout the process, especially during conflict (Etscheidt \& Knesting, 2007). Members found it essential that team members be able to disagree professionally and continue to discuss options.

The effectiveness of the IEP team affects the outcome of the meeting and can impact the perspectives of the parents involved. Using these strategies to create and run an effective team may greatly benefit IEP meetings. 


\section{Conflict Resolution and Facilitation}

The use of conflict resolution and IEP facilitation should be considered when holding IEP meetings. Conflict does not always have adverse effects on group outcomes. Group conflict research has begun suggesting that group aspects, such as trust, can change the impact of conflict on group outcomes (Jehn, 1997; Jehn \& Bendersky, 2003). Conflict can be used as a discussion to build a consensus (Behfar et al., 2008).

\section{Conflict Resolution}

Conflict resolution or management has been shown to positively restore fairness, process effectiveness, recourse efficiency, working relationships, and satisfaction of team members (Thomas, 1992). According to Tjosvold (1991), using a cooperative approach to conflict management allows for the resolution of the conflict that can be beneficial to the group. Based on Behfar et al.'s (2008) study, teams who had the highest performance and satisfaction were focused on equity. For example, teams who worked to find ways to contribute despite their differences or setbacks were more likely to achieve performance goals and high individual member satisfaction. Teams used techniques such as discussion and debate, open communication, and compromise or consensus to work through different task conflicts. Using "non-emotional and fact-driven discussions helped team members understand how the group reached consensus" (Behfar, 2008, p. 183).

\section{Facilitation of the IEP}

In the 1960s, the formal process of meeting facilitation was developed to help business groups work effectively and productively (Doyle, 1996). There are now several models of IEP facilitation. According to Mueller (2009), the following seven components are needed for a successful IEP facilitation: 
(a) a neutral facilitator, (b) an agenda, (c) meeting goals created by each member of the team, (d) ground rules, (e) an environment that fosters collaboration, (f) communication strategies that eliminate any power imbalance, and (g) the use of a parking lot, which is a written record where the facilitator can respectfully place any off-topic ideas that come up in the meeting, so that they may be addressed more efficiently at the meeting's end. (as cited in Mason \& Goldman, 2017, p. 213).

During a study by Mason and Goldman (2017), results indicated 24 of the 43 state educational agencies were currently using facilitation and all of those using facilitation were satisfied with the process. Additionally, results suggested that IEP facilitation improved relationships and reduced conflict; however, not all agencies collected data from parents, so data was minimal. The use of facilitation is an effective tool to help groups work effectively and productively both in the field of education (Mason \& Goldman, 2017; Mueller, 2007) and beyond (Doyle, 1996).

\section{Staff Training}

Educational research supports the need for teacher training to develop teachers' abilities to involve parents and facilitate an effective IEP meeting (Dotger, 2009; Elbaum et al., 2016; Klingner \& Harry, 2006; Murray et al., 2008; Whitbread et al., 2007). Research has shown teacher education programs (TEPs) lack opportunities to develop the skills teachers need to interact with parents and be an educational resource (Epstein, 2005; Epstein \& Sanders, 2006; Ferrara \& Ferrara, 2005; Hiatt, 2001). Additionally, TEPs provide limited coursework and time for teachers to develop skills to support parent participation in meetings (Klingner \& Harry, 2006; Murray et al., 2008; Whitbread et al., 2007). The following sections discuss the research on staff training. 


\section{Selective Prioritization}

The first option for training teachers is not training but rather a way to approach recommendations. Many teachers look to research for practice recommendations; however, this becomes a problem due to the amount of information accessible (Elbaum et al., 2016). Elbaum et al. (2016) discussed the wealth of recommendations in the literature about parent involvement in special education and suggested that this wealth of suggestions may pose a challenge to educators. An example of this wealth of knowledge can be found in Hoover-Dempsey et al.'s (2005) list of 30 specific strategies to promote parent involvement or Brandon and Brown's (2009) list of 30 strategies to increase African American parent involvement. McCheney et al. (2012) found that business and marketing experts suggested that implementing too many strategies leads to poor implementation and undesirable outcomes. Instead of attempting to implement a laundry list of strategies, Elbaum et al. (2016) recommended selective prioritization, which involved "understand(ing) which dimensions of parents' experiences with schools contribute most strongly to parents' perceptions" and "identify(ing) a parsimonious set of recommendations to improve schools' facilitation of parent involvement" (p. 16). Elbaum et al.'s (2016) results indicated the two most significant variables in increasing parent engagement were direct communication and perceptions of the services provided to their student.

Fishman and Nickerson (2014) found direct communication from teacher to parent was the only significant predictor of parent involvement. According to Thijs and Eilbracht (2012), direct communication may improve the quality of interpersonal bonds and increase communication about the student, leading to a better understanding of the student and their needs. According to Elbaum et al.'s (2016) study, parents' perception that their child was making progress due to the services provided was a predictor of parents' perceptions of the school's 
parent engagement efforts. Parents who perceive their child is making progress due to the program provided, services, level of teacher competence, or staff flexibility are more likely to feel the school is making attempts to engage them.

\section{Meeting Simulations}

Applied simulation has been used in education through simulated parent-teacher conferences, using actors as parents to train teachers (Dotger, 2009; Dotger et al., 2008, 2010). Dotger (2009) used the simulations to target teachers' communication skills and allow teachers to interact with parents from various backgrounds. The study found teachers "developed an increased awareness" (Dotger, 2009, p. 93) of the parents and their perspectives. Similarly, Dotger et al. (2008) used simulation to conduct parent-teacher conferences so preservice teachers could learn to engage with parents. Teachers reported that this approach was authentic and could be valuable for new teachers.

Selective prioritization and meeting simulations are two techniques that can be used to support special education teachers in running IEP meetings. These techniques should be further researched in the field of special education.

\section{Parent Training}

Unlike educators, parents often start their student's educational experience with little knowledge about special education and no professional background in education. Families with students in special education need help to explain their students to others, gain knowledge and skills, access services, and gain information about financial support (Bailey \& Simeonsson, 1998). One method to help parents and guardians is to provide or encourage them to attend training. The following sections provide literature on training that could be beneficial to parents of children in special education. 


\section{Special Education Trainings}

Rios and Burke (2021) conducted a systematic literature review of the effectiveness of special education programs for parents of children with disabilities. The main purpose of the review was to focus on children with intellectual or developmental disabilities and Latino families. However, the outcomes of the study may be beneficial to all special education parents. Results indicated that parent program interventions might have "positive effects on knowledge, advocacy, and empowerment" (Rios \& Burke, 2021, p. 215) of parents.

Citil (2020) conducted a semi-experimental study in Turkey to understand the effectiveness of a parent training program for families of children with special needs. Results found parents who completed the training had more knowledge of their legal rights after the training than they did before. Of the participants, 93.3\% indicated the training met their expectations for learning about legal rights, and all participants indicated they were happy they participated in the program and thought it would be helpful to other families.

\section{Parent Engagement and Empowerment Program}

The Parent Engagement and Empowerment Program (PEP) was developed in 1993 by a workgroup of Family Peer Advocates (FPA) and policymakers (Rodriguez, 2011). The workgroup was formed to address parent access to mental health services. To improve children's access to services, the workgroup suggested: "including experience(d) peer(s), parents, as family advocated to work directly with parents" (Rodriquez, 2011, p. 398). PEP moves away from a fully clinical-led model, in which parents build skills to manage children's symptoms, to a family-led model, in which the focus is to build skills to increase parents' self-care and coping (Hoagwood et al., 2010). According to Rodriguez et al. (2011), in PEP, the training and consultation are led by both the FPA and a mental health provider. Using this model, the mental 
health provider tends to treat the child as their patient, while FPAs treat the entire family as the focus. PEP has an entire conceptual framework to help families by including experienced peer families as well as mental help providers. During a study of the effectiveness of this program, Rodriguez et al. found family empowerment, mental health services efficacy, and selfassessment of skills all increase over time. This type of parent program does not directly link to the parent of children in special education; however, the concepts or framework could be beneficial for parents of children with all disabilities, not just mental health concerns.

\section{Parent-Professional Partnership and Empowerment}

Partnerships between parents and school professionals to increase empowerment are relatively new (Stoner et al., 2005). Parents are usually at a disadvantage when working with school professionals, but these partnerships need to be an "equal division of power" (Morrow \& Malin, 2004, p. 164) with shared decision making (Hodge \& Runswisk-Cole, 2008). Dunst and Dempsey (2007) conducted a study that focused on the relationships between parents and professionals as they related to empowerment. The study found that parents' sense of control is impacted by the type of support they receive from school professionals. Murray et al. (2016) conducted a study to "provide educators with hands-on family engagement experiences, but also to empower parents of children with disabilities" (p. 148). During the study, parents took a 16week semester course, Consultation and Collaboration with Families and Colleagues, alongside education students. Four major themes were discovered, parents transitioned (a) from judgmental and impersonal to caring professionals, (b) from intimidation to confidence, (c) from defensiveness to trusting professionals, and (d) from despair to hope. Additionally, study findings indicated parents participating in the course contributed to parent empowerment by feeling they had an active role in the decision-making process, access to resources, causing a 
change in their life and community, feeling a sense of belonging, having self-efficacy, feeling hope, learning to think critically, and receiving respect.

Parent training has been found to positively impact parents' perceptions (Rios \& Burke, 2021). Using parent training to empower parents may increase active parent participation and be a useful tool for all special education programs.

\section{Conclusion}

The perspectives of parents in the IEP meeting have been researched extensively in the traditional public-school setting. In most studies, parents at traditional public schools felt they participated in the IEP process and had positive relationships with the educators on their students' IEP team (Fish, 2008; Garriott et al., 2000; Salembier \& Furney, 1997; Spann et al., 2003). However, there were large groups of parents, in each study, who found it challenging to participate (Cavendish \& Conner, 2018; Lovitt \& Cushing, 1999), engaged in passive involvement (Garriott et al., 2000), and had negative experiences with educators (Tucker \& Schwartz, 2013; Zeitlin \& Curcic, 2014). The views of all these parents provide quality information to the IEP team and can shape how educators approach future IEP meetings.

When students transition to NPSs, their parents become part of a population with a unique view of the IEP meeting process. These parents rely on the NPSs and the school district to help their children succeed. Currently, there is no research on parents' perspectives of the IEP meeting at NPSs. This gap in research between public and NPSs was explored in this research study. Exploring this gap in the research can allow for the creation of more effective IEPs for students receiving special education services. NPSs will be able to create an environment during the IEP meeting that allows parents to be comfortable and open with the IEP team. Additionally, data collected by this study may inform future training of staff at NPSs. 


\section{Chapter 3: Methods}

In Chapter 2, previous research on parent perspectives of involvement and parenteducator relationships during IEP meetings in the traditional school setting was discussed. Research conducted with parents at nonpublic schools (NPSs) was included, and a gap in the research was found in parent perspectives during IEP meetings at NPSs. This study focused on collecting survey and interview data from parents whose children attend or attended NPSs on their perspectives of involvement and parent-educator relationships during IEP meetings at NPSs.

This chapter addresses the research procedures used to conduct this study. Topics included in this chapter are (a) the research design, (b) research format, (c) survey access and recruitment, (d) interview recruitment, (e) population and sampling, (f) survey instrument, (g) pilot study and survey review, (g) interview instrument, (h) procedures for data collection, (i) survey data analysis, (j) interview data analysis, (k) ethical considerations, (l) benefits to respondents, (m) presenting results, (n) study strengths, and (o) study limitations.

\section{Research Questions}

The purpose of this study was to attempt to understand the perspectives of parents of students at nonpublic schools as they experience IEP meetings. The following research questions helped guide the researcher through the creation of methods for this study:

- Question 1: How do parents of students receiving special education services perceive their level of involvement during the IEP meeting process at nonpublic schools?

- Question 2: How do parents of students receiving special education services perceive their relationships with the IEP team during the IEP meeting process at nonpublic schools? 
- Question 3: Do parent perceptions of involvement in the IEP meeting process at a nonpublic school vary across demographic variables (e.g., age of the child, eligibility category, number of years in special education, race and ethnicity, parent educational level)?

$\circ$ Question 3A: Is there a difference between perceptions of parent involvement among parents with different educational levels?

○ Questions 3B: Is there a difference between perceptions of parent involvement among parents who self-identify in different race/ethnicity categories?

Q Questions 3C: Is there a difference between perceptions of parent involvement among parents whose children have been in special education longer than 5 years and those with children in special education less than 5 years?

During the survey portion of the study, the researcher served as an objective observer and was independent of the actual study. The survey was created based on a traditional paradigm to quantify parent perspectives so they could be better understood, and the research process was deductive. In comparison, the interview portion of the research used an interpretive paradigm because it allowed for more emphasis to be placed on the experiences of the participants. In the interpretive paradigm researchers, "value people's subjective interactions and understanding of their experiences and circumstances" (Leavy, 2017, p. 13). Using this paradigm allowed the researcher to seek meaning in the individual experiences of the parents at NPSs. Using both survey and interview data allowed for a well-rounded and in-depth understanding of the parents' perspectives. 


\section{Research Design}

This study used a convergent mixed-method design to merge quantitative and qualitative data to answer the three research questions. A mixed-method design was selected to reduce the limitations of quantitative and qualitative research conducted on its own (Creswell \& Creswell, 2018) and gain a more thorough answer to the research questions. A convergent design was used to "compare different perspectives drawn from quantitative and qualitative data" (Creswell \& Creswell, 2018, p. 216) and provide a reliability check for the quantitative data. Creswell and Creswell (2018) stated the premise of convergent mixed method design "is that both qualitative and quantitative data provide different types of information ... and together they yield results that should be the same" (p. 217). The quantitative and qualitative data were collected at the same time, merged, and then compared.

The quantitative phase of the study started first and was considered the dominant method; however, once the qualitative phase started, both qualitative and quantitative phases ran concurrently until the end of the data collection process (Kroll \& Neri, 2009; see Figure 3.1). The qualitative phase, which is considered the second method, was nested within the quantitative phase. A few participants who provided quantitative data in the survey were selected to participate in the qualitative data collection process. These participants were selected based on convenience (e.g., volunteers) and were not purposefully selected based on their responses to the survey, as would be the case in an explanatory mixed-method design (Creswell \& Creswell, 2018). 


\section{Figure 3.1}

\section{Study Design: Convergent Mixed Method Design}

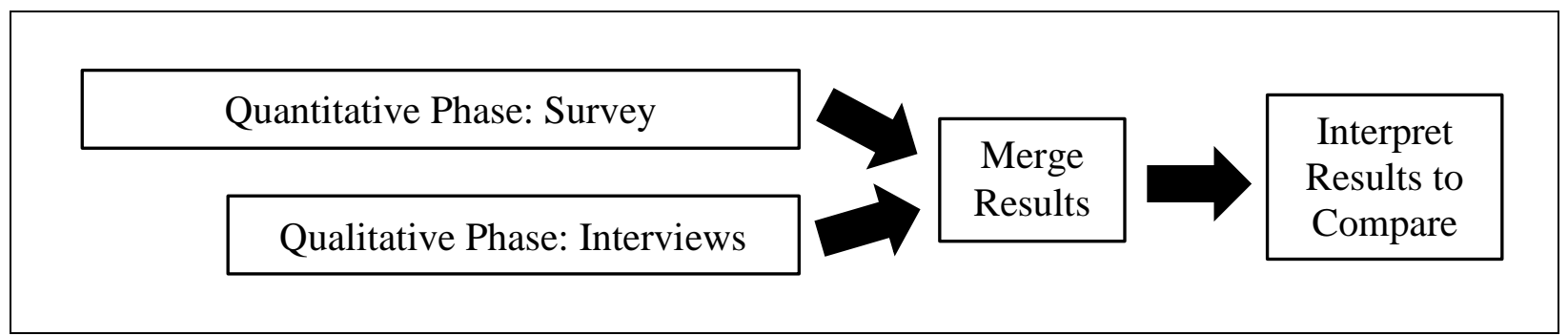

Note. Adapted from Research Design, 5th ed., by J. W. Creswell and J. D. Creswell, 2018, p. 218. Copyright 2018 SAGE Publications.

The interviews were able to provide more data toward the research question; however, analyzing interview data can be time-consuming, and the quality of the data collected should be considered (Marshall \& Rossman, 2016). Using interview data for the current student was appropriate because the goal was to understand the parents' views. Marshall and Rossman (2016) stated that when using interviews, researchers should be able to prove the goal of their research to "undercover and describe the participants' perspectives on events - that is, that the subjective view is what matters" (p. 151). For the current research, gathering data on parents' unique perspectives of their IEP experiences was the primary goal of the research study.

\section{Research Format}

The researcher used Qualtrics XM, an online survey tool that allows for surveys creation, distribution, and analysis through an online platform. Qualtrics XM allowed the researcher to easily collect survey data and allow for comfort and confidentiality during interviews. The survey was web-based, and the interviews were conducted using a video conferencing platform. 


\section{Web-Based Survey}

Over the history of survey research, the format of the survey has evolved based mostly on access to technology (Dillman et al., 2014). In the early 2020s, the internet was the largest area for survey collection and allowed researchers to connect quickly with large samples (Fowler, 2014). Web-based or computer-assisted survey formats have some significant advantages. The program can skip questions based on previous answers, adjust language based on the primary language of the respondent, and respondents seem to be more comfortable entering information about sensitive topics into a computer instead of talking to an interviewer. Additionally, web surveys are attractive because they are low-cost, quick, and can be used on a large scale (Dillman et al., 2014).

The current study used a web-based survey design to provide easy access for respondents and quick data collection. The survey was sent to respondents through email and completed electronically. The use of a web-based format for this survey allowed the researcher to provide the survey in two languages, Spanish and English. This format allowed questions to be skipped based on respondents' answers to previous questions. In addition to being web-based, the survey was self-administered due to the personal nature of some of the questions. Computer-assisted self-administration has been shown to have more effective results when compared to in-person interviews (Aquilino, 1994; Dillman \& Tarnai, 1991; Tourangeau \& Smith, 1998; Turner et al., 1998).

\section{Self-Administration}

The survey was self-administered to ensure confidentiality and provide parents with the comfort to answer potentially stress-provoking questions about their experiences in IEP meetings. Fowler (2014) suggested self-administration of surveys is thought to be the best 
method when dealing with sensitive topics because respondents do not have to share socially undesirable opinions directly with an interviewer. Using a self-administered survey was initially selected instead of interviews to provide more confidentiality and ensure respondents felt as comfortable as possible answering questions about sensitive topics. Using self-administered surveys allowed the researcher to obtain a sample of participants for the interview portion of the study, based on parents who felt comfortable participating.

\section{Video Conference Interview}

A video conferencing platform was used to allow for higher levels of confidentiality and increase the comfort of respondents (Dixon, 2012; Evans et al., 2010; Willis, 2012). The interviews were conducted via Zoom, a web-based video communication system. Zoom allowed the researcher to connect with respondents in a comfortable and safe environment (Evans et al., 2010). Respondents were able to stay in their own homes and did not have to turn on the video. The ability to keep their video off increased the confidentiality of respondents. The respondents were provided the option of calling in using a Zoom phone number or using the Zoom video option. Additionally, Zoom allowed for audio recording, which was used with the respondent's consent. Video recording was not used. Zoom also allowed for transcription of the video session. This service was used but not relied on for accuracy. Transcripts were reviewed for accuracy by the researcher.

\section{Survey Access and Recruitment}

The researcher gained access to the NPSs' parents through three sources. The researcher contacted NPSs directly, contacted school district representatives, and used Facebook parent groups to recruit parents to participate. 


\section{NPS Recruitment}

The first method used to access parents at NPSs was by contacting the NPSs directly. The researcher used three methods to create a list of NPSs. Those methods include: (a) personal and professional contacts, (b) the California Department of Education (CDE) School Data Directory, and (c) the California Association of Private Special Education Schools (CAPSES) county directory. All schools contacted during the recruitment phase were located in Los Angeles, Orange, San Diego, San Bernardino, and Riverside counties.

\section{Personal and Professional Contacts}

First, the researcher used personal and professional connections to contact NPS administrators who may be willing to participate in the study. Connections included close friends who worked at NPSs, school psychologists who worked collaboratively with NPSs, administrators who contracted with NPSs, and members of the research team who worked closely with NPSs on a professional basis. All NPSs identified by these contacts were emailed by the personal or professional contact using an email template (see Appendix A).

\section{CDE School Directory}

Second, the researcher used the CDE directory of schools to search for all schools located in Los Angeles, Orange, San Diego, San Bernardino, and Riverside counties. The list of schools was created twice. The first list of Nonpublic Nonsectarian Certified Schools was created on October 20, 2020. At that time, 100 schools in Los Angeles, Orange, and San Diego counties had a status of "Active," which indicated the school was currently open. Schools open in December 2020 included 61 in Los Angeles County, 16 in Orange County, and 23 in San Diego County. During multiple attempts, over 4 months, all 100 schools in the three counties were contacted by the researcher in at least one of the following ways: (a) calls directly to schools, (b) emails sent 
to administrators or contact emails, and (c) contact forms completed on the school websites. Based on these attempts, a few schools declined to participate; however, most schools did not respond to the initial email. Two schools in Orange County, one in Los Angeles and one in San Diego County, agreed to participate.

On July 12, 2021, the CDE school directory was downloaded, and a list of all schools within San Bernardino and Riverside counties was created. The researcher contacted the eight NPSs in San Bernardino County and the eight in Riverside County; however, no school agreed to participate.

\section{CAPSES Directory}

The third method of contacting NPSs was through the California Association of Private Special Education Schools (CAPSES) county directories for Orange, San Diego, and Los Angeles counties. Twenty-three schools were contacted. Some of the schools contacted were already identified by the CDE directory of schools; however, CAPSES provided additional contact information such as phone numbers or websites. After using personal and professional contact, the CDE directory of schools, and CAPSES directories, four schools agreed to participate in the study.

\section{School District Representative Recruitment}

The second method of recruiting NPS parents was through personal or professional connections to school districts. The researcher contacted three professional contacts, one in each of the three counties being studied: (a) Orange, (b) San Diego, and (c) Los Angeles. The contact in Orange was not able to connect the research with any district representatives; however, they were able to recommend the use of the CAPSES website. The contact in Los Angeles County connected the research to one NPS representative, but the school declined participation. The 
contact in San Diego County connected the researcher to two school district representatives. Both representatives agreed to send the survey to their NPS parents. The school district representatives were employed in districts in San Diego County and the Inland Empire. The parents contacted by the district representative had students who were placed at multiple NPSs. The NPS information for these students was not collected due to a potential breach of confidentiality.

\section{Facebook Parent Groups}

To increase survey participation, the researcher requested to join 14 Facebook groups in July 2021. Facebook groups were identified using the following keywords: (a) special education advocacy, (b) special education advocacy California, (c) NPS students, (d) California special education parents, (e) special education and IEP group, (f) special education California, (g) parent advisory group, (h) parent advisory group California, and (i) parent group California Autism. When requesting to join Facebook groups, many groups ask questions before approving users to join. The researcher had to answer questions about why she wanted to join groups, if she was an educator, and if she had a student with a disability. The researcher stated she was a student and school psychologist conducting a research study for a dissertation. She also indicated she would only be posting one time. After being approved to join nine groups, the researcher posted the survey information and link to each group page using a template (see Appendix B). The researcher was approved to join and post in the following Facebook groups: (a) Special Education IEP \& 504 Plan Support Group; (b) San Diego Family Resource Pg: Autism, ADHD, Sensory, Down Syndrome, etc.; (c) ADHD/IEP/504/Dysgraphia/Special Needs - Child Advocate to Assist Parents; (d) Special Education/IEP Support Group; (e) Special Education IEP Help Center for Educators and Parents; (f) California Concerned Parents for Public Education; (g) 
Special Needs Parents Support \& Discussion Group; (h) Autism+Mom Social \& Beyond; and (i) North County Families/Children with Special Needs.

Additionally, the researcher liked five Facebook pages about special education parents, parent advocates, and parent autism groups. All of these were companies that support parents of children with special needs. Some pages were private and others were public. The researcher messaged private pages and attempted to post information on public pages; however, none of these pages agreed to allow the information and link to be posted on their company's Facebook page.

\section{Interview Recruitment}

The last question of the survey asked respondents if they would be interested in participating in an interview about their perspectives during IEP meetings at NPSs. This question asked parents who were interested in participating in an interview to list their contact information. All parents who listed their contact information were contacted using the email or phone number provided. A recruitment email template was sent to all interested respondents (see Appendix C). Phone calls were made to those who listed their phone number as the best form of contact. The information from the template email was used during the phone calls to ensure all study details were provided to possible interview participants. Parents who agreed to participate were sent a digital informed consent document, and a Zoom interview was scheduled. Interviews were scheduled over the phone and a link was provided for participants to join the over the phone or through video conference.

\section{Population and Sampling}

When selecting a sample, the goal is to select a sample that will most represent the full population (Fowler, 2014). There are many principles to follow to select a sample that is an 
accurate representation of the target population (Dillman et al., 2014). These principles included the procedures used to select people for the survey and strategies to minimize sampling errorthe following section details the population and sampling methods.

\section{Population}

A target population is the group of interest (Patten, 2017) to which the study is attempting to be generalized (Dillman et al., 2014). For this study, the population included parents with a child in special education attending an NPS in Southern California at the time of the study. The NPS parents were selected based on access and convenience. NPSs and district representatives were recruited first and then asked to disseminate the survey via email. Facebook recruitment was used to increase survey completion.

The population included parents and guardians whose student was currently attending an NPS in Southern California. The population was determined based on inclusion criteria. To be included in the study, participants had to meet four requirements. First, the respondents had to have a student in special education at the time of the study. Second, their student in special education had to be currently attending an NPS. Third, the NPS had to be located in California. Fourth, the parent had to have attended at least one IEP meeting at an NPS. Information about how inclusion criteria were met is now discussed.

First, the respondent had to have a student currently in special education. The first question was, "Is your child in special education?" If respondents answered No, they were directed to the end of the survey. If they answered Yes, they were directed to the next question and able to continue through the survey.

Second, respondents' students had to be currently attending an NPS. For respondents who were recruited through an NPS or district representative, it was already known the respondents 
had a student attending an NPS because they were contacted based on their student's school enrollment. For respondents who were recruited through Facebook, a question was added at the beginning of the survey that asked, "Does your student attend an NPS in California?" If respondents selected No, they were directed to the end of the survey. If they selected Yes, they were directed to continue the survey.

Third, all respondents had to be in California because the definition of an NPS differs from state to state in the United States. This study focused on NPSs in California. Respondents were only included if they indicated they lived in a county in California. If a respondent indicated they lived in a county outside of California, they were not included in the results. This step was crucial for participants who were recruited from Facebook groups. All participants indicated which county they lived in. While reviewing the data, only one participant was from outside of the state. That participant's responses were not included. All other participants were located in Southern California.

Lastly, all parents had to have attended an IEP meeting at an NPS. Participants were asked, "How many IEP meetings have you attended at a nonpublic school (current school and any past nonpublic schools)?" Parents were only included if they provided an answer to this question and had attended at least one IEP at an NPS.

\section{Access to the Sample}

The researcher gained access to the sample through two main sources. The first source was directly working with NPSs. The second source was through Facebook groups for parents with students in special education. Descriptions of the two groups used to create the population are described in detail in the following sections. 


\section{NPS Access}

In October 2020, there were 208 NPSs open in Los Angeles, Orange, and San Diego counties. By July 2021, only 100 of those schools were listed as open on the California Department of Education database. All 100 schools in Los Angeles, Orange, and San Diego were contacted. In July 2021, the 17 open NPSs in San Bernardino and Riverside counties were also contacted. Only four schools agreed to participate. Two schools were in Orange County, one in Los Angeles County and one in San Diego County. The two district representatives were located in school districts in San Diego County and Riverside County. One school agreed to send the survey to current students and students who had attended the school within the last 2 years. All other schools agreed to send the survey to only current students.

Each school provided the researcher with the total number of students attending their school. Each school district representative provided the researcher with the number of parents they were able to send the survey. Table 3.1 shows the total number of survey recipients for each school and school district representative. Based on the reported totals for each school and representatives, the survey was sent to approximately 166 parents before being posted on Facebook groups.

\section{Table 3.1}

Total Possible Survey Recipients by School or Representative

\begin{tabular}{lcc}
\hline \multicolumn{1}{c}{ School or representative } & Current students & Attended in the last 2 years \\
\hline School 1 & 40 & 20 \\
School 2 & 26 & - \\
School 3 & 20 & - \\
School 4 & 53 & - \\
School district representative 1 & 1 & - \\
School district representative 2 & 6 & - \\
Total & 146 & 20 \\
\hline
\end{tabular}

Note. Each school provided the data unique to its campus. Not all schools provided data or contact information for students who attended in the last 2 years. 
The NPSs included students with a range of special education eligibility, race and ethnicities, ages, and socioeconomic status. School demographic information was collected from each school's School Accountability Report Card (SARC) and reported next. Each school was required to post its most recent SARC on its school website and be accessible to the public. All four of the schools that participated in the study included their SARC on their website. School 1, 2, and 3 had their 2018-2019 SARC posted, while School 4 had their 2017-2018 SARC posted on their website. The demographic information of the parents contacted by the school district representative was not able to be collected and is not included in the tables.

Table 3.2 shows the totals of students enrolled in each grade during the 2018-2019 for Schools 1-3 and the 2017-2018 school year for School 4, at each of the four schools that provided their SARC data. Schools 1 and 2 included kindergarten through 12th grade. School 3 had middle school and high school students, sixth through 12th grades. School 4 had elementary and middle school students, kindergarten through eighth grade. Based on the SARCs posted on the school websites, the four schools combined had 188 students.

\section{Table 3.2}

SARC Population Grade Tools

\begin{tabular}{lccccc}
\hline \multicolumn{1}{c}{ Grade } & School 1 & School 2 & School 3 & School 4 & Total \\
\hline Kindergarten & 0 & 0 & - & 1 & 1 \\
First grade & 1 & 1 & - & 3 & 5 \\
Second grade & 3 & 0 & - & 6 & 9 \\
Third grade & 1 & 0 & - & 12 & 13 \\
Fourth grade & 6 & 0 & - & 7 & 13 \\
Fifth grade & 3 & 1 & - & 12 & 16 \\
Sixth grade & 5 & 1 & 0 & 12 & 18 \\
Seventh grade & 6 & 3 & 2 & 8 & 19 \\
Eighth grade & 5 & 3 & 5 & 9 & 22 \\
Ninth grade & 3 & 3 & 9 & - & 15 \\
10th grade & 3 & 3 & 9 & - & 13 \\
11th grade & 1 & 5 & 7 & - & 11 \\
12th grade & 0 & 7 & 4 & - & 15
\end{tabular}




\begin{tabular}{lccccc}
\hline \multicolumn{1}{c}{ Grade } & School 1 & School 2 & School 3 & School 4 & Total \\
\hline Ungraded secondary & - & 15 & - & - & 15 \\
Total students & 40 & 42 & 36 & 70 & 188 \\
\hline
\end{tabular}

Note. Missing information was not provided in the school SARC.

Table 3.3 provides average percentages for race and ethnicity provided in the SARCs for the 2018-2019 school year for Schools 1-3 and the 2017-2018 school year for School 4.

\section{Table 3.3}

SARC Population Race and Ethnicity

\begin{tabular}{lc}
\hline \multicolumn{1}{c}{ Category } & \% of total enrollment \\
\hline Black or African American & 5.76 \\
American Indian or Alaskan & 0.5 \\
Asian & 5.51 \\
Filipino & 0.25 \\
Hispanic or Latino & 53.43 \\
Native Hawaiian or Pacific Islander & 1.26 \\
White & 30.1 \\
Two or more races & 6.67 \\
\hline
\end{tabular}

Additional data that was reported in the SARCs included totals for socioeconomically disadvantaged, English learners, and foster youth were included. Data for each category was not provided by all four schools. Three schools reported the number of foster youth in attendance. The total number of foster youth in attendance at the three schools was 12. Two schools reported totals for socioeconomically disadvantaged students and English learners. At those two schools, there were 154 socioeconomically disadvantaged students and 44 English learners. 
Tables 3.2 and 3.3 include data for students who attended the four schools during the years specified on each SARC. The specific demographic information of the end sample is provided in Chapter 4.

\section{Facebook Groups Access}

After schools were recruited and surveys were sent out, Facebook was used to increase the sample. The researcher joined multiple Facebook groups focused on the topics of special education, advocacy, parents, and California. All parents who were members of these groups had the opportunity to complete the survey. Parents were asked to only complete the survey if they had a student who currently attended an NPS in California. Multiple survey questions were used to ensure parents fit the inclusion criteria.

\section{Sampling}

Research on survey methods shows a significant variance in what is recommended for determining sample size. Based on the literature, studies that use questionnaires typically include at least 50 participants (Cavendish \& Conner, 2018; Dickson \& DiPaola, 1980; Fish, 2008;

Garriott et al., 2000; Patel \& Stevens, 2010; Tucker \& Schwartz, 2013), but can include thousands if a large national survey instrument is used (Coots, 1998; Slade et al., 2018; Wagner et al., 2012).

Convenience sampling was used to obtain the sample for the current study. Convenience sampling is part of nonprobability sampling. Nonprobability sampling is the most common sampling method when studying parent perspectives and the IEP process (Agran \& Hughes, 2008; Burke \& Sandman, 2015; Cavendish \& Conner, 2018; Fish, 2008; Garriott et al., 2000; Lo, 2008; Patel \& Stevens, 2010; Slade et al., 2018). Nonprobability sampling can be problematic because the results cannot be generalized to the entire population; however, there is a time when 
random sampling is not practical, cost-efficient, or time-efficient (Nardi, 2018). Due to the type of sampling used, results were limited and not generalizable to all NPS students; however, the information collected can be beneficial to all NPSs in California and can be adapted to each unique school.

Emails were sent to one parent of each student. Parents were accessed through their student's NPS, a district representative, or a group on Facebook. All parents had the opportunity to complete the survey; however, not all who completed the survey were included in the final sample. Inclusion criteria were followed to select the final sample. Examples of surveys that were not included were participants who were not in California or did not complete at least the demographics and one full section of the survey.

Parents who completed the survey had the opportunity to provide their contact information at the end of the survey if they were interested in participating in an interview. Eight parents provided contact information. All eight respondents were contacted to gain consent for them to participate in a Zoom interview. Only parents who participated in the survey were eligible to participate in the interview process.

\section{Survey Instrument}

The survey was based on past research by Fish (2008) and Tucker and Schwartz (2013), and specific questions were modified from these seminal studies. The survey instrument is discussed in detail next. Information provided about the instrument includes (a) the foundational surveys, (b) survey and question format, (c) content-based questions, (d) demographics, (e) pilot study, and (g) an additional survey review. A copy of the full survey can be found in Appendix D. 


\section{Foundation Surveys}

The survey used in this study was based on two key studies in parent perspectives of IEP meetings. The two studies were Tucker and Schwartz (2013) and Fish (2008). Tucker and Schwartz surveyed 135 parents of children with a diagnosis of autism spectrum disorder to explore their perceptions of collaboration in special education. Tucker and Schwartz's survey was designed in multiple stages, which included a review of literature, question design, and an extensive review process. After questions were drafted and categorized, three parents of children with autism spectrum disorder took the survey and gave extensive feedback about the content and readability. The second step was to have a volunteer take the survey in front of the first author. The volunteer read the questions aloud and answered verbally. Once each question was answered, the volunteer and researcher reviewed the question for readability and discussed potential answers. The final survey included five sections: (a) collaboration, (b) supportive practices and professional behavior, (c) conflict and resolution, (d) service needs, and (e) educational and outcome priorities.

Fish's (2008) survey was given to 51 parents who had children child in special education. Their responses provided insight into parent perceptions of IEP meetings. The survey was pilot tested on parent support group members before its use and included six sections.

Questions from both foundational surveys were used in the creation of the survey. Many questions were used with limited or no wording changes. If these questions were altered, it was to change one word to more directly address the population being studied. For example, many questions were changed from using "school staff" to "NPS staff." Very few questions were significantly changed from the original foundation survey question. If they were altered significantly, the question topic remained the same. After questions from both surveys were put 
together into one survey, additional questions were added to support the initial questions.

Additionally, many multiple-choice questions required additional response choices to ensure all possible options were available. More about the exact questions and changes are included later in this chapter.

\section{Survey Format}

The web-based survey was developed using Qualtrics XM. The survey included 53 questions and was estimated to take 22 minutes (see Appendix D). The survey was divided into four main sections, which included: (a) demographics, (b) parent perspectives and experiences in IEP meetings prior to virtual learning, (c) parent perspectives and experiences in IEP meetings during virtual learning, and (d) additional questions (see Table 3.5).

Table 3.4

\section{Survey Question Topics by Section and Subsection}

\begin{tabular}{lcc}
\hline \multicolumn{1}{c}{ Sections and subsections } & Number of questions & Question numbers \\
\hline Demographics & 15 & $1-15$ \\
Prior to virtual learning & 1 & 16 \\
Involvement & 10 & $17-26$ \\
Communication & 5 & $27-31$ \\
Parent-educator relationships & 9 & $32-40$ \\
Conflict & 4 & $41-44$ \\
During virtual learning & 7 & $45-51$ \\
Additional questions & 1 & 52 \\
$\quad$ Interview option & 1 & 53 \\
\hline
\end{tabular}

The first section of the survey was demographics. This section gathered demographic data about each respondent and provided information to assist with inclusion criteria. This section included 15 questions, Questions 1-15.

The second section was about parents' experiences prior to virtual learning and gathering information about parents' perspectives about IEP meetings at NPSs prior to virtual learning and 
the school closures due to the COVID-19 global pandemic. This section included four subsections and a total of 29 questions. The section started with Question 16 that asked, "Have you attended an IEP meeting in person, at a nonpublic school?" and then continued with the four subsections. If parents answered $\mathrm{No}$, they were directed to skip to the next major section during virtual learning. Subsections prior to virtual learning included: (a) involvement, (b) communication, (c) parent-educator relationships, and (d) conflict with 10, five, nine, and four questions, respectively.

The third section, during virtual learning, asked questions about parents' perspectives of IEP meetings that were held virtually. This section included seven questions, Questions 45-51. This section included questions about (a) involvement, (b) communication, and (c) parenteducator relationships. This section required parents to compare their experiences during virtual learning to experiences prior to virtual learning.

The last section of the survey was additional questions. This section included one openended question and one interview option question. Two buttons were included at the bottom of each page to allow respondents to move to the next page or go back. Dillman et al. (2014) suggested surveys always allow respondents to go back because it can help if respondents make a mistake, forget to report something, or lose track of the flow of the survey conversation and need to go back to review content. The back button is used very rarely (Couper, 2008); however, it has been shown to significantly increase survey completion (Couper et al., 2011).

\section{Survey Language}

The survey was available to respondents in Spanish and English. Respondents could select between English and Spanish before opening the informed consent page. English and Spanish were selected based on demographic information for California. While $55.87 \%$ of 
California residents speak only English, 44.13\% speak other languages (U.S. Census, 2018). Spanish is the second most common language spoken by California residents, after English. Spanish is spoken by $28.7 \%$ of California residents. The next most common category of language, at 9.9\%, is Asian and Pacific Island languages.

\section{Translation}

The survey, informed consent, and all recruitment documents were translated from English to Spanish. Research on interpretation and translation suggests translators should be fluent in both languages and bicultural (Harry, 1992; Jung, 2011). According to Harry (1992), being fluently bilingual and bicultural allows interpreters to understand the "subtle nuances of language" (as cited in Jung, 2011, p. 24). Many difficulties with quality interpretation come from the interpreter's lack of cultural understanding and awareness (Chen et al., 2000; Hwa-Froelich $\&$ Westby, 2003; More et al., 2013). This need for an understanding of cultural differences increases the need for a translator who is bicultural. In addition to the need to be bicultural, the interpreter's knowledge of the topic being interpreted is important. Researchers suggest interpreters should have training or experience in the field of education, including the use of special education terms and procedures common in IEPs (Hart et al., 2012; Lo, 2008; More et al., 2013). In summary, translators should be fluently bilingual, bicultural, educated, and knowledgeable in IEP terminology and processes.

The translator used in this study was recommended by a school psychologist working in Los Angeles County. Her primary language was Spanish, and she was fluent in both Spanish and English. The translator worked as a translator and interpreter in a school district in Los Angeles County and had a history of working in this role for 11 years, since 2010. Her education in translation and interpreting included a court interpreter program certificate and telephone 
interpreter customer service program certification, both from Southern California School of Interpretation/Translation. Additionally, she had knowledge and experiences working in the field of special education, both as an instructional aid and as an interpreter and translator. She has interpreted numerous IEP meetings and helped translate many IEP documents and assessment reports. The translation was reviewed for accuracy by the researcher and two individuals whose primary language is Spanish.

\section{Questions Development}

As discussed previously, the survey was broken up into four main sections: (a) demographics, (b) prior to virtual learning, (c) virtual learning, and (d) additional questions. Each section includes questions from four main sources: (a) the Tucker and Schwartz (2013) survey, (b) the Fish (2008) survey, (c) a professional review of the current survey, and (d) suggestions from respondents who participated in the pilot study. When developing the survey questions, some questions were used as written in the Tucker and Schwartz and Fish surveys, although others were altered to better fit the current study and be more understandable to the target audience. Table 3.6 shows a visual representation of which questions were selected from each source. Specific questions in each section are discussed in the following sections.

\section{Table 3.5}

Survey Questions Based on Section and Initial Source

\begin{tabular}{|c|c|c|c|c|}
\hline \multirow[t]{2}{*}{ Section and subsections } & $\begin{array}{c}\text { Tucker \& } \\
\text { Schwartz (2013) }\end{array}$ & Fish (2008) & $\begin{array}{c}\text { Professional } \\
\text { review }\end{array}$ & Pilot \\
\hline & \multicolumn{4}{|c|}{ Question numbers } \\
\hline Demographics & $5,6,9$ & $3,4,7,10,11,13$ & $1,2,12,14,15$ & 8 \\
\hline Prior to virtual learning & & & 16 & \\
\hline Involvement & $20,23-26$ & & 17,21 & $18,19,22,31$ \\
\hline Communication & 28,30 & & 27,29 & \\
\hline Relationships & & $33-40$ & 32 & \\
\hline Conflict & $41,43,44$ & & & 42 \\
\hline
\end{tabular}




\begin{tabular}{|c|c|c|c|c|}
\hline \multirow[t]{2}{*}{ Section and subsections } & $\begin{array}{c}\text { Tucker \& } \\
\text { Schwartz (2013) }\end{array}$ & Fish (2008) & $\begin{array}{l}\text { Professional } \\
\text { review }\end{array}$ & Pilot \\
\hline & \multicolumn{4}{|c|}{ Question numbers } \\
\hline During virtual learning & & & $45-51$ & \\
\hline Additional questions & & 52,53 & & \\
\hline
\end{tabular}

\section{Involvement}

In the section prior to virtual learning, involvement was the first subsection. The involvement subsection included 10 questions. Of these 10 questions, five were based on questions included in the Tucker and Swartz (2013) survey. Three questions were based on professional feedback, and two were included based on the review and pilot process.

Five questions were based on questions included in the Tucker and Swartz (2013) survey. Those included Questions 20, 23, 24, 25, and 26. Question 20 had a wording change based on the pilot review. It was suggested the question be changed from "I feel involved in the collaboration and planning of the IEP document" to "I feel involved in the creation of the IEP document." This wording change made it clear what collaboration and planning were referring to in this situation. Questions 23, 25, and 26 were included with only minor working changes from the original Tucker and Swartz survey. Based on the pilot study, two additional answer options were included for Question 23, "sent me the draft report before the meeting" and "having me work on academics and/or behavior at home." All the answer choices were changed for Question 26 because the original answer choices were limited and not based on the NPS setting. Lastly, Question 24 was based on the question in Tucker and Swartz survey that read, "The most important thing an IEP team does or has done to collaborate with me and make me feel included is?" This question was changed from a multiple-choice question to a scaled question, where respondents were asked to rate their level of agreement for each of the original multiple-choice answers. The next question read, "The IEP team has collaborated with me by:" and respondents 
were asked to rate their level of agreement for the following statements: "Including me in the assessment process," "Including my suggestions for goals and objectives for the IEP," "Including my suggestions for curriculum or instructional approaches," and "Asking for my input during the meeting." The last statement was included based on professional review suggestions.

Three questions were included in the involvement subsection based on professionals' reviews of the survey. The first question, Question 17, asked respondents to rate their level of involvement during the IEP meeting on a scale from 1-4, with 1 being not involved at all and 4 being involved as much as I should be. This question was developed based on professional feedback to collect a rating for parents' perspectives of their involvement. The other two questions included based on professionals' review of the survey asked respondents to rate the statement from strongly agree to strongly disagree. The statements were, "I feel nonpublic school staff attempt to involve me throughout the IEP meeting" and "I feel my understanding of my child is recognized during the IEP meeting." This last question was based on research that indicates that many parents feel educators do not recognize their knowledge about their child (MacLeod et al., 2017; Valle, 2011).

Two questions were added to the involvement subsection based on the pilot study. Question 19 was added to clarify parent perspectives between NPS staff and school district staff. This question was identical to Question 18; however, "nonpublic school staff" was changed to "school district staff," and the question clarifies the meetings are being held at NPSs. The questions read, "I feel school district staff attempt to involve me throughout IEP meetings held at nonpublic schools." The last question added based on the pilot study was Question 22. It read, "I feel the IEP team supported my involvement through the use of my primary language." This question was added after a question about primary language was added to the demographic 
section. If parents indicated their primary language was English, they were not asked Question 22.

\section{Communication}

In the prior to virtual learning section, communication was the second subsection. The communication subsection included five questions. Of these five questions, two were based on questions included in the Tucker and Swartz (2013) survey. Two questions were based on professional feedback, and one was included based on the pilot study process.

Two questions in this subsection were developed based on questions in the Tucker and Swartz (2013) survey, Questions 28 and 30. The questions included similar wording as the original questions. These questions were "How often do nonpublic school staff communicate with you regarding your child?" and "How does your nonpublic school staff communicate with you regarding your child?" The only change made to these questions was the change from school staff to NPS staff. For Question 27, the original answer choices were used. For Question 30, additional answer choices were added based on suggestions from professionals and the pilot study.

Two questions were included in the communication subsection based on feedback from special education professionals who regularly attend IEP meetings at NPSs. Question 27 asked respondents to rate their NPS's level of communication on a scale from 1-4, with 1 being no communication at all and 4 being as much communication as I need. This question was developed based on professional feedback to collect a rating of parents' perspectives of their child's NPS's level of communication. The second question suggested by professionals was Question 29. This question read, "How satisfied are you with the level of communication provided by the nonpublic school?" Respondents were able to rate their level of satisfaction from 
very satisfied to very dissatisfied on a 4-point scale. This question was adapted based on a question in the Tucker and Swartz (2013) survey. The original question asked, "How important is frequent communication with school staff regarding your child's progress and educational program?" Professional feedback indicated most respondents would agree communication is important, and frequency was hard to quantify. For these reasons, the question was changed to ask about communication satisfaction.

One question was added to the communication subsection based on pilot testing of the survey. Question 31 was added to the end of the communication subsection. The question asked, "My nonpublic school staff communicates with me about the following, at least monthly (select all that apply)." Eight responses were included based on suggestions from the pilot review and professional feedback.

\section{Parent-Educator Relationship}

In the prior to virtual learning section, the parent-educator relationship was the third subsection. The parent-educator relationship subsection included nine questions. Of these nine questions, eight were based on questions included in the Fish (2008) survey. One question was added during the review process based on professional recommendations.

Seven of the eight questions based on the Fish's (2008) survey were included with no modification. The questions included Questions 33 to 40. The questions were 4-point scale questions that required respondents to rate the statement from strongly agree to strongly disagree. The questions were worded as follows: "Educators provide a welcoming atmosphere for you during IEP meeting," "I am treated respectfully by educators during IEP meetings," "I am treated as an equal decision-maker during IEP meetings," "I am able to talk openly and freely with educators during IEP meetings," "My input is valued by IEP team members during IEP 
meetings," "Overall, IEP team meetings maintain positive relations with me during IEP meetings," and "Overall, I feel comfortable during IEP meetings." The last question included the statement, "During IEP meetings, my overall relationship is positive towards," and required respondents to use the statement to rate their level of agreement for several NPS and district staff. The list of staff was altered to include staff involved in IEP meetings at NPSs, but the starter statement remained the same as the original statement in the Fish (2008) survey.

One question was included based on professional feedback. Question 32 was added to the beginning of the subsection to gather a rating from respondents on their relationships with NPS staff. This question asked, "Rate your relationship with nonpublic school staff during IEP meetings," and provided a 4-point scale from no relationship to best relationship possible.

\section{Conflict}

In the prior to virtual learning section, conflict was the fourth subsection. The conflict subsection included four questions. Three of the questions were based on questions included in the Tucker and Swartz (2013) survey, and one question was based on the pilot review process.

The two questions in the Tucker and Swartz (2013) survey used when creating the conflict subsection were, "Have you ever experienced conflict with your school team, district, or with a school professional?" and "What types of conflict have you experienced with your school team, district or with a school professional?" The first question was modified to say, "Have you ever experienced conflict during an IEP meeting?" to make the question shorter and more specific. A follow-up question was added to ask who the conflict was with. This question asked, "Who was the conflict with during the IEP meeting." This follow-up question was suggested by respondents in the pilot review process. 
The original question, "What types of conflict have you experienced with your school team, district, or with a school professional" was separated into two questions to ask specifically about conflict with the NPS staff and the district staff. The questions were "What type(s) of conflict have you experienced with nonpublic school staff during the IEP meeting at nonpublic schools?" and "What type(s) of conflict have you experienced with district staff during the IEP meeting at nonpublic schools?” Answer choices included from the Tucker and Swartz (2013) survey were "Disagreement over IEP content," "Disagreement over curriculum or instructional approaches," "Disagreement over school placement," “Disagreement over evaluation results," "Disagreement over discipline issues," "Personality or style conflict," and "difficulty getting cooperation with outside providers." Based on the review and pilot process, the following were added as response choices: "disagreement over eligibility," “disagreement over services," and "no conflict." "No conflict" was added because two questions were separated into NPS staff and district staff, and a respondent could have had a conflict with one group and not the other.

\section{During Virtual Learning}

This section included seven questions, all of which were developed based on suggestions from the professional review process. The first question, Question 45, asked, "Have you had an IEP meeting during virtual learning?" If the respondents answered $N o$, they were directed to skip this section because it did not apply to them.

The remaining six questions in this subsection asked questions about (a) involvement, (b) communication, and (c) relationships. Two similar questions were asked about each topic. The first of the two questions for each topic asked respondents to rate their level of involvement, communication, and relationships with NPS staff during virtual IEP meetings. These questions were identical to the question at the start of each subsection in the Prior to Distance Learning 
section. The second question for each topic asked respondents to indicate their level of agreement from strongly agree to strongly disagree. The statements were as follows: "I have felt more involved at IEP meetings, at my students' nonpublic school, during virtual learning, than I felt prior to virtual learning," "I have received more communication about my student's IEP at the nonpublic school, during virtual learning, than I received prior to virtual learning," and "I feel IEP team members maintain positive relationships with me during IEP meetings, during virtual learning." The researcher decided to use only two questions about each variable to shorten the virtual learning section and collect specific data about perceptions in-person, compared to virtual learning.

\section{Open-Ended and Interview Option Questions}

The last section of the survey was titled additional questions. This section included one open-ended question and three interview option questions. The open-ended question asked, "What can school districts or nonpublic school staff do to improve the involvement of parents, parent-educator relationships, and communication during the IEP meeting?" This question was based on the open-ended questions at the end of the Finish (2008) survey but was modified for the current variables.

The last question was an interview option question and was taken directly from Fish's (2008) survey. This question asked, "If you would like to discuss this topic further by being interviewed by the researcher, please provide your preferred contact method below (telephone, email)? Contact information will remain confidential and will be solely used to contact interview participants." 


\section{Question Format}

The survey included multiple-choice, yes-no questions, scaled questions, and openended questions. Throughout the entire survey, there were six yes-no questions, 20 multiple choice questions, 25 scaled questions, and two open-ended questions. Table 3.7 shows the question format for each question included in the survey.

\section{Table 3.6}

\section{Survey Question Format by Section and Subsection}

\begin{tabular}{lcc}
\hline Sections and subsections & Number of questions & Question numbers \\
\hline Demographics & 2 & 1,4 \\
$\quad$ Yes-no & 13 & $2,3,5-15$ \\
$\quad$ Multiple choice & 3 & $16,25,41$ \\
Prior to virtual learning & 7 & $23,24,26,28,30,31,40$ \\
$\quad$ Yes-no & 19 & $17-22,27,29,32-39,42,43,44$ \\
$\quad$ Multiple choice & 1 & 45 \\
$\quad$ Likert & 6 & $46-51$ \\
During virtual learning & & 52,53 \\
$\quad$ Yes-no & 2 & \\
$\quad$ Likert & & \\
Additional questions & & \\
$\quad$ Open-ended & &
\end{tabular}

\section{Yes-No Questions}

The survey included six yes-no questions. Yes-no questions were included in the demographic section, prior to virtual learning and during virtual learning sections.

Of six yes-no questions, five questions helped determine if the respondent was required to answer additional questions. These questions included: "Is your child in special education?," "Have you attended an IEP meeting, in person, at a nonpublic school?," "Has there been a time you have NOT felt included in your child's IEP meeting?," "Have you ever experienced conflict during an IEP meeting?," and "Have you had an IEP meeting during virtual learning?" For these 
questions, if the respondent answers $N o$, they were directed to skip the rest of that section or subsection. If they answered Yes, they were directed to continue answering questions.

"Is your child in special education?," "Have you attended an IEP meeting, in person, at a nonpublic school?," and "Have you had an IEP meeting during virtual learning?" were all included at the start of a section to help determine if the respondent met the criteria to answer that specific question. For example, if the respondent did not have a student in special education, the survey would have ended because that respondent would not have met the criteria to be included in the study. If they had not attended an IEP meeting in person, they would have been directed to skip the virtual learning section. The same would have happened for an IEP meeting during virtual learning.

Two yes-no questions were included that did not exclude respondents from the entire section, but their responses indicated if further questions were asked about the same topic. "Has there been a time you have NOT felt included in your child's IEP meeting?" and "Have you ever experienced conflict during an IEP meeting?" were used as starter questions. If the respondents answered Yes to either question, then follow-up questions were included to gain more information about their experiences during conflict or during times when they did not feel included.

There was one yes-no question that was independent of other questions and did not impact the flow of the survey. This question was, "Does your child qualify for free or reducedprice lunch at school?" This question was a simple yes-no question, and no follow-up questions were necessary. For questions that required more information than a simple yes or no, a multiplechoice format was used. 


\section{Multiple Choice Questions}

There were 20 multiple choice questions included in the survey. Multiple-choice questions in the demographic sections included questions about (a) county of residence, (b) age of child, (c) respondent role, (d) respondent gender, (e) respondent race and ethnicity, (f) respondent primary language, (g) respondent level of education, (h) the child's disability categories, (i) number of years the child has received special education services, (j) number of years the child has attended an NPS, (k) number of IEP meeting attended at an NPS, (l) time frame of last IEP meeting attended, and (m) number of IEP meetings attended at an NPS in the last year.

Multiple-choice questions were also used to gather information about (a) involvement, (b) communication, (c) parent-educator relationships, (d) conflict, and (e) virtual learning. Many multiple-choice questions provided a free response option, other, please specify or allowed respondents to select I am not sure.

The I am not sure option was used for demographic questions about qualifying for free or reduced-price lunch, the child's disability categories, number of years the child had been receiving special education services, number of years the child has been attending an NPS, time frame of last IEP meeting attended, and number of IEP meetings attended at an NPS in the last year. The answer choice, I am not sure, was not used for questions outside of the demographic section. Removing this choice forced respondents to select an answer instead of selecting I am not sure.

Nine multiple choice questions directed the respondents to "select all that apply," which means they were able to select multiple answers. This allowed for more variety of responses. 
Two of these questions were in the demographic section, and seven were in the prior to distance learning section.

\section{Scaled Questions}

The survey included 25 scaled questions. All the scaled questions used a 4-point Likert scale. For all Likert scale questions, a neutral option was not included to prevent respondents from choosing the middle neutral option and require respondents to choose agree or disagree (Nadri, 2018). The researcher chose not to use a neutral option to force respondents to provide their perspective and not "take the easy way out" (Pattern, 1998, p. 34) by selecting neutral or undecided. There were two different scales used throughout the survey. One scale ranged from strongly disagree to strongly agree, while the other was worded using not at all to as much as I need with modifications based on the question.

There were 17 Likert scale questions with options from strongly disagree to strongly agree. These questions were included in the demographic prior to distance learning and during distance learning sections. These questions gathered data about parents' perspectives of involvement, communication, parent-educator relationships, and conflict during IEP meetings. Questions asked respondents to rate themselves on a number scale from one to four, with one being very little of something and four being the most they felt they needed. One rating question was included at the start of the involvement, communication, and parent-educator relationship subsections.

At the start of the involvement subsection, the questions asked the respondent to rate their level of involvement in the IEP meeting from not involved at all to involved as much as I should be. At the start of the communication subsection, respondents were asked to rate their NPS staff's level of communication during IEP meetings from no communication with me to as much 
communication I need. Lastly, at the start of the parent-educator relationship subsection, respondents were asked to rate their relationship with NPS staff during IEP meetings from no relationship to best relationships possible.

The same three questions about involvement, communication, and parent-educator relationships were asked during the distance learning section, but the questions were altered to say, “in IEP meetings during distance learning," instead of "in IEP meetings."

\section{Open-Ended Questions}

Two open-ended questions were included in the additional questions section of the survey. The first asked respondents, "What can school districts or nonpublic schools do to improve the involvement of parents, parent-educator relationships, and communication during the IEP meeting?" Respondents were provided with unlimited space to write any information they would like to provide. The last open-ended question asked respondents to provide their contact information if they would like to participate in a future interview. Open-ended questions were only used when multiple-choice options would have been excessive, or the researcher wanted respondents to be able to include any information they felt was relevant.

\section{Survey Flow}

The survey was created using Qualtrics, so respondents would only be required to answer questions that pertained to them. Yes-no questions were used to allow respondents to indicate whether a certain question or section would pertain to them. When respondents answered No to any of these questions, the survey flow was altered to eliminate questions that did not pertain to those respondents. Table 3.8 provides a list of the questions that alter the flow of the survey. 
Table 3.7

Survey Path Based on Question Answers

\begin{tabular}{|c|c|c|}
\hline Questions & Yes & No \\
\hline Q1: Is your child in special education? & Continue & $\begin{array}{l}\text { Skip to the end of the } \\
\text { survey }\end{array}$ \\
\hline $\begin{array}{l}\text { Q16: Have you attended an IEP meeting, in person, at a nonpublic } \\
\text { school? }\end{array}$ & Continue & Skip to Q45 \\
\hline $\begin{array}{l}\text { Q25: Has there been a time that you have NOT felt included in } \\
\text { your child's IEP meeting? }\end{array}$ & Continue & Skip to Q27 \\
\hline Q41: Have you ever experienced conflict during an IEP meeting? & Continue & Skip to Q45 \\
\hline Q45: Have you had an IEP meeting during virtual learning. & Continue & Skip to Q52 \\
\hline
\end{tabular}

If respondents answered Yes to any of these questions, they were directed to continue answering questions. If they answered No, Qualtrics directed them to the next applicable section. For example, if a respondent answered No on Question 1, "Is your child in special education?" they were directed to the end of the survey because the survey was designed only for parents of children in special education. The first question was the only question that directed respondents to the end of the survey if they answered No. Other questions have respondents skip as little as one question and up to as much as an entire section of the survey.

\section{Demographics}

Demographic information provided specific information about each participant to help the researcher determine whether the sample represented the demographics of the target population. Demographic information was used to determine which participants met sample inclusion criteria. Lastly, demographic information was used to help answer the third research question. The following sections provide details on where demographics questions are included and how questions content was selected. 


\section{Demographic Question Placement}

There are strengths and limitations to including demographics at the beginning and end. Gilovich et al. (2006) and Steele and Aronson (1995) suggested demographic questions should be included at the end of the survey to avoid stereotype threat, which could lead respondents to respond a certain way. Similarly, some researchers argue demographic questions should be at the end to avoid survey fatigue and get more difficult questions out of the way at the start of the survey (Albert et al., 2009; Bourque \& Fielder, 2002; Colton \& Covert, 2007; Dillman, 2007; Jackson, 2012; Pew Research Center, 2016). For the current survey, demographic information was collected at the beginning of the survey because it was important that participants fully complete the demographic questions. Pew Research Center (2016) suggested including demographic questions at the beginning of the survey when they are needed to determine eligibility, such as the inclusion criteria for the current survey. Having the first question of the survey be "Is your child in special education?" immediately establishes those who meet one of the eligible criteria. All the inclusion criteria used demographic questions, so if participants stopped halfway through the survey, the researcher was able to use the partial survey because inclusion criteria were able to be met. Hughes et al. (2016) added including demographics at the beginning allows the researcher to know who chose not to complete the entire survey.

\section{Demographic Question Content}

The demographic questions were written based on guidance from Moody et al. (2013) and Hughes et al. (2016) to increase the inclusiveness of questions and available responses. Questions were asked about the student, parent, and IEP meetings.

Minimal demographic questions were asked about the student. The two demographic questions about the student included questions about the student's age and disability. The student 
age questions asked, "What is your child's age?" and a drop-down menu was provided with a list of options. Options included 2 or younger, 3 years, 4, 5, 6, 7, 8, 9, 10, 11, 12, 13, 14, 15, 16, 17 , $18,19,20,21,22$, and older than 22 . The student's disability question was based on Fish's (2008) survey. The questions started, "Your child received special education services based upon which of the following disability categories." Respondents were able to select more than one, which indicated the student had primary, secondary, and possibly additional disabilities. Parent demographic questions included questions about (a) role; (b) qualifying for free or reduced-price lunch; (c) gender, race, and ethnicity; (d) primary language; and (e) level of education.

The respondents were asked to choose the role that best fits their role in raising their child. Answer choices included: (a) parent, (b) grandparent, (c) stepparent, (d) foster parent, or (e) other. This question was originally seen in the Tucker and Schwartz (2013) survey and was included to provide demographic data about the type of respondent completing the survey.

Respondents were asked whether their child qualified for free or reduced lunch. This question allowed the researcher to understand the participant's socioeconomic status without asking parents to place themselves in a category. In the Fish (2008) study, parents were asked, "What is your median family income?" This type of question was not used to understand socioeconomic status because respondents tend to not answer questions about money or may stop the survey without completing it.

The gender identity question was written, "What is your gender?" Response options for the gender questions were based on suggestions from Moody et al. (2013) and Hughes et al. (2016) but have been limited to the following: (a) female, (b) male, (c) nonbinary/third gender, (d) prefer to self-describe, and (e) I prefer not to answer. 
The ethnicity and race question stated "Race/Ethnicity" and allowed the respondent to select all that applied to them. The responses for the ethnicity and race question were also based on suggestions from Hughes et al. (2016), who suggested using "some other race, ethnicity, or origin, please specify." Responses included the following: (a) American Indian or Alaska Native; (b) Asian; (c) Black or African American; (d) Hispanic, Latino, or Spanish origin; (e) Middle Eastern or North African; (f) Native Hawaiian or other Pacific Islander; (g) White; (h) some other race, ethnicity, or origin, please specify; and (i) I prefer not to answer. An example for each category was included. The race and ethnicity question allowed respondents to select all groups that applied to them. Allowing respondents to select all created some difficulty with separating respondents into specific groups during data analysis; however, based on information from focus groups, using more options is more inclusive and better describes the mix of families and individuals found in the United States (U.S. Census Bureau, 2013).

Respondents were asked to select their primary language from a list of nine languages. The option to select $O$ ther was included for those whose primary language was not listed. The list of nine languages was developed based on the 2018 U.S. Census Data American Community Survey (ACS) 1-year Estimate for Orange County (U.S. Census Bureau). The languages included: (a) English, (b) Spanish, (c) Chinese (including Mandarin, Cantonese), (d) Korean, (e) Tagalog (including Filipino), (f) Persian (including Farsi, Dari), (g) Arabic, and (h) Japanese.

The question about parent educational level included categories based on the U.S. Census Bureau (2010) with minor changes to wording suggested by Hughes et al. (2016). Responses options for parent educational level included: (a) some high school; (b) high school diploma or equivalent; (c) vocational training; (d) some college; (e) associates degree (e.g., AA, AE, AFA, AS, ASN); (f) bachelor's degree (e.g., BA, BBA, BFA, BS); (g) some post-undergrad work; (h) 
master's degree (e.g., MS, MBA, MFA, MS, MSW); (k) doctoral degree (e.g., EdD, PhD); (1) other, please specify; and (m) I prefer not to answer.

Additional information was collected about the county of residence, number of years the student received special education services, number of years attending an NPS, number of IEP meetings attended at an NPS, time since last IEP meeting, and number of IEP meetings attended in the last year.

\section{Pilot Study and Survey Review}

Once a draft survey was developed from the two foundational surveys, Tucker and Schwartz (2013) and Fish (2008), the survey was reviewed using four stages. This review process was selected based on survey reviews conducted by Tucker and Schwartz, and Fish. In this study, an additional review by experts in the field was conducted at the end of the review process. The review process for this study included: (a) a review by experts in the field, (b) a review by professionals who attend IEP meetings at NPSs, (c) a pilot of the survey, and (d) a final review by experts in the field.

\section{A Review by Experts in the Field}

During the first stage, three experts in the field read the survey with the researcher and provided feedback. Experts were Chapman University professors on the researcher's dissertation committee. The three experts provided feedback on question format, question order, readability, and other possible response choices. The experts provided the researcher with additional questions to consider and suggested limiting demographic questions. A major change suggested during this stage was eliminating or decreasing the questions in the virtual learning section. It was agreed the section should be included, but the number of questions should be reduced. Another suggestion was the addition of overall rating at the start of the involvement, 
communication, and parent-educator relationship subsections. After feedback was reviewed and modifications, the second stage began.

\section{A Review by Professionals}

The second stage of the survey review required professionals who have attended meetings at NPSs, to review the survey. The professionals who reviewed the survey included three school psychologists, one district administrator, and an NPS principal. Four of the five professionals met to discuss the survey and provided feedback based on personal and professional knowledge of parents with children in special education and of families who have experienced at NPSs. The fifth professional provided feedback via email. Feedback included (a) adding response options, (b) allowing parents to select multiple answers, (c) asking separate questions about NPS staff and districts staff, and (d) clarifying certain phrases or terminology. All feedback was considered, and many updates were made based on this stage of the survey review. A question about parent primary language was added to the demographic section, and an additional question about supporting parent primary language was added to the prior to virtual learning section. Additionally, Question 31 and Question 42 were added based on professional feedback. These questions were about types of communication parents received and whom parents had experienced conflict with during IEP meetings, respectively.

\section{Pilot Survey}

The third stage of the review was the pilot study. The pilot study included four individuals — with knowledge or experiences in the area being surveyed — to complete the draft survey through Qualtrics. Participants included two school psychologists, one program specialist, and one parent of a student in special education who had previously attended an NPS. Everyone received the link to the survey and directions for how to complete the survey via email. 


\section{Pilot Survey Directions Based on Survey Flow}

Directions for how to complete the survey differed based on all possible responses available. The researcher provided three different sets of directions to ensure the survey path was correct. These different directions correspond to (a) parents who have attended both in-person and virtual IEP meetings at an NPS, (b) those that have only attended an in-person meeting at an NPS, and (c) parents who have only attended a virtual meeting at an NPS.

Parents who attended a meeting in person and virtually needed to complete the entire survey. To ensure the survey format was correct, the directions provided to these pilot study individuals were to answer Yes to all yes-no questions. This meant these individuals answered Yes to the following questions, which ensured they completed all survey sections: "Is your child in special education?," "Have you attended an IEP meeting, in person, at a nonpublic school?," and "Have you had an IEP meeting during virtual learning?" Three pilot respondents completed the survey using these directions, and all three were able to complete all 53 questions in the survey. Survey completion time for these three individuals was 16 minutes, 23 minutes, and 31 minutes.

The second set of directions was used to represent parents who attended a meeting inperson at an NPS but have not attended a meeting virtually at an NPS. Only one pilot study individual was asked to complete the survey with these directions. They were asked to answer Yes to all yes-no questions, except Question 45, which asked, "Have you had an IEP meeting during virtual learning?" When answering No to this question, Qualtrics should have directed the respondent to skip the virtual learning section and jump to Question 52. During the pilot study, this worked smoothly, and the correct questions were completed. The respondent completed a total of 47 questions. The survey completion time for this respondent was 6 minutes. 
The final set of directions provided to pilot study individuals was used to represent parents who have participated in a virtual IEP at an NPS but have not participated in an in-person IEP at an NPS. Only one pilot study individual was asked to complete the survey with these directions. They were asked to answer Yes to all yes-no questions, except Question 16, which asked, "Have you attended an IEP meeting, in person, at a nonpublic school?" When answering No to this question, Qualtrics should have directed the respondent to skip the prior to distant learning section and jump to Question 45. During the pilot study, this worked smoothly, and the correct questions were completed. The respondent completed a total of 25 questions. The survey completion time for this respondent was 16 minutes.

\section{A Final Review by Experts in the Field}

The final review by experts in the field was the last step in the survey review process. This step included three of the researcher's committee members reading through the survey and providing any final thoughts or suggestions. The major concern during this review stage was the length of the survey. During this final review, the researcher made suggestions of multiple questions that could be eliminated. The final decision was to reduce the number of questions in the virtual learning section to two questions about involvement, communication, and relationships. Each of these topics included one question about parents' overall rating from 1 to 4 and the second question was a Likert scale from strongly agree to strongly disagree about their perspectives of their involvement, communication, and relationships during the IEP meeting. All other suggestions were reviewed, and minor edits were made to the survey. These edits included: (a) spelling, (b) punctuation, and (c) formatting errors. 


\section{Interview Instrument}

Based on the mixed-method design, a survey and interview were used to collect data on parent perspectives. After 21 parents completed the survey, the interview process began. The interview allowed the researcher to follow up on survey questions and quickly gain clarification to ensure their perspectives were being accurately portrayed by their survey and interview data (Marshall \& Rossman, 2016). Additionally, interview data were used to reliability check the survey data.

\section{Interview Format}

The researcher used a semistructured interview design that was scripted and involved specific questions to be asked in the same order (Marshall \& Rossman, 2016). The semistructured format allowed the researcher to ask follow-up questions or ask the participant to clarify their answers when needed. This format was selected because it allowed for the systematic gathering of rich data that could be efficiently analyzed (Galletta, 2013).

The interview was divided into four sections aligned with the sections in the survey. Those sections include: (a) involvement, (b) communication, (c) parent-educator relationships, and (d) conflict (see Appendix E).

\section{Question Development}

The questions for the interview were developed based on the questions in each section of the survey. Each of the four sections started with a statement about how the respondent answered a specific survey question. These statements referred directly to the participant's rating. For example, the first statement in the involvement section was, "In your survey, you rated your level of involvement at a on a scale from $1-4,1$ being not involved at all and 4 being involved as much as I should be." After the initial statements, the interview protocol included two to five 
follow-up questions directly related to the main survey question. All questions were open-ended and allowed respondents to provide as much or as little detail as they felt comfortable.

\section{Involvement}

The involvement section of the interview had two main topics: level of involvement and times respondents did not feel involved in the IEP process. The statement about parents' rating of their involvement included five questions. These questions asked respondents to explain why they selected that rating, describe their involvement in the IEP process, describe their involvement in the IEP meeting, ask about how others in the meeting involved them, and other ways the team could have involved them in the IEP meeting.

The second statement was about any time the respondent did not feel involved and asked them to explain why they felt they were not involved. There were two follow-up questions after this statement. If the respondent indicated they had always felt involved in the IEP meeting, they were not asked these questions. The follow-up questions asked the respondent to describe any time they felt involved and explain what the team members did to make them feel that way.

\section{Communication}

The communication section of the interview included one statement with three follow-up questions. The statement was about how respondents rated the NPS staffs' level of communication on a scale from 1-4, 1 being no communication with me and 4 being as much communication as I need. The follow-up questions asked respondents to explain their rating, provide an example of things the school staff did or did not do to make the respondent feel that way, and describe how the IEP team members could improve the respondent's rating of communication. 


\section{Parent-Educator Relationships}

The parent-educator relationship section of the interview included one statement and five follow-up questions. The statement was about how the respondent rated their relationship with NPS staff on a scale from 1-4, 1 being no relationships and 4 being the best relationship possible. The follow-up questions asked the respondent to explain their rating, provide an example of things the staff did or did not to make the respondent feel that way, describe what would improve their relationship with NPS staff, describe what would improve their relationships with district staff, and explain if there is a difference between their relationship with NPS staff and school district staff.

\section{Conflict}

The conflict section of the interview included one question and one follow-up question. The question asked, "Can you describe any experiences you have had with conflict during IEP meetings at nonpublic schools?" The follow-up question asked respondents to state ways they thought the conflict could have been avoided.

\section{Interview Review}

The interview review process involved two reviews by experts in the field with a background in special education and research. Upon completion of the draft interview protocol, one professional in the field was given the survey to review and provide her critiques. The professional reviewed the interview for question format, bias, leading questions, and thoroughness. The professional made multiple suggestions to the draft. The researcher reviewed the suggestions, updated the draft, and sent it to three other professionals in the field. Additional suggestions were given by each professional. A final draft was created and submitted to the Chapman Institutional Review Board (IRB) for approval. 


\section{Procedures for Data Collection}

The research procedure consisted of six parts: (a) IRB approval, (b) parent recruitment, (c) survey dissemination, (d) survey completion, (e) interview recruitment, and (f) interview completion. First, the researcher received IRB approval from Chapman University. Additional approval was needed when the research switched from survey research to mixed methods.

Second, the researcher recruited NPSs, district representatives and joined Facebook groups to access parents. The survey was disseminated to parents in two waves, the initial email dissemination and the reminder email. Parents provided consent and completed the survey online. After some surveys were completed, parents were recruited to participate in the interview. Lastly, parents participated in an interview with the research, and the survey was closed.

\section{IRB Approval}

The Chapman University’s (2020a) IRB “is the authority that reviews, approves, denies, and provides ongoing oversight of research involving human subjects in accordance with federal regulations" (para. 1). The policies and guidelines listed on Chapman University’s (2020b) website were followed when developing the research proposal and submitting the proposal to the Chapman University's IRB. The policies and guideline documents relevant in this study included: (a) Guidelines for Student Classroom Projects and Research Involving Human Subjects, (b) Guidelines for Recruitment of Research Participants, and (c) Guidelines for the Use of Raffles. Valuable information was gained from the policies and procedures in the areas of informed consent, raffle development and implementation, and general policies. 
Once all documentation was completed, the application was submitted to Chapman University's IRB. The IRB requested small revisions twice before approving the study. Once approved, the researcher started the recruitment process.

\section{Recruitment}

The researcher recruited parents through multiple sources. The source for recruitment was through the NPSs of attendance. The research expanded the sample by recruiting district representatives to reach out to parents and joining Facebook groups to access parents directly. All participation was agreed upon formally for schools and parents. All NPSs who participated completed an NPS site agreement. Parents who accessed the survey through a district representative or Facebook provided their consent during the survey.

\section{NPS Site Agreement}

As stated previously, NPSs were recruited to participate in the survey research. Methods of recruitment included: (a) emails, (b) phone calls, and (c) website contact forms. All school sites had different policies and processes to obtain approval to participate. Some schools required approval from their administrators, while others needed approval from their board of directors prior to agreeing to participate.

Once a school site agreed to participate, they were asked to complete the following process using the NPS Site Agreement template that was emailed to each school (see Appendix F). The school site administrator was asked to copy and paste the information provided onto their school's letterhead, sign, and email a copy to the researcher. The NPS Site Agreement letters obtained prior to submitting to the Chapman University's IRB were included in the IRB submission process. All additional Nonpublic School Site Agreements will be kept as proof of the school's agreements to allow the study to be conducted with their parent populations. 


\section{Survey Dissemination}

Surveys were disseminated through NPSs, district representatives, and Facebook groups. The dissemination process for NPSs and district representatives was the same, while the process for Facebook groups was slightly different.

\section{NPSs and District Representatives}

The researcher sent the parent recruitment email to each school contact (see Appendix G). The email was provided in English and Spanish. The parent recruitment email included: (a) a brief description of the study, (b) the time commitment required, (c) possible risks, (d) how to participate, (e) information about the raffle, and (f) link to access the survey. The first wave of NPSs all sent their parent recruitment emails to all their parents during the same week. One school sent the survey the following week due to contact issues. The second wave of schools sent their emails within a week of agreeing to participate in the study.

Both English and Spanish directions were provided in the email to parents. Schools provided emails in two different ways. Some schools put both the English and Spanish templates in one email and sent it to all parents. Other schools sent two groups of emails and separated those whose primary language was English from those whose primary language was Spanish. Parents whose primary language was not English or Spanish were provided with information in the student's language of instruction, English.

\section{Reminder Email}

One to 2 weeks after the initial survey dissemination, a reminder email was sent to all parents. The researcher provided the template for this email and sent a reminder email to each school site to remind them to send the second email (see Appendix G). Each school sent emails to their parents during the school day. The reminder email was brief and included: (a) a reminder 
about the initial email, (b) a thank you to parents who already completed the survey, and (c) a statement encouraging others to complete the survey. The researcher's contact information was included in the email for any parents who had questions or concerns.

\section{Facebook Group Recruitment}

The researcher joined nine Facebook groups that focused on parents of children in special education, IEPs, parent rights, and advocacy. After being accepted to each group, the researcher would make a post to the page (see Appendix B). The post was brief and included information about the researcher, inclusion criteria, information about the study, contact information, and the survey link. Two weeks after posting to each group page, the researcher commented on the original post, "Still looking for a few more parents! Please help if possible!” All the Facebook pages were sorted by recent activity, so adding a comment to each post caused Facebook to think there was activity on the original post and moved it to the top of the page.

\section{Parent Consent}

The email or Facebook post directed parents to use the provided link to start the survey process. The link led the parent to a consent page. The consent page included all information from the Adult Informed Consent to Participate in Research (see Appendix H). Information provided on this document was extensive and based on Chapman University's (2020a) IRB suggestions. The consent page included the names of the research members Chapman University, as the organization supporting the research; essential information about the study, an invitation to participate; why the respondent was being asked to participate; the purpose for the research; what would be done during the study; how data would be used; possible risks and benefits; the cost of participating; compensation; what to do if the respondents had a problem during the study; and how the information would be protected. The last part of the Adult Informed Consent to 
Participate in Research included the respondent's rights during the study, what to do if they have questions, what would happen if they did not participate or decided to stop participation, and a statement about their consent to participating in the study.

Due to the nature of survey research, a signature was not collected as proof of informed consent. Instead, informed consent was gathered by requiring respondents to mark a box at the end of the Adult Informed Consent to Participate in Research page indicating either "Yes, I consent" or "No, I do not consent." If parents marked "No, I do not consent," they were directed to the end of the survey.

\section{Survey Completion}

Once informed consent was provided, respondents were directed to the next page of the web-based survey. Participants could move forward and backward through the survey. The Qualtrics program saved answers when participants clicked the next button at the bottom of the page. Upon completion of the survey, participants saw a message indicating they had completed the survey with the option to provide an email address to participate in the raffle.

\section{Data Collection}

Qualtrics was used to collect survey data. Qualtrics saved survey data as respondents completed the survey. Surveys were started by 59 participants. Due to the format of the survey, many respondents clicked on the raffle link at the end of the survey, which led them to a different webpage. As a result, they did not submit their survey. Twenty-six participants completed the survey but did not click the submit button. Participants not clicking submit resulted in the Qualtrics XM reporting that they completed $98 \%$ of the survey. At the end of the survey collection process, any survey started but not submitted was closed and the data collected. The participants required no additional steps to turn in the survey. 
Of the 59 surveys that participants started, 14 were less than $98 \%$ complete. Ten surveys were less than halfway completed. Of those 10 , seven surveys were less than $10 \%$ complete, which meant the participant completed four or fewer questions. Most of the participants that completed $10 \%$ or less only answered the first question of the survey, "Is your child in special education?"

\section{Interview Recruitment}

The survey's last question asked respondents to provide their contact information if they were willing to participate in an interview. When respondents provided their information, they provided the researcher with their consent to contact them to participate in an interview. Fifteen respondents provided contact information in the form of email, phone number, or both. All 15 respondents were contacted using the contact information they provided. A template email was used to contact respondents via email (see Appendix C). When respondents were contacted by phone, the same information was used to explain why they were being contacted. During email and phone communication, eight respondents agreed to participate in an interview. All respondents were informed they would receive the informed consent document and the Zoom link through email a day prior to their interview.

\section{Interview Informed Consent}

After respondents agreed to participate in the interview, they were sent two emails. The first email was sent from DocHub.com and included the Interview Adult Informed Consent Form for them to review and sign (see Appendix I). This document included consent to participate in the interview and consent to have the interview audio recorded. The second email was sent by the researcher with the date, time, and Zoom link for the interview. 
At the start of the interview, the informed consent document was reviewed with the participant. The participant was allowed to review the document and ask questions. Everyone who initially agreed to the interview signed the consent form and agreed to be recorded.

\section{Interview Completion}

The researcher used Zoom settings to turn on the audio transcription option before conducting the interviews. At the start of each interview, the researcher informed the participant the interview would be recorded and consent. The recording was started before the first question and stopped after the participant had an opportunity to add any additional comments. At the end of the meeting, the transcription and audio were saved to the cloud server.

The researcher asked questions from the interview protocol (see Appendix E). Participants answered questions based on their experiences. When participants did not fully answer the question or clarification was needed, the researcher asked follow-up questions. Throughout the interview, the researcher provided a review of responses and asked the participant if the information was correct or if the researcher had misinterpreted the participant. During this time, participants were able to correct the researcher and ensure their ideas were correctly understood. After the last question, participants were able to provide any additional thoughts or comments. At the end of the interview, participants were informed the researcher would be using pseudonyms to represent each participant and ensure confidentiality. The researcher allowed the participant to pick the pseudonym that would be used to represent themselves within the study; however, most participants asked the researcher to pick the pseudonym. 


\section{Survey Data Analysis}

Once the survey data were collected, multiple steps were taken to analyze the data. When using a survey, data formatting is required to get the data into a format that can be analyzed (Fowler, 2014). After formatting, the data was cleaned using inclusion criteria. The researcher also eliminated incomplete surveys. After both steps were completed, the data was analyzed using both quantitative and qualitative methods. This section discusses the process used to analyze the data, which included: (a) data formatting, (b) quantitative analysis, (c) response rate, and (d) nonresponse bias.

\section{Data Cleaning and Formatting}

The data were cleaned so that only respondents who answered at least one full section, other than the demographic section, were included. If the respondents completed the demographic section and then stopped or only completed one or two questions of a second section, they were not included in the final sample. After removing respondents who did not meet this criterion, 43 respondents had completed the demographic section and at least one other section of the survey. The data were reviewed to ensure all respondents met inclusion criteria. The following inclusion criteria were used for this study. Respondents must: (a) have a student in special education, (b) the student must be currently attending an NPS, and (c) they must live in California. After reviewing the data, 22 of the previously identified respondents met inclusion criteria. One respondent was excluded because they lived out of state.

Survey data were collected from Qualtrics and uploaded to Statistical Package for the Social Sciences (SPSS). A single entry was included in each field, so nonresponses were not incorrectly coded as a zero. Four-point Likert questions were coded in two ways. When questions used strongly disagree to strongly agree, responses were coded using the code -2 
through +2 with no zero. When questions asked for a rating from 1 to 4 , responses were coded using that same scale. Both formats used lower numbers to represent less satisfaction or less agreement, and high numbers represented higher levels of satisfaction or agreement. Yes-no questions were coded using 1 and 2. Multiple-choice questions were coded based on the number of responses available.

\section{Quantitative}

Descriptive statistics were used to analyze the quantitative data. Descriptive statistics should be used when the purpose is to describe and provide information about the sample (Urdan, 2017). When using descriptive statistics, the data collected applies only to the sample and cannot be generalized; however, statistics collected can be used as a reference for similar programs or populations. The researcher used NPSs from multiple counties in Southern California to ensure a diverse population was used, and therefore, the data could provide information for many similar programs.

First, a descriptive analysis was used to depict the demographics of the sample. Then, descriptive analysis was used to describe parent perceptions of involvement, communication, conflict, and parent-educator relationships. SPSS was used to run the descriptive statistics for each survey item. Frequency distributions were run for all multiple-choice questions. Data being examined included the frequency, percentage, mean, median, and standard deviation.

\section{Response Rate}

Previously, one measure of research quality was surveying response rate (Biemer \& Lyberg, 2003); however, Groves and Peytcheva (2008) conducted a meta-analysis that concluded the response rate was not predictive of nonresponse bias validity. Bias and statistical precision are both properties of survey quality affected by the response rate. Groves et al. (2009) indicated 
the assumption that there was a connection between response rate and quality was based on the idea that the higher the response rate, the more likely the sample will represent the population. Meterko et al. (2015) argued precision and nonresponse bias should both be considered when determining the success of a survey.

Researchers recommend that response rates be in the $70 \%$ to $85 \%$ range (Babbie, 2004; Singleton \& Straits, 2010). Other researchers have shown that these high response rates have become increasingly difficult to reach (Groves et al., 2009; Keeter et al., 2006).

An estimated response rate was calculated after respondents completed the survey; however, an exact response rate was not available. The survey was sent to all parents at each NPS; however, it is unknown how many parents received the email requesting participation. An estimated response rate was calculated based on the number of parents who were sent the survey and the number of parents who completed the survey. The response rate was only calculated for surveys sent through an NPS or district representative. The estimated response rate was $14.38 \%$. The response rate for surveys accessed through a link in a Facebook group was not calculated.

\section{Nonresponse Bias}

Nonresponse bias or error "is the difference between the estimate produced when only some of the sample units respond compared to when all of them respond" (Dillman et al., 2014, p. 3). Nonresponse bias occurs when characteristics of those who do not complete the survey are significantly different from those who completed the survey in a way that is relevant to the study results. For example, if all parents who have experienced conflict with NPS administrators choose not to complete the survey, there would be a nonresponse bias that results in lower rates of conflict with nonpublic administrators. 


\section{Reducing Nonresponse}

Nonresponse can be reduced during the design and data collection phase of the survey (Rea \& Parker, 2014). The current study was web-based, and the survey link was sent by email. When sending surveys by email, sending them from a familiar individual or institution helps increase the response rate (Fowler, 2014). The survey was sent by a school representative to increase the rate of response. Other steps to increase response rate included using a welldeveloped instrument, providing a financial incentive, and repeated contacts, which included multiple methods of contact (Fowler, 2014; Rea \& Parker, 2014). For this survey, the instrument was pilot tested to ensure it was well developed. A raffle was used as a form of financial incentive. Participants were able to opt into the raffle by submitting their email at the end of the survey. The raffle winners received gift cards from Amazon. All Chapman University's (2020a) IRB guidelines were followed for the use of a raffle. The email addresses were collected using a Google Doc, so identifiable data were not linked to their survey responses. The repeated contact method was used, and multiple methods of contact were used. The survey was sent by email and in paper format. It was sent out twice by school personnel.

\section{Interview Data Analysis}

Interviews were scheduled with eight survey respondents. Recordings and transcripts of each interview were saved to the cloud. The following steps were taken to analyze the interview data: (a) transcripts were edited for accuracy, (b) NVivo 12 was used to code transcripts, and (c) codes were analyzed.

\section{Transcription Editing}

Zoom creates an audio and transcript file of any recorded meetings. Immediately after each interview ended, the researcher reviewed the transcript file and edited the transcript using 
Zoom. This process involved the researcher listening to the audio recording and editing the transcript based on the audio. The original Zoom transcription accurately transcribed most of the interview information for all the interviews. Corrections were made when the researcher or participant mumbled, mispronounced a word, or spoke quietly. The final transcripts included repeated words and when participants stumbled over words; however, fillers were not always included in the transcription. For example, fillers like "hmm" or "umm" were not included in the transcript.

Internet connection issues caused a few mistakes with transcription; however, when these issues occurred, the researcher asked follow-up questions or asked the participant to repeat their statement. When these issues occurred in the audio of the researcher, transcription was edited to match the original question. These corrections were made for ease during analysis.

\section{Primary Language Transcription}

Six of the interview participants identified English as their primary language. One participant identified their primary language as American Sign Language (ASL), and one participant's primary language was Spanish.

The participant who used ASL indicated she was comfortable using the chat box instead of an interpreter during the interview. The interview and the participant communicated using the chat box, and the Zoom chat was downloaded at the end of the interview. No additional editing was necessary for that transcript.

A Spanish interpreter was used during the interview with the Spanish-speaking participant. The interpreter was provided a copy of the questions before the interview. During the interview, the researcher asked each question, the interpreter would repeat the question in Spanish, and the participant would respond. The interpreter would interpret the participant's 
response. The researcher asked follow-up questions when necessary. The same transcription editing process was used to edit the Spanish interview; however, translation of the participant's responses was added to the process. The transcription was edited, and a Spanish translator translated the Spanish responses into English.

\section{Coding}

All eight transcripts were uploaded to NVivo 12, a qualitative data analysis software. After being uploaded, the researcher began the coding process. Three methods of coding were used to analyze the eight interviews and their qualitative data. Structural coding was used in Phase 1 to categorize the data based on question topics. Descriptive coding was used in Phase 2 to code individual phrases and group those codes into categories. The final phase of coding used value coding to code participant comments based on positive and negative attitudes.

\section{Structural Coding}

The first stage of coding used structural coding, also referred to as "anchor coding," "utilitarian coding," "index coding," "referential coding," and "macro-coding" (Saldaña, 2021). Structural coding uses a content-based phrase to identify a large section of data related to a specific topic or research question (MacQueen et al., 2008) and is a form of question-based coding (Saldaña, 2021). Namey et al. (2008) stated structural coding "acts as a labeling and indexing device, allowing researchers to quickly access data likely to be relevant to a particular analysis from a larger data set” (p. 141). This form of coding was selected because it is appropriate for "virtually all qualitative studies" (Saldaña, 2021, p. 130), particularly those using semistructured interviews, and allows the researcher to code and categorize data to be compared.

The researcher used structural coding to code each interview into large question-based sections based on the questions and topics discussed in the interview. The initial four structural 
codes were identified prior to starting the coding process. These codes were involvement, communication, relationships, and conflict. These four codes directly corresponded with questions in the interview.

After deciding on the four codes, the interviewer coded participant responses to interview questions using the four principal codes. During this process, three additional codes were

developed and used. These codes included (a) COVID-19, (b) parent education, and (c) final thoughts. All eight interviews were coded based on these seven question-based codes. Individual interviews were split into seven codes so that data relating to each topic could be quickly accessed and analyzed during the next coding phase.

\section{Descriptive Coding}

Descriptive coding was used in the second phase of coding. Descriptive coding is also known as topic coding, topic tagging, or index coding (Saldaña, 2021). Descriptive coding describes a short passage or statement using a word of a short phrase. Tesch (1990) indicated these codes should represent the topics of the data, what the data are about instead of representing the content of the data. Saldaña (2021) compared descriptive coding to the hashtag phenomenon in that it links comparable data. Descriptive coding was selected based on its ability to be used in various qualitative studies; it suggested use by beginning qualitative researchers and its ability to link similar content.

Once the content was initially coded using descriptive coding, the initial codes were grouped into categories. One structural and descriptive coding was completed, the researcher had data organized with structural codes, descriptive categories, and descriptive codes. 


\section{Value Coding}

Value coding "is the application of codes to qualitative data that reflect a participant's values, attitudes, and beliefs, representing his or her perspectives or worldview" (Saldaña, 2021, p. 167). Value coding was used to code participant attitudes. According to Saldaña (2021), “an attitude is the way we think about feel about ourselves, another person, things or ideas" (p. 168). Participant comments about NPSs were coded as positive or negative attitudes.

\section{Ethical Considerations}

The researcher obtained permission to conduct the study from the IRB at Chapman University before starting the research process. Other ethical considerations included informing respondents, protecting respondents, and benefits to respondents.

\section{Informing Respondents}

During the study, all possible efforts were taken to ensure the respondents were informed about the study. One way the researcher accomplished this was by including as much information as possible to the respondents during the initial dissemination process (Fowler, 2014). The initial email included a link to the informed consent page before starting the survey. This page included the following: (a) researchers' name, (b) Chapman University as the sponsoring organization, (c) an accurate description of the purpose of the research, (d) a confidentiality statement, and (e) a statement that participation is voluntary, asserting the option to discontinue participation without consequence and assurance questions could be left unanswered (Fowler, 2014).

Informing respondents comes with the responsibility to ensure respondents were given information before consenting, and the respondent has documented their consent. For survey research, respondent signatures are not usually documented because doing so is not always 
feasible (Fowler, 2014). For this study, the informed consent page was included at the start of the survey. Respondents clicked the link in the initial email, and it directed them to the informed consent page, created based on the Chapman University's (2020a) IRB recommendations. At the bottom of this page, a checkbox was included to indicate consent to participate. This box was used to document the respondent's understanding of the purpose and their consent to participate. Respondents were given the option of "Yes-I consent" or "No-I do not consent." If participants did not provide consent, they were not asked any further questions and were directed to the end of the survey.

During the interview process, informed consent was required before the interview started. This was a different informed consent from the form participants received prior to the survey. Participants were provided with the informed consent document, allowed time to look over the information, and were able to ask questions. This differed from the process of obtaining consent prior to the survey because this process involved a digital signature instead of checking a box. Participants were not required to participate in the interview. Additionally, participants were asked to consent to be audio recorded. All participants agreed to be recorded.

\section{Protecting Respondents}

Many steps were taken to protect respondents throughout the research process. The most significant step taken was having the review and approval of the study by the Chapman IRB before conducting any research. During the review process, the researcher considered possible risks to participants, procedures to increase confidentiality, and data storage.

\section{Possible Risks}

Best efforts were taken to protect respondents during the study; however, despite the efforts of the researcher, there are always some risks to participating in research. As stated by 
Chapman University's (2020a) IRB, any study involving data collection has the possibility of breaching confidentiality. These risks were mitigated by taking reasonable steps to protect against the breach of confidentiality, which included not collecting identifiable information during the survey process and ensuring data presentation did not allow others to identify the respondents or schools who participated. More information about how confidentiality was ensured is provided next.

Other risks included possible emotional or psychological distress because the surveys involved questions about experiences that could cause distress to remember. All respondents were provided with the researcher's contact information so they could talk if they experienced emotional or psychological distress. The researcher has professional experience with counseling and support services that could have helped respondents in the event they needed support. The occurrence of other rare side effects was possible. Respondents could have also experienced a side effect that had not occurred before; however, the risk was minimal.

\section{Confidentiality}

Reasonable steps were taken to protect respondent privacy and the confidentiality of data. Fowler (2014) suggested standards to minimize the chances of breaking confidentiality. The following confidentiality protocols were based on Fowler's (2014) suggestions. As suggested by Chapman University's IRB, the only people who had access to research records were members

of the research team, the IRB, and any other person, agency, or sponsor as required by law. All people who had access to the data were required to commit in writing to confidentiality. Study data were not sent to researchers outside of Chapman University. Any identifying personal was removed before being shared with anyone outside the research team. 
Any links between responses and identifiers were minimized by removing identifiers from the data as soon as possible and not permitting individuals who could identify a respondent based on their answers to see the survey data. If respondents provided contact information, their contact information was removed and stored separately. Contact information was used solely for contact purposes and was not linked to survey data. Surveys were stored digitally and required a password to access. Interview participants were given pseudonyms for confidentiality purposes.

Information from this study may be published in scientific journals or presented at scientific meetings, but the data will be reported as a group or summarized data, and data from small categories will be presented so that individuals are not able to be identified based on categorical data.

\section{Data Storage}

The data collected during this study were stored electronically through a secure server and were only accessible by the members of the research team during the study. When using Zoom, NVivo 12, and SPSS a password-protected cloud server was used and only accessed on a password-protected computer. The data will be accessible for 10 years after the study is complete. After 10 years, the raw survey data will be destroyed, along with any identifiers. Audio recordings were deleted after they were transcribed. All transcriptions were saved using pseudonyms.

\section{Benefits to Respondents}

Respondents may have received both extrinsic and intrinsic benefits from participating in this research. All possible risks and benefits of participation were provided to possible participants using the informed consent form at the start of the survey before they consented to participate. 


\section{Extrinsic Benefits}

All participants had the opportunity to receive extrinsic benefits. Extrinsic benefits were provided in the form of three gift cards distributed using a raffle. Those who wished to be included in a raffle provided their email address at the end of the survey. No purchase was necessary to participate in the raffle. Completion of the survey was necessary to participate in the raffle. Once the survey was closed, respondent emails were placed in alphabetical order. Every eighth email was selected to win a gift card. The number eight was selected by a research team member with no access to the email list. The raffle and monetary compensation were used to increase response rates and provide an extrinsic benefit to participation.

\section{Intrinsic Benefits}

Respondents may have received intrinsic benefits for participating in the research. Respondents may have received the enjoyment of helping contribute to the purpose of the study. Respondents had the opportunity to provide their opinion in a structured way that may help shape NPSs' procedures in the future.

\section{Presenting the Results}

The results are presented in Chapters 4 and 5 of this dissertation. Four principles were used to present results: (a) the audience was identified, (b) the level of analytical detail was decided, (c) an appropriate writing style was chosen, and (d) results were presented as a whole (Birks \& Mills, 2011). Those who were identified as the audience were the participants, the NPS, and school districts. Each NPS that participated in the study was provided with a PDF copy of the full dissertation. The researcher was available through email to answer any questions. Each school was encouraged to inform their parents of the results. 


\section{Strengths}

This study provided some significant strengths to the field. Along with participant benefits, it was the researcher's ethical responsibility to all participants to "maximize the value to the community" (Fowler, 2014, p. 144). Strengths of this study included a clearer understanding of the topic being examined, which may lead to the creation of training to improve IEP meetings, improve students' educational experiences, reduce conflict and resources for NPSs. Additionally, this study's format and the possibility for future research in this area are major strengths of the current study.

Providing the field with parents' perspectives of IEP meetings at an NPS was the primary strength of this study. This population has rarely been researched, and little is known about their perspective. The data collected will allow districts and NPSs to alter how they approach IEP meetings at NPSs, so they can increase parent involvement and positive relationships between parents and staff. Questions about relationships, conflict, and communication may be very enlightening to educators.

The second strength is the possibility for the creation of training for those running IEP meetings at NPSs. Currently, there is training on how to run an IEP meeting at traditional public schools; however, there is no training designed specifically for IEP meetings at NPSs. Results from this survey may provide and a better understanding of how to structure IEP meetings at NPSs to increase parent involvement, communication, and positive parent-educator relationships. This information could help improve training for NPS or districts staff. Data collected may be used in future research to create training to help future educators increase parent involvement and lead to more positive parent-educator relationships. 
The third possible strength of this study is a better educational experience for students attending NPSs. IEP meetings determine students' educational plans for the upcoming year. Understanding parent perspectives can help improve relationships between team members at IEP meetings and, as a result, improve the educational plan for each student.

Special education meetings can be filled with tension, and thousands of cases are filed with the Office of Administrative Hearings every year. In 2019, there were 4,538 cases filed with the Office of Administrative Hearings for Special Education (California Department of General Services, 2021). Increasing communication and improving relationships based on the information collected during this study could reduce the number of cases filed by parents and school districts for students at NPSs.

Lastly, this study may increase research in this area and provide insight into the improvements needed to be made at NPSs. Shining a light on these issues may cause funding sources to become available to improve NPSs, IEP meetings, and the interactions between school districts and parents whose students attend NPSs.

The survey's format was a major strength of the current study. The current study used a self-administered web-based format. Web-based surveys are inexpensive, can access a potentially large sample, and data are easy to manage (Granello \& Wheaton, 2004; Umbach, 2004). There was no cost to send a web-based survey, and the data collected can be directly loaded into a spreadsheet or data analysis program. Umbach (2004) indicated another advantage to web-based surveys is the ability to have a quick turnaround from when the respondent completes the survey to when it is available to the researcher. Unlike mail surveys, web-based survey data are available immediately. 
Lastly, parents of students at NPSs are a population that has not been extensively studied. A major strength of this study was the potential for it to lead to future research. Additional research may be considered to add to the field and increase knowledge about those who attend NPSs, their parents, and how to alter processes in this environment.

\section{Limitations}

Limitations with the current survey study included: (a) lack of generalizability, (b) low response rate, (c) limitations associated with self-administered surveys, and (d) limitations with sampling. Each of these limitations is discussed in more detail next.

Generalizability was a significant limitation for this study because there was little generalizability. The results of this study apply to parents in the NPSs being studied. Results may apply to parents of children in other NPSs in Southern California with similar demographics; however, because all NPSs have very different populations, generalizability cannot be assumed. Additionally, allowing respondents to only access the survey in English and Spanish further limited the sample.

Descriptive surveys were used to gather data about attitudes, behaviors, and events. They are the purest form of survey (Coughlan et al., 2009). One limitation of descriptive surveys is that they provide a "snapshot" of the phenomenon being studied and do not allow for changes over time or because of unforeseen variables (Mckenna et al., 2006). This study provided a snapshot of how parents perceived their experiences at the time of taking the survey; however, this research does not allow for the collection of data over time. For example, future studies may wish to implement an IEP procedure, based on this research, to increase parent involvement. This type of study would allow for the collection of pre- and post-data and would measure the 
change of perspectives over time. The current study's goal was to collect information to inform future research in the field.

Low response rate is a significant disadvantage during web-based surveys (Granello \& Wheaton, 2004) and self-administered questionnaires (Coughlan \& Ryan, 2009). Low response rate and possible nonresponse bias can be reduced by using multiple follow-ups. In this research, the respondents were contacted twice, using two forms of communication. Other factors that affected response rates included unequally distributed internet access throughout the population, and those who had access may not be computer literate (Coughlan \& Ryan, 2009).

Due to the nature of self-administered survey research, there were several limitations. The respondent may not complete the survey themselves or may have used help to complete the survey. When others completed or helped with survey completion, they affected how the results represented the sample. The biggest problem with others helping complete the survey did not know if this happened. Other limitations to self-administered surveys included difficulty reading, interpreting words, or writing, which can exclude groups from completing the survey (Hallberg, 2008).

Lastly, the sampling method for the survey and interview was for participants to volunteer their participation. Those who agreed to participate in the study may have a similar view, but those views may not accurately represent the population. Results of the study were very positive regarding parent perspectives of involvement and relationships at NPSs. A more extensive sample of parents may have different results. Additionally, interview results aligned with survey results; however, those who had very positive experiences may have been more likely to volunteer to participate in an interview. 
Limitations were noted before the start of the study, and extensive effort was taken to reduce limitations as much as possible. Limitations that could not be accommodated included limited generalizability, low response rate, limitations associated with self-administered surveys, and limitations with sampling.

\section{Summary}

Minimal research has been conducted using information from students and parents with insight on NPSs in California. This chapter presented the research methods for investigating parent perspectives of their involvement, communication, and parent-educator relationships during IEP meetings at NPSs. A web-based, self-administered survey was used as a collection instrument. After the survey, consenting respondents were contacted to participate in an interview to gain more individual perspectives and clarify survey responses. The sample size for the survey was 42 guardians of students receiving special education services, currently attending an NPS in Orange, Los Angeles, or San Diego county. The interview sample included eight survey participants.

Before the study, Chapman University's IRB approval was gained for the survey and interviews. Participants were recruited through their student's NPS, district representatives, personal contacts, and Facebook groups. The survey was disseminated by email by the NPSs or district administrators and through a post on Facebook groups. All communication with parents was based on templates. Information sent by district representatives and NPSs were provided to guardians in English and Spanish. The information posted in Facebook groups was provided in English only.

The survey instrument collected quantitative data using multiple-choice questions about demographics, involvement, and parent-educator relationships. Descriptive analysis was used to 
analyze all quantitative data. The interview collected qualitative data using a semistructured format that allowed respondents to provide details about their survey responses and increase the data collected about parent perspectives. The data collected were analyzed using structural, descriptive, and value coding. The results were presented to all possible stakeholders in the most accessible format for stakeholders. There were several significant strengths of this study. This study allows educators from school districts and NPSs to understand parent perspectives during IEP meetings at NPSs. 


\section{Chapter 4: Results}

Chapter 3 covered the study methods and procedures. The study used a convergent mixed-method design to understand parent perspectives during IEP meetings at nonpublic schools (NPSs). Data collection instruments included a web-based survey and semistructured interviews. The quantitative survey data were analyzed using descriptive statistics, while the qualitative interview data were coded using multiple coding phases to develop themes.

This chapter provides the results of the quantitative and qualitative data. The presentation of results will follow a nested approach. Quantitative survey results were primary, while qualitative interview data were secondary.

\section{Survey Demographics}

Forty-two participants completed the survey with information about their experiences at IEP meetings. All participants completed 57\%-100\% of the survey. Two participants completed $57 \%$ of the survey, which was equal to the demographic and involvement sections. One participant completed $80 \%$ of the survey, and the remaining participants completed the survey in its entirety. The demographic section of the survey was comprised of 16 questions. Participants were asked questions about themselves, their students attending the NPS, and their IEP attendance.

\section{Participant Demographic}

Participants were asked questions about their county of residence, parental role, primary language, gender, race/ethnicity, and their highest level of education. Participant demographic information is provided in Table 4.1. 
Table 4.1

Parent Demographic Information

\begin{tabular}{|c|c|c|c|}
\hline Question & Selection choice & Frequency & Percent \\
\hline \multirow[t]{3}{*}{ Q2: What county do you live in? } & Los Angeles County & 20 & 47.6 \\
\hline & Orange County & 16 & 38.1 \\
\hline & San Diego County & 6 & 14.3 \\
\hline \multirow{5}{*}{$\begin{array}{l}\text { Q5: Please choose the answer that bests fits your } \\
\text { role in raising your child. }\end{array}$} & Parent & 32 & 76.2 \\
\hline & Grandparent & 4 & 9.5 \\
\hline & Stepparent & 3 & 7.1 \\
\hline & Foster parent & 2 & 4.8 \\
\hline & Other: adoptive parent & 1 & 2.4 \\
\hline \multirow[t]{2}{*}{ Q6: What is your gender? } & Female & 30 & 71.4 \\
\hline & Male & 12 & 12.6 \\
\hline \multirow[t]{5}{*}{ Q8: What is your primary language? } & English & 33 & 78.6 \\
\hline & Spanish & 7 & 16.7 \\
\hline & Vietnamese & 1 & 2.4 \\
\hline & Other: American Sign & 1 & 2.4 \\
\hline & Language & & \\
\hline \multirow{7}{*}{$\begin{array}{l}\text { Q7: Your race/ethnicity (select all that apply to } \\
\text { you) }\end{array}$} & White & 19 & 45.2 \\
\hline & $\begin{array}{l}\text { Hispanic, Latino, or } \\
\text { Spanish Origin }\end{array}$ & 14 & 33.3 \\
\hline & Black or African & 4 & 9.5 \\
\hline & American & & \\
\hline & $\begin{array}{l}\text { American Indian or } \\
\text { Alaska Native }\end{array}$ & 3 & 7.1 \\
\hline & Asian & 2 & 4.8 \\
\hline & I prefer not to answer & 1 & 2.4 \\
\hline \multirow{8}{*}{$\begin{array}{l}\text { Q9: What best describes your highest level of } \\
\text { education/degree? }\end{array}$} & Some high school & 3 & 7.1 \\
\hline & $\begin{array}{l}\text { High school diploma or } \\
\text { equivalent }\end{array}$ & 9 & 21.4 \\
\hline & Attended some college & 11 & 26.2 \\
\hline & Associated degree & 8 & 19.0 \\
\hline & Vocational training & 2 & 4.8 \\
\hline & Bachelors' degree & 5 & 11.9 \\
\hline & Master's degree & 3 & 7.1 \\
\hline & Doctoral degree & 1 & 2.4 \\
\hline
\end{tabular}

Participants in three counties took surveys. Participants lived in Los Angeles County $(47.6 \%, n=20)$, Orange County $(38.1 \%, n=16)$, and San Diego County $(14.3 \%, n=6)$. When asked about their role in raising their student, participants described themselves as a parent, 
grandparent, stepparent, foster parent, and adoptive parents. Most participants identified as parents $(76.2 \%, n=32)$. Thirty participants were women $(71.4 \%)$, and 12 were men $(12.6 \%)$. No participants identified as nonbinary/third gender. English was reported as the primary language for most participants $(78.6 \%, n=33)$. The top selected response was White $(45.2 \%, n=19)$ and Hispanic, Latino, or Spanish Origin $(33.3 \%, n=14)$. American Indian or Alaska Native, Asian, Black or African American, and Hispanic, Latino, or Spanish Origin, made up 54.7\% of the participants. Answer choices included: American Indian or Alaska Native (e.g., Navajo Nation, Blackfeet Tribe, Mayan, Aztec, Native Village of Barrow Inupiat Traditional Government, Nome Eskimo Community), Asian (e.g., Chinese, Filipino, Asian Indian, Vietnamese, Korean, Japanese), Black or African American (e.g., Jamaican, Haitian, Nigerian, Ethiopian, Somalian), Hispanic, Latino, or Spanish Origin (e.g., Mexican or Mexican American, Puerto Rican, Cuban, Salvadoran, Dominican, Columbian), Middle Eastern or North African (e.g., Lebanese, Iranian, Egyptian, Syrian, Moroccan, Algerian), Native Hawaiian or Other Pacific Islander (e.g., Native Hawaiian, Samoan, Chamorro, Tongan, Fijian, Marshallese), White (e.g., German, Irish, English, Italian, Polish, French), some other race, ethnicity, or origin, please specify, and I prefer not to answer. When asked about their highest level of education, participants selected from the following answers: Some high school, high school diploma or equivalent, vocational training, some college, associate's degree (e.g., AA, AE, AFA, AS, ASN), bachelor's degree (e.g., BA, BBA, BFA, BS), some postundergrad work, master's degree (e.g., MS, MBA, MFA, MS, MSW), doctoral degree (e.g., EdD, PhD), other, and I prefer not to answer. Based on participant answers, the most selected response has attended some college $(23.8 \%, n=10)$. Most participants (54.7\%) had not completed a college degree program. This group included those with some high school, high school diploma or equivalent, and some college. 


\section{Student Demographics}

Participants were asked questions about their students attending an NPS at the time of the survey. Questions were asked about the student's age if they qualified for free or reduced-price lunch, special education eligibility, and the number of years in special education. Student information is provided in Table 4.2.

\section{Table 4.2}

Student Demographic Information

\begin{tabular}{llcc}
\hline \multicolumn{1}{c}{ Question } & Selection choice & Frequency & Percent \\
\hline Q3: What is your child's age? & 8-10 years old & 16 & 38.0 \\
& $11-13$ years old & 14 & 33.3 \\
& $14-16$ years old & 4 & 9.6 \\
& $17-20$ years old & 8 & 19.1 \\
Q4: Does your child qualify for free or reduced-price & Yes & 28 & 66.7 \\
lunches at school? & No & 8 & 19.0 \\
& I do not know & 6 & 14.3 \\
Q10: Your child receives special education services & Autism Spectrum & 26 & 61.9 \\
based upon which of the following disability & Disorder & & \\
categories (Select all that apply)? & Emotional & 12 & 28.6 \\
& disturbance & & \\
& Intellectual disability & 7 & 16.7 \\
& Specific learning & 6 & 14.3 \\
& disability & & \\
& Speech and language & 5 & 11.9 \\
& impairment & & \\
& Multiple disabilities & 3 & 7.1 \\
Q11: How many years has your child been receiving & Other health & 3 & 7.1 \\
special education services? & impairment & & \\
& Hearing impairment & 2 & 4.8 \\
& Deafness & 1 & 2.4 \\
& Traumatic brain & 1 & 2.4
\end{tabular}


Students' ages ranged from 8-20 years old. To understand socioeconomic status, participants were asked if their students qualified for free or reduced-price lunch. Twenty-eight participants reported their students qualified for free or reduced-price lunch $(66.7 \%, n=28)$.

Twenty-six (61.9\%) participants indicated their student qualified for special education services under the category of autism spectrum disorder, and $12(28.6 \%)$ qualified under emotional disturbance. Nineteen (45.2\%) participants shared their students had more than one eligibility. Other eligibilities included (a) deafness, (b) hearing impairment, (c) intellectual disability, (d) multiple disabilities, (e) other health impairment, (f) specific learning disability, (g) speech and language impairment, and (h) traumatic brain injury. One participant indicated they were not sure about their student's eligibility. All the participants had students receiving special education services.

\section{NPS and IEP Attendance}

To better understand participants' NPS experience, they were asked questions about their students' NPS and IEP attendance. Questions were asked about the number of years their student had attended an NPS, the number of IEP meetings participants attended at NPSs, the number of IEP meetings attended within the last year at the NPS, and the length of time since their last IEP meeting. Data from these questions are presented in Table 4.3.

\section{Table 4.3}

\section{NPS and IEP Attendance Information}

\begin{tabular}{clcc}
\hline \multicolumn{1}{c}{ Question } & Selection choice & Frequency & Percent \\
\hline Q12: How many years has your child been attending a & Less than 1 year & 2 & 4.8 \\
nonpublic school (if your student attended more than one & 1-2 years & 14 & 33.3 \\
nonpublic school, provide the total years for all & 3-4 years & 16 & 38.1 \\
nonpublic school placements)? & 5-6 years & 4 & 9.5 \\
& 6-7 years & 3 & 7.1 \\
& More than 8 years & 3 & 7.1
\end{tabular}




\begin{tabular}{llcc}
\hline \multicolumn{1}{c}{ Question } & Selection choice & Frequency & Percent \\
\hline Q13: How many IEP meetings have you attended at a & 1 or less & 3 & 7.1 \\
nonpublic school (current school and any past nonpublic & $2-4$ & 17 & 40.5 \\
schools)? & $5-7$ & 10 & 23.5 \\
& $8-10$ & 6 & 14.3 \\
& 11 or more & 6 & 14.3 \\
Q15: How many IEP meetings have you attended in the last & None & 6 & 14.3 \\
year for the student attending this nonpublic school & 1 & 10 & 23.8 \\
(Please include both virtual and in-person meetings)? & 2 & 16 & 38.1 \\
& 3 & 5 & 11.9 \\
& 4 & 3 & 7.1 \\
& 5 or more & 2 & 4.8 \\
Q14: When was your last IEP meeting? & & 5 & 11.9 \\
& Within the month & 5 & 35.7 \\
& $1-3$ months & 15 & 35.7 \\
& $4-6$ months & 15 & 7.1 \\
& $7-9$ months & 3 & 7.1 \\
\hline
\end{tabular}

Student attendance at an NPS ranged from less than 1 year to more than 8 years. Most of the participants had students who had attended an NPS for 3-4 years $(38.1 \%, n=16)$ or $1-2$ years $(33.3 \%, n=14)$.

Participants were asked to indicate how many IEP meetings they had attended at any NPS. Answer choices included: one or fewer, two to four, five to seven meetings, eight to 10 , and or more meetings. Most participants have attended two to four $(40.5 \%, n=17)$ or five to seven $(23.5 \%, n=10)$ IEP meetings at a NPS.

All participants should have attended at least one IEP meeting for their student attending the NPS within the last year. Participants were asked how many IEP meetings they attended at their students' NPS within the last year. Answer choices included: "none," "one," "two," "three," "four," "five or more," and "I am not sure." Most participants reported having attended two $(38.1 \%, n=16)$ or one $(23.8 \%, n=10)$ IEP meeting within the last year at an NPS. Six participants (14.3\%) reported they had not attended an IEP meeting at an NPS in the last year. 
Participants were asked when their last IEP, at the NPS, took place. All participants should have attended an IEP meeting within the last year, based on IDEIA; however, three participants $(7.1 \%)$ indicated they had not attended an IEP at the NPS in over a year. Due to distance learning, the participant may have been confused by the question. They may have not physically attended an IEP meeting in person. It is also possible that the NPS did not hold an IEP meeting within the last year and is out of compliance. Most participants reported attending an IEP meeting within $1-3$ months $(35.7 \%, n=15)$ or $4-6$ months after completing the survey $(35.7 \%, n=15)$.

\section{Survey Results}

Survey results include six sections. The first section was the total ratings for involvement, communication, and relationships. In the survey, each of the three main variable sections started with a scale question that asked participants to rate their experience from $1-4$. The results for these three questions are provided in the first section. These overall ratings of communication, involvement, and parent-educator relationships were used to answer Research Questions 1 and 2. They were also used during the analysis for Research Question 3. The following five sections were (a) involvement, (b) communication, (c) parent-educator relationships, (d) conflict, and (e) virtual learning. The involvement and communication section were used to answer Research Question 1, while the parent-educator relationship and conflict sections were used to answer Research Question 2. The virtual learning section was included as additional information collected during the survey but did not directly relate to a research question. The following sections include (a) total ratings of involvement, communication, and relationships; (b) Research Question 1; (c) Research Question 2; (d) Research Question 3; and (e) Additional Data. 


\section{Total Rating of Involvement, Communication, and Relationships}

The prior to distance learning section included three subsections: involvement, communication, and parent-educator relationships. The first question in each of these sections was a scale question that asked participants to rate their experience of involvement, communication, and parent-educator relationships while attending IEP meetings at the NPS. These questions provided data for Research Questions 1 and 2. Based on participant responses, most participants rated their experiences during IEP meetings at NPSs in the high range, suggesting they felt their involvement $(64.1 \%, n=25)$, communication $(52.6 \%, n=20)$, and relationships $(50.0 \%, n=17)$ was as good or strong as they felt they should be. Mean scores closest to 4 indicated satisfaction, while scores closest to 1 indicated lack of involvement, communication, or positive relationships. Based on the mean score of all three questions, participants' ratings of involvement in the IEP meetings at an NPS were rated the highest $(M=$ 3.49). Median scores for involvement and communication were 4, while parent-educator relationships median scores were 3.5. Results for those three summary questions are in Table 4.4.

\section{Table 4.4}

Ratings for Overall Involvement, Communication, and Relationships

\begin{tabular}{lccccccc}
\hline \multicolumn{1}{c}{ Question } & $\begin{array}{c}1 \\
\text { Low }\end{array}$ & 2 & 3 & $\begin{array}{c}4 \\
\text { High }\end{array}$ & $M$ & $S D$ & $M d n$ \\
& $n(\%)$ & $n(\%)$ & $n(\%)$ & $n(\%)$ & & & \\
\hline Q17. Involvement & $2(5.1)$ & $2(5.1)$ & $10(25.6)$ & $25(64.1)$ & 3.49 & 0.823 & 4 \\
Q27. Communication & $1(2.6)$ & $5(13.2)$ & $12(31.6)$ & $20(52.6)$ & 3.34 & 0.815 & 4 \\
Q32. Relationships & $3(8.8)$ & $3(8.8)$ & $11(32.4)$ & $17(50.0)$ & 3.24 & 0.955 & 3.5 \\
\hline
\end{tabular}

The following sections provide the results of survey and interview data about involvement, communication, parent-educator relationships, conflict, group data, and during distance learning. 


\section{Research Question 1}

Research Question 1 asked, "How do parents of students receiving special education services perceive their level of involvement during the IEP meeting process at nonpublic schools?" All questions in the Involvement and Communication sections of the survey sections provided data to answer Research Question 1.

\section{Involvement}

The involvement subsection of the survey goes from Questions 17-26. The questions in this section included the overall involvement rating questions, six scale questions, one yes-no question, and two multiple-choice questions. The overall involvement rating questions are in Table 4.4.

The six scale questions use a 4-point scale from strongly disagree to strongly agree. Participant responses to these scale questions are provided in the next two tables. Scale questions used a rating from -2 for strongly disagree to positive +2 for strongly agree. Mean scores closer to -2 suggest disagreement, while those closer to +2 suggest stronger agreement. Table 4.5 shows the mean score on involvement questions ranging from 0.92 to 1.68 . Means scores suggested most participants fell within the agree to strongly agree range. The lowest mean score ( $M=$ 0.92) was for the question about school district staff attempts to involve participants throughout the meetings. The second-lowest mean score $(M=0.97)$ was for the question asking about feelings of involvement in creating the IEP document. The question with the highest mean (i.e., Question 18) also had the highest median score $(M d n=2)$, while the other three questions had a median score of 1.0. 
Table 4.5

Ratings for Participant Ratings on Involvement Questions

\begin{tabular}{|c|c|c|c|c|c|c|c|}
\hline Question & $\begin{array}{c}\text { Strongly } \\
\text { disagree } \\
n(\%)\end{array}$ & $\begin{array}{c}\text { Disagree } \\
n(\%)\end{array}$ & $\begin{array}{l}\text { Agree } \\
n(\%)\end{array}$ & $\begin{array}{l}\text { Strongly } \\
\text { agree } \\
n(\%)\end{array}$ & $M$ & $S D$ & $M d n$ \\
\hline $\begin{array}{l}\text { Q18. I feel nonpublic school } \\
\text { staff attempt to involve } \\
\text { me throughout IEP } \\
\text { meetings }\end{array}$ & 0 & 0 & $12(31.6)$ & $26(61.9)$ & 1.68 & 0.471 & 2 \\
\hline $\begin{array}{l}\text { Q19. I feel school district } \\
\text { staff attempt to involve } \\
\text { me throughout IEP } \\
\text { meetings held at the } \\
\text { nonpublic school }\end{array}$ & $2(5.1)$ & 7 (17.9) & $13(33.3)$ & 17 (43.6) & 0.92 & 1.285 & 1 \\
\hline $\begin{array}{l}\text { Q20. I feel involved in the } \\
\text { creation of the IEP } \\
\text { document }\end{array}$ & $1(2.6)$ & 7 (17.9) & $15(38.5)$ & $16(38.1)$ & 0.97 & 1.181 & 1 \\
\hline $\begin{array}{l}\text { Q21. I feel my } \\
\text { understanding of my child } \\
\text { is recognized during IEP } \\
\text { meetings }\end{array}$ & $1(2.4)$ & $3(7.1)$ & $19(45.2)$ & $16(38.1)$ & 1.18 & 0.970 & 1 \\
\hline
\end{tabular}

Participants were asked to rate their level of agreement from strongly disagree to strongly agree for the starter statement "The IEP team has collaborated with me by" with the following statement endings: "including me in the assessment process," "including my suggestions for goals and objectives for the IEP," "including my suggestions for curriculum or instructional approaches," and "asking for my input during the meeting." Participant responses to these statements are provided in Table 4.6. The means for each of these questions were calculated based on a scale from -2 to +2 . All the means fell between -1 and $+1(0.36-0.95)$, which suggests participants' ratings were between disagree and agree. All four statements had median scores of 1.0. 
Table 4.6

Ratings of How the IEP Team Collaborates With Guardians

\begin{tabular}{|c|c|c|c|c|c|c|c|}
\hline Question 24 statements & $\begin{array}{c}\text { Strongly } \\
\text { disagree } \\
n(\%)\end{array}$ & $\begin{array}{c}\text { Disagree } \\
n(\%)\end{array}$ & $\begin{array}{l}\text { Agree } \\
n(\%)\end{array}$ & $\begin{array}{l}\text { Strongly } \\
\text { agree } \\
n(\%)\end{array}$ & $M$ & $S D$ & $M d n$ \\
\hline $\begin{array}{l}\text { Including me in the } \\
\text { assessment process }\end{array}$ & $5(13.2)$ & $8(21.1)$ & $18(47.4)$ & $7(18.4)$ & 0.36 & 1.364 & 1 \\
\hline $\begin{array}{l}\text { Including my suggestions } \\
\text { for goals and objectives } \\
\text { for the IEP }\end{array}$ & $3(8.1)$ & $10(27.0)$ & $14(37.8)$ & $10(27.0)$ & 0.48 & 1.367 & 1 \\
\hline $\begin{array}{l}\text { Including my suggestions } \\
\text { for curriculum or } \\
\text { instructional approaches }\end{array}$ & $3(8.3)$ & $4(11.1)$ & $19(52.8)$ & $10(27.8)$ & 0.81 & 1.215 & 1 \\
\hline $\begin{array}{l}\text { Asking for my input during } \\
\text { the meeting }\end{array}$ & $4(10.8)$ & $2(5.4)$ & $17(45.9)$ & $14(37.8)$ & 0.95 & 1.268 & 1 \\
\hline
\end{tabular}

One of the involvement multiple-choice questions asked participants, "What does your child's educational/IEP team do to include you in the IEP meeting process?” Participants were able to select all that applied. More than half of the participants selected "sent me a draft report before the meeting" $(52.6 \%, n=20)$. Half of the participants selected "asking for my input into the draft IEP, prior to the meeting" $(50.0 \%, n=19)$ and "planning and writing goals and objectives with me" $(50.0 \%, n=19)$. More specific results for this question are provided in Table 4.7.

\section{Table 4.7}

Techniques to Include Guardians in the IEP Process

\begin{tabular}{lcc}
\hline \multicolumn{1}{c}{ Q23: Selection choice } & Frequency & Percent \\
\hline Sent me a draft before the meeting & 20 & 52.6 \\
Asking for my input into the draft IEP, prior to the meeting & 19 & 50.0 \\
Planning and writing goals and objectives with me & 19 & 50.0 \\
Including me in the assessment process & 16 & 42.1 \\
Having me work on academics and/or behavior at home & 16 & 42.1 \\
Including input from outside providers (e.g., private service providers) & 12 & 31.6 \\
Other: No written response & 1 & 2.6 \\
\hline
\end{tabular}


At the end of the involvement section, participants were asked if there had ever been a time they felt included in their child's IEP meeting at the NPS. Of the 38 participants who answered this question, 28 answered No (88.9\%). Ten participants answered Yes $(11.1 \%)$, indicating they had felt not included in the IEP meeting process at an NPS. The follow-up to this question was a multiple-choice question asking for clarification about why the participants did not feel included. More than half of parents selected "my input was not taken seriously" (70\%, $n$ $=7)$, "goals and services were developed without my input" $(60 \%, n=6)$, and "the meeting felt rushed" $(60 \%, n=6)$. Participant responses are provided in Table 4.8 .

Table 4.8

Reason's Participants Felt They Were Not Involved in the IEP Process

\begin{tabular}{lcc}
\hline \multicolumn{1}{c}{ Q26: Selection choices } & Frequency & Percent \\
\hline My input was not taken seriously & 7 & 70 \\
Goals and services were developed without my input & 6 & 60 \\
The meeting felt rushed & 6 & 60 \\
The IEP team did not ask if I had any questions & 3 & 30 \\
I was not given time to fully understand all of the information provided & 3 & 30 \\
The IEP team did not answer my questions & 2 & 20 \\
I was not called to consult prior to the IEP meeting & 2 & 20 \\
I was not given time to consider if I agree with the IEP & 1 & 10 \\
\hline
\end{tabular}

Language. At the start of the survey, participants were able to select English or Spanish as the survey language. During the demographic section, participants were asked to indicate their primary language. Thirty-three participants reported English as the primary, while nine participants reported having primary languages other than English. Seven participants reported Spanish, one reported Vietnamese, and one reported American sign language (ASL) as their primary language. When participants reported their primary language was not English, they were asked to provide a rating of strongly disagree to strongly agree for the following: "I feel the IEP 
team supported my involvement through the use of primary language." The participant who reported their primary language being ASL did not answer the language question included in the involvement section. All eight other participants reported agreement that their NPS staff supports their involvement using their primary language. Four participants rated that they agree (50.0\%), and four rated they strongly agree $(50 \%)$.

\section{Communication}

In the area of communication, participants were asked about their overall level of satisfaction with the communication provided by the NPS their student attends. Participants' responses to that question were provided in Table 4.4. Additional questions included how the NPS communicated with guardians, how often they communicated, and what was communicated. In addition to the overall communication rating, this section included one 4-point scale question and three multiple-choice questions. Questions within this section provided data for Research Question 1.

The 4-point scale question asked participants to rate how satisfied they were with the level of communication provided by their student's NPS from very dissatisfied to very satisfied on a 4-point scale. Most of the participants selected either very satisfied $(46.2, n=18)$ and satisfied $(38.2 \%, n=15)$. Question 22 had a mean score of 1.10 and a median score of 1.0 (see Table 4.9). 
Table 4.9

Satisfaction Regarding NPS Communication

\begin{tabular}{|c|c|c|c|c|c|c|c|}
\hline Question & $\begin{array}{c}\text { Very } \\
\text { dissatisfied } \\
n(\%)\end{array}$ & $\begin{array}{l}\text { Dissatisfied } \\
n(\%)\end{array}$ & $\begin{array}{l}\text { Satisfied } \\
n(\%)\end{array}$ & $\begin{array}{c}\text { Very } \\
\text { satisfied } \\
n(\%)\end{array}$ & $M$ & $S D$ & $M d n$ \\
\hline $\begin{array}{l}\text { Q22: How satisfied are you } \\
\text { with the level of } \\
\text { communication provided by } \\
\text { the nonpublic school? }\end{array}$ & $2(5.1)$ & $4(10.3)$ & $\begin{array}{c}15 \\
(38.5)\end{array}$ & $18(46.2)$ & 1.10 & 1.165 & 1 \\
\hline
\end{tabular}

The communication section included three multiple-choice questions. These questions asked how often the NPS communicated with the participants, how they were communicated with them, and what topics were communicated with participants monthly. Results for these three questions are provided in Table 4.10.

Table 4.10

NPS Communication: How Often, Methods, and Topics

\begin{tabular}{|c|c|c|c|}
\hline Question & Selection choice & Frequency & Percent \\
\hline \multirow{5}{*}{$\begin{array}{l}\text { Q28: How often do nonpublic school } \\
\text { staff communicate with you regarding } \\
\text { your child? }\end{array}$} & Monthly & 5 & 12.8 \\
\hline & Weekly & 8 & 20.5 \\
\hline & Several days per week & 5 & 12.8 \\
\hline & Every day & 5 & 12.8 \\
\hline & As needed & 16 & 41.0 \\
\hline \multirow{8}{*}{$\begin{array}{l}\text { Q30: How does your nonpublic school } \\
\text { staff communicate with you regarding } \\
\text { your child (select all that apply)? }\end{array}$} & Phone calls & 27 & 64.3 \\
\hline & Emails & 22 & 52.4 \\
\hline & Video calls & 20 & 47.6 \\
\hline & In-person & 13 & 31.0 \\
\hline & Paper letters & 8 & 19.0 \\
\hline & Parent communication platform & 5 & 11.9 \\
\hline & Learning platform & 1 & 2.4 \\
\hline & Google docs & 1 & 2.4 \\
\hline \multirow{6}{*}{$\begin{array}{l}\text { Q31: My nonpublic school staff } \\
\text { communicates with me about the } \\
\text { following, at least monthly (select all } \\
\text { that apply)? }\end{array}$} & Academic performance & 28 & 66.7 \\
\hline & Behavior & 23 & 54.8 \\
\hline & Goal progress & 14 & 33.3 \\
\hline & Attendance & 10 & 23.8 \\
\hline & Health & 9 & 21.4 \\
\hline & Mental health & 5 & 11.9 \\
\hline
\end{tabular}




\begin{tabular}{llcc}
\hline Question & Selection choice & Frequency & Percent \\
\hline & Discipline & 4 & 9.5 \\
Other: & & \\
& Lesson plans and homework & 1 & 2.4 \\
& As needed & 1 & 2.4 \\
\hline
\end{tabular}

Question 28 asked participants to select how often the NPS staff communicated with them regarding their students. The highest selected response was NPS staff communicated with them as needed $(41.0 \%, n=16)$. Most participants reported they received information from NPS staff by phone $(64.3 \%, n=27)$ or email $(52.4 \%, n=22)$. After indicating how NPSs communicated with them, participants were asked what they communicated about, at least monthly. The two discussed subjects were academic performance $(66.7 \%, n=28)$ and behavior $(54.8 \%, n=23)$. Two participants selected Other and wrote in an answer. One participant wrote in "lessons plans or homework," and another wrote in "as needed."

\section{Research Question 2}

Research Question 2 asked, "How do parents of students receiving special education services perceive their relationships with the IEP team during the IEP meeting process at nonpublic schools?" All questions in the Parent-Educator Relationships and Conflict sections of the survey sections provided data to answer Research Question 2.

\section{Parent-Educator Relationships}

The parent-educator relationships section of the survey started with an overall rating of participants' relationships with educators during IEP meetings at NPSs. Participant responses to this question are provided in Table 4.4. After this initial rating, participants were asked seven 4point scale questions with a scale from strongly disagree to strongly agree. All parent-educator relationships questions provided data to answer Research Question 2. 
The seven 4-point scale questions included six addressing aspects of relationships and one about specific relationships with nonpublic and district staff. The six questions addressing different aspects of parent-educator relationships are listed in Table 4.11. The mean scores for these questions are provided. Mean scores closest to +2 indicate strongly agree, while scores closest to -2 indicate strong disagreement. Based on the mean scores in Table 4.11, most participants agreed or strongly agreed to the statements. The highest agreement was reported about Question 33, “educators providing a welcoming atmosphere for participants during IEP meetings" $(M=1.33, M d n=1)$, followed closely by Question 39, "overall, I feel comfortable during IEP meetings" $(M=1.27, M d n=2)$. Although indicating agreement, the lowest mean score was about participants feeling the IEP team values them during IEP meetings $(M=0.81)$.

Table 4.11

Relationship Questions

\begin{tabular}{|c|c|c|c|c|c|c|c|}
\hline Question & $\begin{array}{l}\text { Strongly } \\
\text { disagree } \\
n(\%)\end{array}$ & $\begin{array}{c}\text { Disagree } \\
n(\%)\end{array}$ & $\begin{array}{l}\text { Agree } \\
n(\%)\end{array}$ & $\begin{array}{l}\text { Strongly } \\
\text { agree } \\
n(\%)\end{array}$ & $M$ & $S D$ & $M d n$ \\
\hline $\begin{array}{l}\text { Q33. Educator provided a } \\
\text { welcoming atmosphere for you } \\
\text { during IEP meetings. }\end{array}$ & 0 & $2(5.6)$ & $\begin{array}{c}18 \\
(50.0)\end{array}$ & $16(44.4)$ & 1.33 & 0.756 & 1 \\
\hline $\begin{array}{l}\text { Q34. I am treated respectfully by } \\
\text { educators during IEP meetings. }\end{array}$ & $1(2.4)$ & $5(11.9)$ & $\begin{array}{c}13 \\
(31.0)\end{array}$ & $18(42.9)$ & 1.14 & 1.134 & 1 \\
\hline $\begin{array}{l}\text { Q35. I am treated as an equal } \\
\text { decision maker during IEP } \\
\text { meetings. }\end{array}$ & $1(2.7)$ & $5(13.5)$ & $\begin{array}{c}18 \\
(48.6)\end{array}$ & $13(35.1)$ & 1.00 & 1.080 & 1 \\
\hline $\begin{array}{l}\text { Q36. I am able to talk openly and } \\
\text { freely with educators during IEP } \\
\text { meetings. }\end{array}$ & $2(5.4)$ & $3(8.1)$ & $\begin{array}{c}16 \\
(43.2)\end{array}$ & $16(43.2)$ & 1.11 & 1.125 & 1 \\
\hline $\begin{array}{l}\text { Q37. My input is valued by IEP } \\
\text { team members during IEP } \\
\text { meetings. }\end{array}$ & $2(5.4)$ & 7 (18.9) & $\begin{array}{c}15 \\
(40.5)\end{array}$ & $13(35.1)$ & 0.81 & 1.266 & 1 \\
\hline $\begin{array}{l}\text { Q38. Overall, IEP team members } \\
\text { maintain positive relations with } \\
\text { me during IEP meetings. }\end{array}$ & $2(5.6)$ & $3(8.3)$ & $\begin{array}{c}14 \\
(38.9)\end{array}$ & $17(47.2)$ & 1.14 & 1.150 & 1 \\
\hline $\begin{array}{l}\text { Q39. Overall, I feel comfortable } \\
\text { during IEP meetings. }\end{array}$ & $1(2.7)$ & $3(8.1)$ & $\begin{array}{c}33.3 \\
(37.8) \\
\end{array}$ & $19(51.4)$ & 1.27 & 1.018 & 2 \\
\hline
\end{tabular}


The last question in the communication subsection asked participants to indicate how strongly they agreed to have positive relationships with a list of nonpublic and public-school staff. Ratings for each IEP team member are provided in Table 4.12. Mean scores for each type of team member are provided. The score closest to -2 indicated strong disagreement to having a positive relationship, while scores closest to +2 indicated strong agreement to having a positive relationship with those team members. Based on the results, means scores were all positive. Mean scores for NPS staff ranged from 0.56-1.24, while mean scores for district staff ranged from 0.52-0.54. Besides ratings for paraprofessionals at NPSs, participants' mean scores of agreement about positive relationships with all other IEP team members from the NPSs were rated higher than for district IEP team members. The highest median score was for special education teachers at NPSs $(M=1.24, M d n=2)$.

\section{Table 4.12}

Positive Relationships With Staff

\begin{tabular}{|c|c|c|c|c|c|c|c|}
\hline Q40: Staff type & $\begin{array}{c}\text { Strongly } \\
\text { disagree } \\
n(\%)\end{array}$ & $\begin{array}{c}\text { Disagree } \\
n(\%)\end{array}$ & $\begin{array}{l}\text { Agree } \\
n(\%)\end{array}$ & $\begin{array}{c}\text { Strongly } \\
\text { agree } \\
n(\%)\end{array}$ & $M$ & $S D$ & $M d n$ \\
\hline \multicolumn{8}{|l|}{ Nonpublic school } \\
\hline $\begin{array}{l}\text { Para-professionals or } \\
\text { aids }\end{array}$ & $2(7.4)$ & $8(29.5)$ & 7 (25.9) & $10(37.0)$ & 0.56 & 1.450 & 1 \\
\hline Administrators & $3(9.4)$ & $1(3.1)$ & $\begin{array}{c}13 \\
(40.6)\end{array}$ & 15 (46.9) & 1.13 & 1.212 & 1 \\
\hline $\begin{array}{l}\text { Special education } \\
\text { teacher }\end{array}$ & $3(9.1)$ & $1(3.0)$ & $\begin{array}{c}10 \\
(30.3)\end{array}$ & 19 (57.6) & 1.24 & 1.226 & 2 \\
\hline Service provider & $2(5.9)$ & $4(11.8)$ & $9(26.5)$ & 19 (55.9) & 1.15 & 1.258 & 1 \\
\hline \multicolumn{8}{|l|}{ District } \\
\hline Administrator & $4(15.4)$ & $3(11.5)$ & $\begin{array}{c}13 \\
(50.0)\end{array}$ & $6(23.1)$ & 0.54 & 1.392 & 1 \\
\hline $\begin{array}{l}\text { Special education } \\
\text { teacher }\end{array}$ & $3(11.1)$ & $5(11.9)$ & $9(33.3)$ & $10(37.0)$ & 0.67 & 1.441 & 1 \\
\hline Service provider & $3(11.1)$ & $7(25.9)$ & $7(25.9)$ & $10(37.0)$ & 0.52 & 1.503 & 1 \\
\hline
\end{tabular}




\section{Conflict}

The conflict section included four questions. All conflict questions provided data to answer Research Question 2. The first question asked participants, "have you ever experienced conflict during an IEP meeting.” Based on answers to this Question, 22 participants (59.5\%) indicated they had had no conflicts during IEP meetings at NPSs. Fifteen participants (40.5\%) indicated they had conflicts during IEP meetings at NPSs. The 15 participants who reported having experienced conflict were asked to answer the remaining three multiple-choice questions in the subsection. These three questions asked participants whom they had conflicts with and what the conflicts were about. Table 4.13 provides results for participants who reported having conflicts during IEP meetings at NPSs. This question was divided into two sections: NPS staff and local school district staff. The 15 participants who had conflict were able to select all individuals that apply to them. Three participants selected Other and indicated they had experienced conflict with "staff members from their students' old school," "their ex-wife," and "school district staff." "School district staff members" was included in Table 4.13 under local school district. The other two responses that were written in could not be categorized into Table 4.13.

Table 4.13

Conflict With Nonpublic and District Educators

\begin{tabular}{lcc}
\hline \multicolumn{1}{c}{ Q42: Staff type } & Nonpublic school & Local school district \\
& $n(\%)$ & $n(\%)$ \\
\hline Administrator (e.g., principal, program specialist) & $7(46.7)$ & $4(26.7)$ \\
Special education teacher & $2(13.3)$ & $2(13.3)$ \\
Service provider (e.g., speech, OT, psych, PT) & $3(20.0)$ & $3(20.0)$ \\
Other: school district staff & 0 & $1(6.7)$ \\
\hline
\end{tabular}


After identifying with whom they had a conflict, participants were asked two questions about the topics of their conflicts. The first question asked about conflict with NPS staff, and the second asked about conflict with local school district staff. The 15 participants who had experienced conflict with a staff member during an IEP meeting at the NPS were asked about the types of conflicts they experienced with NPS staff and local school district staff. Answer choices for both questions included "disagreements over IEP content," "disagreements over placement decisions," "disagreements over services," "disagreements over eligibility," "disagreements over evaluation results," and "disagreements over curriculum or instruction approaches." The two most common reasons for conflict with NPS staff at IEP meetings was disagreement over IEP content $(33.3 \%, n=5)$ and disagreement over curriculum or instructional approaches $(33.3 \%, n$ $=5)$, while the most common conflict with school district staff was disagreement over curriculum or instructional approaches $(46.7 \%, n=7)$. One participant indicated they had no conflict with district staff during IEP meetings at NPSs. Results for the types of conflict between the school district and NPS staff are provided in Table 4.14.

\section{Table 4.14}

Type of Conflict With Nonpublic and District Educators

\begin{tabular}{lccc}
\hline \multicolumn{1}{c}{ Conflict } & $\begin{array}{c}\text { Nonpublic school } \\
\text { staff } \\
n(\%)\end{array}$ & $\begin{array}{c}\text { Local school } \\
\text { district staff } \\
n(\%)\end{array}$ & $\begin{array}{c}\text { Total } \\
n(\%)\end{array}$ \\
\hline Disagreements over IEP content & $5(33.3)$ & $6(40)$ & $11(73.3)$ \\
Disagreements over placement decision & $3(20)$ & $6(40)$ & $9(60)$ \\
Disagreements over services & $3(20)$ & $6(40)$ & $9(60)$ \\
Disagreements over eligibility & $4(26.7)$ & $5(33.3)$ & $9(60)$ \\
Disagreements over evaluation results & $3(20)$ & $3(20)$ & $6(40)$ \\
Disagreements over curriculum or & $5(33.3)$ & $7(46.7)$ & $12(80)$ \\
$\quad$ instruction approaches & & & \\
Disagreements over discipline issues & $2(13.3)$ & $1(6.7)$ & $3(20)$ \\
Personality of style conflicts & $1(6.7)$ & 0 & $1(6.7)$
\end{tabular}




\begin{tabular}{lccc}
\hline \multicolumn{1}{c}{ Conflict } & $\begin{array}{c}\text { Nonpublic school } \\
\text { staff } \\
n(\%)\end{array}$ & $\begin{array}{c}\text { Local school } \\
\text { district staff } \\
n(\%)\end{array}$ & $\begin{array}{c}\text { Total } \\
n(\%)\end{array}$ \\
\hline $\begin{array}{l}\text { Difficulty getting cooperation with } \\
\text { outside services }\end{array}$ & $1(6.7)$ & $1(6.7)$ & $2(13.3)$ \\
No conflict & $2(13.3)$ & $3(20)$ & $5(33.3)$ \\
\hline
\end{tabular}

\section{Research Question 3}

Research Question 3 asked, "Do parent perceptions of involvement in the IEP meeting process, at a nonpublic school, vary across demographic variables (e.g., age of the child, eligibility category, number of years in special education, race/ethnicity, parent educational level)?" The overall ratings of communication, involvement, and parent-educator relationships were used during the analysis for Research Question 3.

Descriptive analysis and effect size were conducted to understand parent perceptions of involvement, communication, and parent-educator relationships at NPSs when separated into different demographic groups. Demographic groups included: (a) parent race and ethnicity, (b) student qualification for free or reduced-price lunch, (c) parent education level, (d) student number of years receiving special education services, (e) student number of years attending an NPS, and (f) primary language.

\section{Race and Ethnicity}

The first set of descriptive statistics were conducted to determine differences between parents' perceptions of involvement, communication, and parent-educator relationships when separated by race and ethnicity. Parents were divided into two groups based on their responses to the survey's race and ethnicity demographic question. The researcher created two groups. The first group included parents who indicated their race and ethnicity as White. The second group was titled People of Color and included parents who indicated they were American Indian or Alaska Native; Asian; African American; Hispanic, Latino or Spanish Origin; Middle Eastern or 
North African; and Native Hawaiian or Other Pacific Islander. Table 4.15 includes mean scores separated by topic and race.

Table 4.15

Descriptive Analysis - Race and Ethnicity

\begin{tabular}{llcccc}
\hline \multicolumn{1}{c}{ Topic } & \multicolumn{1}{c}{ Groups } & $N$ & $M$ & SD & Std. Error \\
\hline Involvement & POC & 20 & 3.50 & .946 & .212 \\
& White & 18 & 3.44 & .705 & .166 \\
& Total & 38 & 3.47 & .830 & .135 \\
\cline { 2 - 5 } Communication & POC & 19 & 3.58 & .607 & .139 \\
& White & 18 & 3.06 & .938 & .221 \\
\multirow{3}{*}{ Parent-educator relationships } & Total & 37 & 3.32 & .818 & .135 \\
\cline { 2 - 6 } & POC & 17 & 3.29 & .985 & .239 \\
& White & 16 & 3.13 & .957 & .239 \\
& Total & 33 & 3.21 & .960 & .167 \\
\hline
\end{tabular}

The effect size, calculated using eta squared, was .001 for involvement, .105 for communication, and .008 for parent-educator relationships. Cohen's (1988) classification indicated that .01 as small effect, .06 as a medium, and .14 as a large effect. This suggested that the actual difference between the mean scores between parents who identified as White and those that identified as People of Color was very small for involvement and relationships but high for communication.

\section{Free or Reduced-Price Lunch}

The second set of descriptive statistics were conducted to determine differences between parents' perceptions of involvement, communication, and parent-educator relationships when separated by students' eligibility for free or reduced-price lunch. Parents were divided into two groups based on their responses to the survey's free or reduced-price lunch demographic question. The researcher created two groups. The first group included parents who indicated their students did not qualify for free or reduced-price lunch. The second group included parents who 
indicated their student did qualify for free or reduced-price lunch. Parents who reported that they did not know if their students qualified were not included in the analysis. Table 4.16 includes mean scores separated by topic and eligibility for free or reduced-price lunch.

Table 4.16

Descriptive Analysis - Qualification for Free or Reduced-Price Lunch

\begin{tabular}{llcccc}
\hline \multicolumn{1}{c}{ Topic } & \multicolumn{1}{c}{ Groups } & $N$ & $M$ & $S D$ & Std. Error \\
\hline Q17: Involvement & Does not qualify & 8 & 3.38 & 1.061 & .375 \\
& Qualifies & 26 & 3.54 & .647 & .127 \\
& Total & 34 & 3.50 & .749 & .128 \\
\cline { 2 - 6 } Q27: Communication & Does not qualify & 8 & 3.00 & 1.195 & .423 \\
& Qualifies & 25 & 3.40 & .707 & .141 \\
& Total & 33 & 3.30 & .847 & .147 \\
\cline { 2 - 6 } Q32: & Does not qualify & 8 & 3.00 & 1.309 & .463 \\
Parent-educator & Qualifies & 22 & 3.36 & .727 & .155 \\
relationships & Total & 30 & 3.27 & .907 & .166 \\
\hline
\end{tabular}

The effect size, calculated using eta squared, was .009 for involvement, .042 for communication, and .033 for parent-educator relationships. This suggests that the actual difference between the mean scores between parents whose students qualify for free or reducedprice lunch and those who do not was varied for involvement, communication, and relationships.

\section{Level of Education}

The third set of descriptive statistics were conducted to determine differences between parents' perceptions of involvement, communication, and parent-educator relationships when separated into groups based on parents' highest level of education. Parents were divided into two groups based on their responses to the survey's highest level of education demographic question. The first group was labeled "High School and Some College" and included parents who indicated they completed some high school, high school diploma or equivalent, vocational training, and some college. The third group was labeled "College Degree" and included parents 
who indicated they completed an associate degree, bachelor's degree, some postundergrad work, a master's degree, and a doctoral degree. Table 4.17 includes mean scores separated by topic and parents' highest level of education.

Table 4.17

Descriptive Analysis - Highest Level of Education

\begin{tabular}{lllllc}
\hline \multicolumn{1}{c}{ Topic } & \multicolumn{1}{c}{ Groups } & $N$ & $M$ & SD & Std. Error \\
\hline Q17: Involvement & High school or some college & 22 & 3.45 & .800 & .171 \\
& College degree or higher & 15 & 3.47 & .915 & .236 \\
& Total & 37 & 3.46 & .836 & .138 \\
\cline { 2 - 5 } Q27: Communication & High school or some college & 21 & 3.24 & .831 & .181 \\
& College degree or higher & 15 & 3.40 & .828 & .214 \\
& Total & 36 & 3.31 & .822 & .137 \\
\cline { 2 - 5 } Q32: & High school or some college & 19 & 3.05 & .970 & .223 \\
Parent-educator & College degree or higher & 13 & 3.46 & .967 & .268 \\
relationships & Total & 32 & 3.22 & .975 & .172 \\
\hline
\end{tabular}

The effect size, calculated using eta squared, was .000 for involvement, .010 for communication, and .044 for parent-educator relationships. This suggests that the actual difference between the mean scores between parents with different levels of education was small for involvement, communication, and relationships.

\section{Years Receiving Special Education Services}

The fourth set of descriptive statistics were conducted to determine differences between parents' perceptions of involvement, communication, and parent-educator relationships when separated into groups based on the student's number of years receiving special education services. Parents were divided into two groups based on their responses to the number of years in special education demographic questions on the survey. The first group included parents who indicated their student had been receiving special education services for 4 or fewer years. The second group included parents who indicated their student had received special education 
services for 5 or more years. Table 4.18 includes mean scores separated by topic and the number of years the student received special education services.

Table 4.18

Descriptive Analysis - Number of Years Receiving Special Education Services

\begin{tabular}{llllcc}
\hline \multicolumn{1}{c}{ Topic } & \multicolumn{1}{c}{ Groups } & $N$ & $M$ & $S D$ & Std. Error \\
\hline Q17: Involvement & 4 or less & 13 & 3.38 & .650 & .180 \\
& 5 or more & 26 & 3.54 & .905 & .177 \\
& Total & 39 & 3.49 & .823 & .132 \\
\cline { 2 - 5 } Q27: Communication & 4 or less & 13 & 3.00 & 1.080 & .300 \\
& 5 or more & 25 & 3.52 & .586 & .117 \\
Q32: & Total & 38 & 3.34 & .815 & .132 \\
\cline { 2 - 6 } Parent-educator & 4 or less & 13 & 3.08 & 1.038 & .288 \\
relationships & 5 or more & 21 & 3.33 & .913 & .199 \\
& Total & 34 & 3.24 & .955 & .164 \\
\hline
\end{tabular}

The effect size, calculated using eta squared, was .008 for involvement, .094 for communication, and .018 for parent-educator relationships. This suggests the actual difference between the mean scores between parents whose students have been in special education less than five or five or more was very small for involvement and relationships but medium for communication.

\section{Number of Years at an NPS}

The fifth set of descriptive statistics were conducted to determine differences between parents' perceptions of involvement, communication, and parent-educator relationships when separated into groups based on the student's number of years attending an NPS. Parents were divided into two groups based on their responses to the number of years their students attended an NPS question on the survey. The first group included parents who indicated their student had been attending an NPS for 4 or fewer years. The second group included parents who indicated 
their student had been attending an NPS for 5 or more years. Table 4.19 includes mean scores separated by topic and the number of years the student attended an NPS.

Table 4.19

Descriptive Analysis - Number of Years Attending an NPS

\begin{tabular}{llcccc}
\hline \multicolumn{1}{c}{ Topic } & \multicolumn{1}{c}{ Groups } & $N$ & $M$ & $S D$ & Std. Error \\
\hline Q17: Involvement & 4 or less year & 29 & 3.34 & .897 & .167 \\
& 5 or more years & 10 & 3.90 & .316 & .100 \\
& Total & 39 & 3.49 & .823 & .132 \\
\cline { 2 - 5 } Q27: Communication & 4 or less year & 29 & 3.21 & .861 & .160 \\
& 5 or more years & 9 & 3.78 & .441 & .147 \\
Q32: & Total & 38 & 3.34 & .815 & .132 \\
\cline { 2 - 5 } Parent-educator & 4 or less year & 26 & 3.12 & 1.033 & .202 \\
relationships & 5 or more years & 8 & 3.63 & .518 & .183 \\
& Total & 34 & 3.24 & .955 & .164 \\
\hline
\end{tabular}

The effect size, calculated using eta squared, was .089 for involvement, .091 for communication, and .053 for parent-educator relationships. This suggests that the actual difference between the mean scores between parents whose students attended an NPS for less than 5 years or 5 or more years was low for relationships and medium for involvement and communication.

\section{Language}

The last set of descriptive statistics were conducted to determine the differences between parents' perceptions of involvement, communication, and parent-educator relationships when separated into groups based on parents' primary language. Parents were divided into two groups based on their responses to the primary language question on the survey. The first group included parents who indicated their primary language was English. The second group was labeled Other Language and included parents who indicated their primary language was Spanish, Vietnamese, 
Chinese, Korean, Tagalog, Persian, Arabic, Japanese, or Other. Table 4.20 includes mean scores separated by topic and primary language.

Table 4.20

Descriptive Analysis - Primary Language

\begin{tabular}{llcccc}
\hline \multicolumn{1}{c}{ Topic } & \multicolumn{1}{c}{ Groups } & $N$ & $M$ & $S D$ & Std. Error \\
\hline Q17: Involvement & English & 31 & 3.52 & .769 & .138 \\
& Other language & 8 & 3.38 & 1.061 & .375 \\
& Total & 39 & 3.49 & .823 & .132 \\
\cline { 2 - 5 } Q27: Communication & English & 30 & 3.30 & .837 & .153 \\
& Other language & 8 & 3.50 & .756 & .267 \\
& Total & 38 & 3.34 & .815 & .132 \\
\cline { 2 - 5 } Q32: & English & 27 & 3.22 & .934 & .180 \\
Parent-educator & Other language & 7 & 3.29 & 1.113 & .421 \\
relationships & Total & 34 & 3.24 & .955 & .164 \\
\hline
\end{tabular}

The effect size, calculated using eta squared, was .005 for involvement, .010 for communication, and .001 for parent-educator relationships. This suggests that the actual difference between the mean scores between parents whose primary language was English and those whose was another language was very small for involvement, communication, and relationships.

\section{Additional Data}

The survey collected data to answer all three research questions. Additionally, the survey collected additional data about IEP meetings during virtual learning. Due to the COVID-19 global pandemic, there was a shutdown and schools switched to virtual IEP meetings. Seven survey questions were added to the survey to understand parent perspectives of involvement, communication, and parent-educator relationships during virtual IEP meetings with NPSs. 


\section{Virtual Learning}

Of the 42 participants who completed the survey, eight reported that they had not attended an IEP meeting during virtual learning, 29 indicated they had an IEP meeting during virtual learning at an NPS, and one selected "I am not sure." The 29 who reported having attended an IEP meeting during virtual learning were asked six questions about their experiences. The six questions included three 4-point scale questions from none to as much as possible and three 4-point scale questions from Strongly Disagree to Strongly Agree. One question of each type was asked for involvement, communication, and relationships, which resulted in two questions for each topic. The scale questions from none to as much as possible are provided in Table 4.27. Mean scores for these three questions are provided. Scores range from 1 to 4 . Mean scores closest to 1 indicate no involvement, communication, or relationships, while scores closer to four indicate as much as the participant would like. Mean scores for these three indicate high ratings for involvement, communication, and parent-educator relationships $(M=3.28,3.04$, 3.35, respectively). The mean score for relationships during meetings during virtual learning was the highest $(M=3.35)$, with half the participants selecting the highest rating $(50 \%, n=13)$ and a median score of 3.5. The distance learning involvement rating during IEP meetings had a mean score slightly lower than relationships $(M=3.28)$; however, the median was higher $(M d n=4)$, suggesting ratings that clustered closer to 4 . The distance learning communication rating had a mean score of 3.04 and a median of 3 . All three scores were similar to the overall ratings provided by parents for meetings prior to distance learning, as seen in Table 4.21. 
Table 4.21

Participant Overall Ratings During Virtual Learning

\begin{tabular}{lccccccc}
\hline \multicolumn{1}{c}{ Question } & $\begin{array}{c}1 \\
\text { Low }\end{array}$ & 2 & 3 & $\begin{array}{c}4 \\
\text { High }\end{array}$ & $M$ & $S D$ & $M d n$ \\
& $f(\%)$ & $f(\%)$ & $f(\%)$ & $f(\%)$ & & & \\
\hline Q46. Involvement & $1(4.0)$ & $4(16.0)$ & $7(28.0)$ & $13(52.0)$ & 3.28 & 0.891 & 4 \\
Q48. Communication & $2(7.4)$ & $6(22.2)$ & $8(29.6)$ & $11(40.7)$ & 3.04 & 0.980 & 3 \\
Q50. Relationships & $2(7.7)$ & 0 & $11(42.3)$ & $13(50)$ & 3.35 & 0.846 & 3.5 \\
\hline
\end{tabular}

The scale questions about distance learning IEP meetings using the scale from strongly disagree to strongly agree are provided in Table 4.22. Mean scores for these three questions range from -2 to +2 . Scores closest to -2 indicate strong disagreement, while scores closest to +2 indicate strong agreement. All three questions had mean scores falling between agree and disagree (0.04-0.75). Median scores for involvement and relationships fell in the agree range $(M d n=1)$, while the median score for communication fell in the disagree range $(M d n=-1)$. Participants were most likely to disagree with the statement, "I have received more communication about my student's IEP at the nonpublic school, during virtual learning, than I received prior to virtual learning."

\section{Table 4.22}

\section{Meetings During Virtual Learning}

\begin{tabular}{|c|c|c|c|c|c|c|c|}
\hline Question & $\begin{array}{c}\text { Strongly } \\
\text { disagree } \\
f(\%)\end{array}$ & $\begin{array}{c}\text { Disagree } \\
f(\%)\end{array}$ & $\begin{array}{l}\text { Agree } \\
f(\%)\end{array}$ & $\begin{array}{c}\text { Strongly } \\
\text { agree } \\
f(\%)\end{array}$ & $M$ & $S D$ & $M d n$ \\
\hline $\begin{array}{l}\text { Q47. I have felt more involved at } \\
\text { IEP meetings, at my student's } \\
\text { nonpublic school, during virtual } \\
\text { learning, than I felt prior to virtual } \\
\text { learning. }\end{array}$ & $1(3.6)$ & $\begin{array}{c}12 \\
(28.6)\end{array}$ & $\begin{array}{c}10 \\
(23.8)\end{array}$ & $5(11.9)$ & 0.21 & 1.287 & 1 \\
\hline
\end{tabular}




\begin{tabular}{lccccccc}
\hline \multicolumn{1}{c}{ Question } & $\begin{array}{c}\text { Strongly } \\
\text { disagree } \\
f(\%)\end{array}$ & $\begin{array}{c}\text { Disagree } \\
f(\%)\end{array}$ & $\begin{array}{c}\text { Agree } \\
f(\%)\end{array}$ & $\begin{array}{c}\text { Strongly } \\
\text { agree } \\
f(\%)\end{array}$ & $M$ & $S D$ & $M d n$ \\
\hline $\begin{array}{l}\text { Q49. I have received more } \\
\text { communication about my student's }\end{array}$ & 0 & 15 & 10 & $3(10.7)$ & 0.04 & 1.170 & -1 \\
$\quad \begin{array}{l}\text { IEP at the nonpublic school, during } \\
\text { virtual learning, than I received }\end{array}$ & & $(53.6)$ & $(35.7)$ & & & & \\
$\begin{array}{l}\text { prior to virtual learning. } \\
\text { Q51. I feel IEP team members } \\
\text { maintain positive relations with me } \\
\text { during IEP meetings, during } \\
\text { virtual learning. }\end{array}$ & 0 & $7(25.0)$ & 14 & $7(25.0)$ & 0.75 & 1.110 & 1 \\
& & & $(50.0)$ & & & & \\
\hline
\end{tabular}

\section{Interview Demographics}

During the survey, 15 parents provided their contact information at the end of the survey to express their interest in participating in an interview. Eight parents participated in parent interviews. The remaining survey participants were unable to be reached during multiple attempts made by the researcher. The eight parents are referred to using pseudonyms. Parent interviews were conducted with Claudia, James, Lillian, Linda, Mindy, Paseagal, Rosey, and Samuel.

Six interview participants were female (75\%), and two were male (25\%). Seven of the participants had students currently attending an NPS, and one had a student who attended an NPS within the last year. Five participants (62.5\%) identified as parents, one as a grandparent $(12.5 \%)$, one as a stepparent (12.5\%), and one as an adoptive parent (12.5\%) to the student attending an NPS.

Six of the interview participants identified English as their primary language. One participant was deaf and used ASL as her primary form of communication. She agreed to use the Zoom chat during the interview. One participant identified Spanish as his primary language. An interpreter was used during the Zoom interview along with translation services to help transcribe the interview. 


\section{Interview Results}

The following structural codes were selected before starting the coding process:

involvement, communication, and parent-educator relationships. All participant responses to questions about involvement, communication, parent-educator relationships, and conflict were coded using structural coding. The second phase involved individual coding statements using descriptive coding. The last phase of coding was grouping descriptive codes into categories (see Table 4.23).

Table 4.23

Structural and Descriptive Codes and Categories

\begin{tabular}{|c|c|c|}
\hline Structural code & Descriptive category & Descriptive codes \\
\hline \multirow[t]{16}{*}{ Involvement } & How educators involve parents & Ask questions \\
\hline & & Communicate \\
\hline & & Compare multiple settings \\
\hline & & Discuss IEP \\
\hline & & Interpreter \\
\hline & & Involve other organizations \\
\hline & & Listen to parents opinions \\
\hline & & Provide advice \\
\hline & & Provide IEP data prior to IEP \\
\hline & How parents get involved & Provide input \\
\hline & & Communicate \\
\hline & & Discuss goals and services \\
\hline & & Listen (passive involvement) \\
\hline & & Check IEP document \\
\hline & Causes for feeling not involved & Feeling blamed \\
\hline & & Feeling ignored \\
\hline \multirow[t]{9}{*}{ Communication } & How parents communicate & Ask questions \\
\hline & & Provide input \\
\hline & Positive communication & Available and open \\
\hline & & Regular communication \\
\hline & Things school communicates & Topics of communication \\
\hline & Problems with communication & Feeling ignored \\
\hline & & Focus on school only \\
\hline & & Passive communication \\
\hline & & Limited topics of time \\
\hline
\end{tabular}




\begin{tabular}{lll}
\hline Structural code & \multicolumn{1}{c}{ Descriptive category } & \multicolumn{1}{c}{ Descriptive codes } \\
\hline Relationships & Things that affect relationships & Ability to communicate \\
& & Know students' needs \\
& New team members \\
& Parent feelings \\
& Staff qualities \\
& Teamwork \\
\hline
\end{tabular}

After initial structural codes were identified, three additional codes were added.

Structural codes included the following: (a) involvement, (b) communication, (c) parenteducator relationships, (d) conflict, and (e) district versus NPSs. Each section includes a summary of the quantitative data gathered during the survey and a more detailed explanation of the qualitative interview data.

\section{Involvement}

Quantitative survey results indicated that parents' overall ratings of involvement were high, with more than half of the participants $(64.1 \%, n=25)$ rating their level of involvement in the IEP meeting as "as much as I should be." Interview data validated these high levels of involvement. After identifying all participant responses about involvement and using descriptive codes to code individual statements, the researcher identified three categories discussed by participants regarding involvement at NPS. The three categories were (a) how educators involved parents, (b) how parents get involved, and (c) causes for feeling not involved. These categories included information about parent perspectives during IEP meetings while their student attended the NPS.

\section{How Educators Involve Parents}

The first category identified within the involvement section was How Educators Involve Parents. Survey results indicated that most parents agreed or strongly agreed, respectively, that NPS staff attempted to involve them in throughout the IEP meeting $(31.6 \%, n=12 ; 61.9 \%, n=$ 
26), district staff attempted to involve them throughout the IEP meeting $(33.3 \%, n=13 ; 43.6 \%$, $n=17)$, they felt involved in the creation of the IEP document $(38.5 \%, n=15 ; 38.1 \%, n=16)$, and they felt their understanding of their child was recognized $(45.2 \%, n=19 ; 38.1 \% . n=16)$. These results matched with comments made by participants during interviews. During participant interviews, all participants were able to identify ways in which educators involved them during the IEP meeting and with their student's education while attending the NPS. Parents stated NPSs had done the following to involve them: (a) communicate, (b) listen to parent opinions, (c) compare multiple settings, (d) discuss the IEP document, and (e) provide IEP data prior to the IEP. One parent discussed how educators allowed her to involve other organizations during the IEP meeting. Involving outside organizations was not brought up by any other participant in the current sample. Two participants discussed the use of an interpreter and its ability to affect involvement. Discussion about the effects of interpreters is included in the Communication section.

Communicate. Participant statements during their interview suggested communication was the most common way educators involved them in their students' IEP meetings and education process. Comments about how educators involved parents through communication included asking for parent input, providing advice, and allowing for open communication. Lillian reported high levels of involvement and said, "they would talk to me about the IEP" and "I felt like they were talking directly to me." While Rosey stated, "they're very open, they keep the dialogue open." Claudia and Rosey made statements about educators providing their opinions and advice, while Lillian commented about educators asking her questions to communicate. Claudia voiced, "they give me the best advice possible." Rosey said, "we'll talk about it (a goal) and be able to revise it to bring it down to something he's more able to reach." Finally, Lillian 
said, "asking me for input, if I was seeing the same things" and "also asking my input about what kinds of things I was seeing that she (the student) might need to work on." These statements made during interviews confirmed the results of the survey. Survey results found that $50 \%$ of parents $(n=19)$ indicated the IEP team asked for their input into the draft IEP before the meeting and were included in the planning and writing goal and objectives. Additionally, most parents reported being satisfied $(38.5 \%, n=15)$ or very satisfied $(46.2, n=18)$ in the level of communication the NPS staff provided.

Listening to Parent Opinions. The second most discussed way educators involved parents was by listing to parents' opinions. Four of eight interview participants made direct comments about educators listening to their opinions and related this action to feeling high levels of involvement. Lillian stated, "they always take in consideration for my opinion" and Mindy said, "they were very interested in all of my input everywhere, so I felt very involved." Claudia commented, "I felt like I was listened to during the meeting." Interview data corresponded with survey data. Survey results indicated that $50 \%$ of parents $(n=19)$ felt the IEP team attempted to include them by asking for their input into the draft IEP. Additionally, parents rated that they agreed $(45.9 \%, n=17)$ or strongly agreed $(37.8 \%, n=14)$ that the IEP team asked for their input during the meeting.

Compare Multiple Settings. Two participants discussed how educators made them feel more involved by comparing the student's behavior and present levels across multiple settings, such as home, school, and community programs. Educators compared students' present levels across settings by asking parents about students' abilities at home and attempting to understand what strategies and techniques worked best across settings. Lillian said: 
They would tell me ... this is how she's doing this at school, how have you seen it at home, how did she do on the homework? Are you seeing this go other places? So, there was a back and forth discussion where I felt really involved in it and they weren't just telling me how she was doing at school.

During this statement, Lillian indicated she could have a "discussion" with the school team to understand her students' abilities in multiple settings. Rosey echoed Lillian's comment when she stated, "they talk to me, they find out what's going on at home . . . they really try to find out like what works for him at home and they tell me what works at the school, so we can collaborate." Both participants indicated the importance of the school understanding how the student does in the home setting and how providing this information increased their feelings of involvement.

Discuss IEP Document. When discussing how educators involved participants during the IEP meeting, many participants rated their involvement as high during the IEP meeting. One reason for this high involvement was the discussion about aspects of the IEP. Lillian reported educators involved her by "reviewing the progress" on goals and "letting me know how their assessments in their testing are going," and "giving me input into just how her services are going and ... (if) there should be any changes." Samuel said he was involved when educators would let him know how his student was doing at school.

Provide IEP Data Prior to the Meeting. Three participants stated receiving IEP data before the IEP meeting was one-way educators helped involve them in the IEP process. Parents responded that they have received "progress," "copies of the IEP," "current levels," “assessment" results, "proposed goals," and "a daft of everything before the IEP." During the survey, $52 \%$ of participants $(n=20)$ stated the IEP team included them by sending them a draft before the meeting. 


\section{How Parents Get Involved}

The second category in the involvement section was How Parents Get Involved. During interviews, participants discussed how they get involved in the IEP meeting and the education of their students while their student is attending an NPS. Codes within this category included: (a) communicating, (b) helping to develop goals and services, (c) listening, and (d) checking the IEP document.

Communicating. Participants reported communication was one way they were involved in the IEP and education of their students. Parents made statements about their communication and ability to provide their input to the educators. Claudia stated, "I let them know everything that needs to be arranged with him. ... I make it clear what he needs ... so I get really involved with his needs." James reported, "I'm in constant communication with various people on the team," "I give my input on assessments and things," and "I participate and ask questions and give my input." Both James and Claudia used their communication with educators during the IEP meeting to be involved.

Helping to Develop Goals and Services. During IEP meetings, educators often discuss goals and services. Three participants stated they got involved by helping to develop goals and services for their students. Parents indicated they asked questions about progress on goals and present levels and provided input for new goals and services. Linda told the researcher, "I check if he had met all the goals that we put in the year before" and "ask questions about (if) he met the goal," while James commented, "I am involved in developing the goals and recommending things in the areas that need to improve." During the survey, 50\% of participants $(n=19)$ stated the IEP team included them planning and writing goals and objectives with them. 
Listening. One parent indicated his main form of involvement was listening during IEP meetings. He reported asking questions when he did not know or understand something, but he "like(s) to attend to hear about (student's) behavior and what can be done to help him advance." This type of involvement would be considered passive, based on past research. This parent did not report any active participation during his interview; however, he indicated that his involvement was high and had no suggestions for improvement.

Checking the IEP Document. Two participants disclosed checking the IEP document before signing in the agreement was one of the ways they were involved in the IEP meeting. Both participants stressed the importance of ensuring all information discussed within the meeting was included in the IEP document. Linda made the following statement:

I check the IEP because everything that I says in the meeting has to be put on paper ... I . .. share that with the IEP team and say now he's struggling, he's been good, or he's taking this kind of medication.... So, it has to be establishing the IEP.

Portions of Linda's statement were omitted for confidentiality purposes, but the meaning remains that all information discussed in the IEP meeting must be included within the IEP document. Mindy's statement about signing the IEP stressed the same thing:

I almost always don't sign the IEP at the meeting, so I can take it home and look over it again myself at home and there's never any issue with that. And if I want to change something or add something there accommodating with that as well. Along with stressing the importance of reviewing the IEP document, Mindy appreciated the NPS team accommodated her request to review the document at home before signing. Both Mindy and Linda discussed reviewing the IEP document as a way they stayed involved. 


\section{Causes for Feeling Not Involved}

Quantitative survey data showed that $11 \%$ of participants $(n=10)$ did not feel involved during an IEP meeting. More than half of those participants reported the following reason for feeling not involved: my input was not taken seriously $(70 \%, n=7)$, goals and services were developed without my input $(60 \%, n=6)$, and the meeting felt rushed $(60 \%, n=6)$. The only reason included in the survey and confirmed during interviews was the feeling of not being taken seriously. During interviews, the researcher asked questions about when participants may not have felt involved in the IEP process within the NPS setting. Very few participants had examples of times they did not feel involved in the IEP process. Only one participant explained a time when they did not feel involved, and two cases were identified. Those causes included one parent feeling blamed and feeling ignored. Claudia disclosed her concerns about her student's suspected disability and said, "I would be ignored" and "they wouldn't consider me at all." During a second example, Claudia communicated she "was blamed for things, for example, his aggression." This participant reported that she was now at a new NPS, but her experiences in the past pushed her to advocate for her student.

\section{Communication}

Communication was identified as a structural code before the coding process began. Quantitative survey results indicated that parents' overall ratings of communication were high, with more than half of the participants $(52.6 \%, n=20)$ rating their level of communication in the IEP meeting as "as much as I should be." Interview data validated these high levels of communication. All responses to questions about communication were coded as communication. After structural coding was completed, the research used descriptive coding to code each response in the communication code. These descriptive codes were then grouped into categories. 
Communication categories include: (a) how parents communicate, (b) things schools communicate, (c) positives about communication from schools, (d) problems with communication, and (e) interpreters.

\section{How Parents Communicate}

The first category for communication was How Parents Communicate. When participants were asked about their communication with NPS staff, participants voiced two ways they felt they communicated with educators at the NPS. Participants communicated with educators at the NPSs by asking questions and providing their input. When discussing communication, James told the researcher, "I have to ask a lot of questions," and Rosey said, "I can call the school at any time if there's any questions."

Rosey also reported she would ask the school questions about her students' behavior, especially when her student tried to explain something that happened. She told the researcher her student often struggled to communicate, and the school was "always really good about clarifying it, so I can kind of see it from an expert perspective.” Both Rosey and James asked questions as a way to communicate with educators, while Claudia stated, "I'm able to communicate with them what I need."

\section{Things Schools Communicate}

The second category under communication is Things Schools Communicate. Participants shared a range of topics schools communicated about with parents during IEP meetings and regular communication. These topics were grouped into student updates and school updates. Survey results found the most common topics communicated to parents by NPS staff were academic performance $(66.7 \%, \mathrm{n}=28)$ and behavior $(54.8 \%, n=23)$. 
Student Updates. Student updates were the most discussed topic by participants during the interviews. Four parents reported their student's NPS communicated with them about how their student was doing at school. Schools were reported to provide parents with information about their student's day or week, behavior, academics, and student needs. In the area of student updates, the behavior was discussed the most. James voiced schools communicated about "how his students' behavior has been and like if there was anything he did really well that day." James suggested the school send home more information about his student's work in class. Other topics such as academic updates were discussed briefly by the other two parents. Two parents made comments about NPSs being open to communicating about students' needs. Claudia stated the NPS is "able to communicate with me what he needs," and Linda informed the researcher the school communicated about "stuff that he needs mostly."

School Updates. James expressed the NPS his student attends usually sends updates about what is happening on campus or upcoming events. A parent said, "When they're in school, they send out like a weekly newsletter type thing just of what's going on with the school, not my (student)." This parent also recommended the school send more information about what each class was working on academically, so parents were more aware of what their student was learning throughout the year.

\section{Positives About Communication From Schools}

When participants were asked about their perspectives about communication during IEP meetings at their students' NPS, all participants rated the school's communication as a 3 or 4 on a scale from 1-4. Paseagal provided a statement that summarized most of the participant's ratings; "they communicate great." When discussing the things NPSs do to communicate with 
parents, participants identified the following positive things schools did communicate. NPSs provided regular communication and were available and open.

Provide Regular Communication. Regular communication was portrayed as important by interview participants. Participants reported both getting and wanting regular communication from NPS staff. According to participants, regular communication meant both daily or weekly communication and quick communication about the important things that come up, such as behavior, a good or bad day, and emergencies. Participants indicated they would receive regular updates, and Lillian commented, "if there was something that happened that day, there was a note that came home, there was a call, there was an email so that I could discuss it with (the student) after school." Claudia reported, "it is really less stressful” because she received communication through emails and by phone, "and it's not even just in the IEP meeting."

Available and Open. The second positive identified about NPSs' communication was their ability to be available and open with parents. Mindy stated, "they were pretty much always available, over the phone or dropping off (and) picking up, they were available." The staff was also open to communicating, and Mindy said, "it was never just go away." By stating this, Mindy was referring to the NPS being open to talking to her and not making her feel as though they wanted her to leave them alone.

\section{Problems With Communication From Schools}

Despite the positive attributes participants were able to identify about NPSs' communication, participants listed a few problems with their current or previous NPSs' communication. Problems included (a) feeling ignored, (b) limited topics or time in which communication occurred, and (c) feeling educators were defensive. Each of these problems was discussed by only one participant. Claudia reported feeling educators "were always defensive" or 
were "on the defensive," especially when she would attempt to discuss challenges at home. She felt her concerns about her student's behavior and difficulties at home were "totally ignored." Her time with her student was not necessary because it was not at school. James felt educators at the NPS would talk to him "only when we get close to IEPs or assessments . . . unless I have a question or they have an issue," and he stated besides a monthly update in person during pick up, “I really don't know what they're working on." His comments during his interview suggested not all information was communicated, and communication may occur more at specific times, such as before an IEP or assessment.

\section{Interpreters}

Two of eight interview participants indicated their primary language was not English and they required interpreters during IEP meetings and for communication with NPS staff. This interview did not ask any specific questions about the use of interpreters; however, participants shared a small amount of information throughout the interview about their experiences. Both participants reported when an interpreter was available; they could successfully communicate and be involved in the IEP meeting and the education of their students; however, they reported a few challenges. One participant reported feeling embarrassed to ask questions because he did not want to bug the interpreter or Spanish-speaking staff. When asked how he felt about communication during IEP meetings with an interpreter, Samuel reported, "I don't understand English perfectly and I kind of feel embarrassed sometimes." He then shared that even with an interpreter, "I kind of feel embarrassed for bugging (them)." The other participant shared challenges with scheduling. Paseagal stated "sometime interpreter (did) not show up (and the) IEP (was) delay(ed)" and a "few time(s) (the meeting was) delay(ed) cause no interpreter (was) available." This participant explained her current NPS had taken responsibility for getting an 
interpreter to all her meetings, so meetings did not need to be rescheduled. These two participants shared some of the challenges of using an interpreter and how those challenges impact their involvement and communication.

\section{Parent-Educator Relationships}

Quantitative survey results indicated that parents' overall ratings of parent-educator relationships were high, with half of the participants $(50 \%, n=17)$ rating their level of communication in the IEP meeting as "as good as they should be." Interview participants discussed their relationships with educators during IEP meetings and throughout their experiences at NPSs. The conversations about relationships were overwhelmingly positive, and when asked how NPS staff could improve, none of the participants had any suggestions for improvement. The only descriptive category for relationships was labeled effective relationships characteristics.

\section{Effective Relationships Characteristics}

Effective Relationship Characteristics was the only category under parent-educator relationships, and it included characteristics participants identified as affecting parent-educator relationships. The following were codes included under this category: (a) ability to communicate, (b) knowing student needs, (c) length of time on the IEP team, (d) staff qualities, and (e) teamwork.

Ability to Communicate. Educators' ability to communicate with parents was the most discussed characteristic during the interviews, impacting parent-educator relationships. Five parents spoke about communication and its importance for relationships. While the other three participants discussed the importance of communication throughout their interviews, they did not directly link communication to relationships. The following were a few comments that link 
educators' ability to communicate with their relationships with parents. Claudia stated at her student's last NPS, “the person and the teacher involved, I didn't have any relationships at all, there was no way ... I was able to communicate with that person." Then she divulged that at her student's current NPS, “it's a really good relationship that I have with them" because if there is a problem, "I communicate it with her (the principal), and she gets the whole staff together to get it communicated." Another participant, James, reported with "various team members I have a closer relationship than other, but that's just because we communicate more." Linda said, "I can call them and communicate with them easily. They are always there to answer my questions." Participant comments solidified the importance of communication when building parenteducator relationships. During the survey, the participants reported they agreed $(43.2 \%, n=16)$ or strongly agreed $(43.2 \%, n=16)$ that they were able to talk openly and freely with educators during IEP meetings. The interview data confirm these results.

Knowing Student Needs. During discussions about parent-educator relationships, three participants discussed the importance of knowing the student and understanding the student's needs. Rosey said, "the nonpublic school, they tend to more of what the child's needs are" and "they're more hands-on. I see in the NPS that they can pretty much tell me day to day ... what was going on with him.” While Rosey’s statement was direct, Paseagal explained NPS staff understood her student and who he was as a special needs. The last participant who mentioned the link between understanding students' needs and parent-educator relationships was Claudia. She discussed how NPSs have few students, which allows them to "communicate more with the parents and pay attention to the student's needs."

Length of Time on IEP Team. Each member of the IEP team has been part of that student's team for a different amount of time. Many team members change often, and this 
frequent change of team members could impact the relationships between parents and educators. One participant, James, commented on his relationships with IEP team members. He voiced: Various team members, I have a closer relationship than others, but that's just because we communicate more and maybe have been interacting longer, you know something you get new people every year and those people I'm not as close with as the ones that have been there for a while.

This quote suggested the length of time parents know each educator is essential in building their relationship.

Staff Qualities. Each participant described their relationship, and all participants shared qualities they valued in their NPS educators. All eight participants reported NPS educators were at least one of the following: (a) dedicated, (b) patient, (c) polite, (d) honest, (e) experienced, and (f) team members. These qualities were reported for a variety of staff members. When discussing a behavioral aid, Claudia expressed, "he was super patient with (student)" and showed his dedication because "he's always willing to give it a try." Rosey indicated staff was "very, very good, very cordial," "very responsive," "trained," "more apt to think outside the box," and "they've just been honest." Linda expressed her "admiration for what they do" as school staff at an NPS because she "know(s) how hard it is to be in a school class ... so my admiration for them it's huge." Lillian discussed NPSs staff's ability to work as a team as a quality that affected her relationships with staff positively. She voiced, "I really feel like part of a team like we're working together," and "teamwork really makes a difference, it really does, because we really . . . trying to make sure these kids can do it everywhere, not just at school, so working together ... really makes a difference." Each participant made at least one comment about personal qualities team members have that affect their relationships positively. Overlap was seen between 
interview data and survey data in the areas of providing a welcoming atmosphere and treating parents with respect.

\section{Conflict}

Experiences of conflict were discussed at the end of each interview. Participants were asked, "can you describe any experiences you have had with conflict during IEP meetings at nonpublic schools?" Participants' experiences with conflict at NPSs varied. Of eight interview participants, two reported having no conflict, two had a conflict with a school district or special education local plan area (SELPA) employee, and four had a conflict with NPS staff during an IEP meeting at an NPS. The survey found that a lower percentage of parents had experienced conflict during an IEP meeting at an NPS $(40.5 \%, n=15)$.

Two different participants stated they had a conflict with a school district or SELPA employee while attending an IEP meeting at an NPS. The first participant experienced a conflict with district team members when the district team member disagreed with the student's present levels and wanted to change her services and placement. The second participant experienced conflict with a SELPA employee, who told the participant, "that's just the way things are done, and you have to accept it," and the participant disagreed. This participant reported the disagreement was about adding a goal in a specific area.

Four participants reported having conflict with NPS staff during an IEP meeting at an NPS. Of the four participants, conflict ranged from minor conflict to high levels of conflict. A minor conflict was experienced by Linda, who had a "disagreement . . . once, but it was not a big deal." Based on the participant's explanation of the situation, the participant thought her student was ready for something, but the team had a discussion, and the participant understood their point of view. Rosey, who experienced conflict with an NPS team member, shared the 
disagreement was about requesting additional testing to look at the participant's new areas of concern. Rosey indicated she has had "several times where I haven't seen eye to eye" with a district staff member. She reported she had no conflict with NPS staff at her student's current school.

Claudia, who reported experiencing conflict, reported including an outside services provider in the IEP meeting, who would only observe, but the school team refused to allow the additional person to attend the meeting. Additionally, this participant had a conflict arise due to student behavior. The student accessed a tool and was going to use it in an unsafe way toward staff. The staff responded but left marks and scratches on the student because she had "fake long nails." This behavioral situation caused conflict with school staff during the IEP meeting and discomfort for the participant. Paseagal, the last participant who experienced conflict with an NPS team member, reported: "bad experiences" at her student's last school, where she felt the school broke the law. She did not believe the student was in the correct placement and felt discriminated against because of her disability. This conflict led to a change of placement for the student based on the participant's request.

Six of eight participants experienced some form of conflict with IEP team members during an IEP at their student's NPS. Two experienced conflicts with a district or SELPA team member, and four experienced conflicts with an NPS team member. During interviews, the reasons for conflict varied and did not overlap significantly with the reasons for conflict identified reported during the survey. The most common reasons for conflict identified on the survey were disagreements over curriculum or instruction approaches $(80 \%, n=12)$, disagreements over IEP content $(73.3 \%, n=11)$, disagreements over placement decisions $(60 \%$, 
$n=9)$, disagreements over services $(60 \%, n=9)$, and disagreements over eligibility $(60 \%, n=$

9).

\section{Public Versus NPS}

Six of seven participants reported having more trouble with relationships with staff at public schools than NPSs. Things that were identified as having an impact on parent-educator relationships were involvement and understanding, class size, and educator education. These three were discussed by two or more participants and are explained in more detail next. Things that were only reported by one parent included: the guardian feeling valued, staff teaching styles, teamwork, and parents feeling during the meeting.

\section{Understanding Students Needs}

Understanding students' needs and abilities were discussed throughout all interviews and were important to all interview participants. Five participants reported the district or public school did not understand their student's needs. It was indicated NPS staff understood the students' disabilities, knew what their triggers were, and knew what was going on with them daily. The same level of understanding was not seen from public school staff.

\section{Class Size}

Two participants identified class size as a difference between public and NPSs. Both participants indicated NPSs have smaller class sizes and fewer students, which makes it easier for the teacher to communicate and nothing gets missed. When describing a public school, Claudia said, “I think the reason why the relationships wasn't as strong was because there was too many students involved in the class." Claudia also shared, "I think when it comes to a special ed child, they need to have less students so they could be able to communicate more with parents and pay attention to the students' needs." Rosey added public school staff "don't really notice a 
whole bunch, a lot of stuff gets missed." Both participants agreed communication was important, and class size seemed to impact their communication and relationships with staff.

\section{Education}

Interview participants suggested education was an important factor when communicating and having positive relationships with school staff. Three participants explained their experiences with public school staff who lacked education in specific areas, such as behavior. The public-school staffs' lack of education caused conflict and disagreements between the staff and the participants. Samuel expressed, "in public (schools), there are people who have no experience in how to treat this kind of children." The same three participants reported NPS staff to have more experiences and are "trained and . . . more apt to think outside of the box."

\section{Value Coding - Positive and Negative Comments}

As part of the interview coding process, value coding was used to code participant attitudes toward NPSs. Positive and negative comments about NPSs were coded and separated into comments about involvement, communication, and relationships. Table 4.24 provides a quantitative view of the positive and negative comments.

Table 4.24

Parent Comments About NPSs During Interviews

\begin{tabular}{lcccccccc}
\hline Participant & Parent involvement & \multicolumn{2}{c}{$\begin{array}{c}\text { Parent } \\
\text { communication }\end{array}$} & $\begin{array}{c}\text { Educator-parent } \\
\text { relationships }\end{array}$ & \multicolumn{2}{c}{ Totals } \\
\cline { 2 - 9 } & + & - & + & - & + & - & + & - \\
\hline Claudia & 4 & 1 & 6 & 6 & 7 & 2 & 17 & 9 \\
James & 1 & 0 & 0 & 2 & 2 & 0 & 3 & 2 \\
Lillian & 4 & 0 & 1 & 0 & 3 & 0 & 8 & 0 \\
Linda & 4 & 0 & 2 & 0 & 7 & 0 & 13 & 0 \\
Mindy & 4 & 0 & 1 & 0 & 2 & 0 & 7 & 0 \\
Paseagal & 6 & 1 & 4 & 0 & 0 & 0 & 10 & 1 \\
Rosey & 3 & 0 & 5 & $3 *$ & 7 & $3 *$ & 15 & $6^{*}$ \\
Samuel & 1 & 1 & 2 & 0 & 5 & 0 & 8 & 1 \\
\hline Total & 27 & 3 & 21 & 11 & 33 & 5 & 81 & 19 \\
\hline
\end{tabular}

Note. All comments were related to COVID-19 and distance learning situations. 
During interviews, all the participants made more positive than negative comments about NPSs (see Table 4.24). When comparing positive and negative comments about parent involvement $(+27,-3)$, parent communication $(+21,-11)$, and parent-educator relationships $(+33$, -5), parents had more positive comments than negative comments about their experiences in all three areas.

\section{Conclusion}

Chapter 4 provided the quantitative and qualitative results collected using the survey and interview instruments. Both the survey and interview instrument collected data on parent perspectives of IEP meetings at NPSs, specifically perspective data about involvement, communication, and parent-educator relationships. The results answered all three research questions, and additional data was provided based on extra information that was collected during the survey and interview. The interview results strongly supported the results found during the survey. The following chapter provides a discussion of the study results, along with limitations, implications, and suggestions for future research. 


\section{Chapter 5: Discussion}

The previous chapter presented the results of the study as they related to the three research questions. Data from surveys were analyzed using descriptive statistics, and interview data were analyzed using structural, descriptive, and value coding. This chapter addresses how the analyzed data answered the three research questions and if the data follows the trend of previous research. The discussion is divided up by research question. Each research question is stated, and findings are discussed in detail. After the discussion of the three-research question, the chapter includes implications, future research, limitations, and a conclusion.

\section{Research Question 1 Findings}

Research Question 1: How do parents of students receiving special education services perceive their level of involvement during the IEP meeting process at nonpublic schools (NPSs)?

Results for this question included data about involvement and communication gathered during the survey and interviews with guardians whose students attended an NPS. Interview and survey data were compared to past research.

\section{Involvement}

The survey and interview asked participants questions about their perspectives of involvement during IEP meetings at NPSs. Based on survey and interview results, most guardians felt they were as involved in IEP meetings at the NPS as they should be. Using a scale from 1-4, most parents selected a 4, indicating high involvement $(64.1 \%, n=25, M=3.49, M d n$ =4). This high rating of involvement corresponded with special education results found by Tucker and Schwartz (2013), who found $71 \%$ of parents rated their involvement as high. Interview results showed similarly high ratings and discussion about involvement during the IEP meeting. Interview participants felt involved in the IEP meeting because they felt a high level of 
communication, felt educators listened to their opinion, compared behavior from home and school, discussed the IEP document, and provided the IEP before the meeting.

\section{Passive and Active Involvement}

Despite high ratings of involvement on the survey and interviews, guardians who rated their involvement highly were found to have a variety of involvement levels during interviews. Based on guardians' explanations of their involvement, the researcher was able to classify their involvement as ranging from passive to active involvement. The definitions used for active and passive involvement were based on past research (Garriott et al., 2000). Six participants (75\%) were classified as having active involvement, and two (25\%) had passive involvement. An important finding was that both parents who had active and passive involvement considered themselves highly involved in the IEP meeting process. Feeling highly involved aligns with past research on active and passive involvement during IEP meetings at public schools (Garriott et al., 2000; Zeitlin \& Curcic, 2014).

The number of active participants found in this study was slightly higher than the $50 \%$ of parents in the public school setting that Garriott et al. (2000) found who engaged in active participation. The higher percentage could be due to the difference in school placement or a limited number of interviews; however, the field could benefit from future research on the difference in passive and active involvement at NPSs compared to public schools.

\section{Educator Attempts to Involve Guardians}

In the survey, guardians were asked to identify how educators included them in the IEP meeting process. Garriott et al. (2000) found the following increased parent involvement: (a) teachers encouraging parents to participate actively, (b) asking for parent input, and (c) providing drafts before the IEP. Two of these overlap with the things identified by parents during the 
survey. During the survey, half or more of the participants who answered the survey question selected "sent me a draft before the meeting" $(52.6 \%, n=20)$, "asking for my input into the draft IEP, prior to the meeting" $(50 \%, n=19)$, and "planning and writing goals and objectives with me" $(50 \%, n=19)$. All three of these were discussed by participants during interviews; however, when guardians were directly asked what educators did to involve them in the IEP meeting, the most common response was open and direct communication during the IEP meeting. Guardian's felt the most involved when educators communicated with them about their students and the IEP. Guardians described feeling comfortable asking questions during the meeting and being able to provide their input into the IEP document.

\section{Communication}

Based on survey results, most guardians felt they received as much communication as they needed from NPSs. Using a scale from 1-4 most parents selected a 4, indicating high levels of communication $(52.6 \%, n=20, M=3.34, M d n=4)$. Additionally, guardians rated their mean level of satisfaction $(M=1.10)$ as falling between satisfied and very satisfied on a scale from very dissatisfied (-2) to very satisfied (+2). The high satisfaction rating and high overall communication ratings from NPSs do not align with research on communication in public schools (e.g., Stanley, 2015; Zeitlin \& Curcic, 2014). Past research in public schools suggests an importance for communication; however, parent ratings of communication suggest problems with communication between public schools and parents whose students are in special education (Stanley, 2015; Zeitlin \& Curcic, 2014). Differences in parent satisfaction of communication between past research in public schools and this study in NPSs may be impacted by many variables. One variable that could be impacting parent satisfaction of communication is school or class size. During a study by Egelson et al. (1996), teachers reported more frequency and better 
communication during the school year when they had smaller class sizes than during previous years. During the same study, parents whose children were in smaller classes indicated that they could talk to teachers almost daily. Class size was discussed by interview participants as a positive trait of NPSs. Participants indicated that when students are in a smaller class, the teachers have stronger relationships with students and can better communicate with parents.

Survey questions were asked about how often NPS staff communicated, how they communicated, and what their communication was about. The most selected answer for how often schools communicated was "as needed" $(41.0 \%, n=16)$. More than half of survey participants reported NPSs communicated through phone calls $(64.3, n=27)$ and emails (52.4\%, $n=22)$, with video calls rated close behind $(47.6 \%, n=20)$. The most discussed topics were academic performance $(66.7 \%, n=28)$ and behavior $(54.8 \%, n=23)$. During interviews, parents agreed they often received communication as needed, but most reported behavior was the most common topic, and educators communicated with them in person during pick up and drop off or by phone. Other forms of communication included email and written letters. Studies in the medical field have found that suburban parents tend to prefer email and younger parents tend to prefer text updates (Rand et al., 2015). This research suggested that parents are increasingly interested in communication via electronics. Interview participants brought up communication during every portion of the interview. Communication was identified as a way parents felt involved and as influencing parent-educator relationships. Education research has found that parent motivation and engagement can be increased through frequent and positive communication with educators (Kim et al., 2013; Semke et al., 2010).

It was challenging to collect accurate data on communication, specifically during IEP meetings at NPSs. Based on interviews, parents appeared to rate their communication based on 
their overall experiences at the NPS, not just the IEP meeting. Due to how questions were worded, the results may have collected perceptions about communication from NPS staff instead of specifically during the meeting. Future research should focus on communication during IEP meetings at NPSs.

\section{Research Question 2 Findings}

Research Question 2: How do parents of students receiving special education services perceive their relationships with the IEP team during the IEP meeting process at nonpublic schools?

Results for this question included data about relationships and conflict gathered during the survey and interview with guardians whose student attends an NPS. Interview and survey data were compared to past research.

\section{Parent-Educator Relationships}

Both interview and survey data showed parents felt they had positive relationships with NPS staff during IEP meetings and outside of the IEP process. Based on survey results, most guardians rated themselves as having the best possible relationship with their NPS staff during IEP meetings. Using a scale from 1-4 most parents selected a 4, indicating the best possible relationship (50\%, $n=17, M=3.24, M d n=3.5)$. Survey participants were asked to rate their level of agreement to multiple statements about things that have been found to affect relationships between guardians and school staff. Response choices included: (a) educators providing a welcoming atmosphere, (b) treating guardians with respect, (c) treating them as equal decision makers, (d) allowing them to talk freely, (e) valuing their input, (f) maintaining positive relations, and $(\mathrm{g})$ making them feel comfortable. For all seven questions, mean ratings fell within the 1-2 range, indicating guardians selected agree or strongly agree, except for 
feeling their input was valued by team members during IEP meetings. The mean score for guardian's input being valued by team members was 0.81 , which fell between disagree and agree. During interviews, communication was discussed by most participants as influencing their relationships with school staff. Past research supports the finding that communication impacts parent-educator relationships (Stanley, 2015; Tucker \& Schwartz, 2013; Zeitlin \& Curcic, 2014).

Parents appeared to have an easier time developing strong relationships with NPS staff, especially those in the IEP meeting. This positive relationship was also seen in interview data, in which parents reported feeling supported and connected to NPS staff. One parent indicated she felt it was easier to have a relationship with the staff at an NPS because they have fewer students than public schools.

Past research found guardians often felt an asymmetrical relationship between themselves and the IEP team at public schools (Valle \& Aponte, 2002; Zeitlin \& Curcic, 2014). This relationship included an imbalance of power and role tension. Guardians in these studies described professionals as "condescending" and found themselves feeling worried, frustrated, and angry (Valle \& Aponte, 2002; Zeitlin \& Curcic, 2014). During interviews with participants in this study, the researcher found many participants had similar things to say about educators during meetings at public schools; however, when it came to their experiences at NPSs, the majority reported big differences. Participants reported feeling they could communicate easily, the staff knew their students, and the staff was described as dedicated, patient, polite, honest, experienced, and team members.

\section{Conflicts}

Both survey and interview results indicate that conflict arises during IEP meeting at NPS, but it is typically easy to work through and does not escalate to bigger problems. One parent 
explained her conflict as part of the discussion process. To assess conflict, survey participants were asked if they had ever experienced conflict at a NPS IEP meeting. Fifteen $(40.5 \%)$ of 37 participants who answered the question, indicated they experienced some form of conflict while attending an IEP meeting at a NPS. Of those who experienced conflict, $12(80 \%)$ had conflict with NPS staff and $10(66.7 \%)$ had conflict with school district staff. For NPS and school district staff, respectively, when asked who the conflict was with, administrators $(46.7 \%, n=7 ; 26.7 \%, n$ $=4)$ were selected more than special education teachers $(13.3 \%, n=2 ; 13.3 \%, n=2)$ and services providers $(20 \%, n=3 ; 20 \%, n=3)$. Conflict was about disagreements over curriculum or instructional approaches $(33.3 \%, n=5 ; 46.7 \%, n=7)$, disagreements over IEP content $(33.3 \%, n=5 ; 40 \%, n=6)$, disagreements over placement decisions $(20 \%, n=3 ; 40 \%, n=6)$, disagreements over services (20\%, $n=3 ; 40 \%, n=6)$, disagreements over eligibility $(26.7 \%, n=$ $4 ; 33.3 \%, n=5)$, and disagreements over evaluation results $(20 \%, n=3 ; 20 \%, n=3)$ with NPS and district staff, respectively.

Interview participants reported having some of the same conflicts with educators during IEP meetings. Six of eight participants reported having some conflict or disagreement with educators during IEP meetings at NPSs. Two of those six had conflicts with the district or special education local plan area (SELPA) staff, while four had conflicts with NPS staff. Conflict with district or SELPA staff included conflicts about goals, present levels, services, and placementthese overlap with results found during the survey. Conflicts between guardians and NPSs staff included conflicts about behavior, injuries, testing requests, and placement decision. Conflicts were not always discussed as negative but instead were referred to as part of communication during IEP meetings. In the research on effective teams, professionalism was important during prereferral meetings because it allowed team members to agree to disagree professionally and 
continue working productively (Etscheidt \& Knesting, 2007). Conflict can have positive or productive outcomes for groups (Jehn, 1997; Jehn \& Banderski, 2003), especially when there is a level of trust among the team. The use of conflict management or facilitation could help support meetings where conflict often occurs.

\section{Research Question 3 Findings}

Research Question 3: Do parent perceptions of involvement in the IEP meeting process at an NPS vary across demographic variables (e.g., age of the child, eligibility category, number of years in special education, race/ethnicity, parent educational level)?

Survey demographic data was used to create groups of parents to be compared. The research questions asked specifically about involvement, but parent perspectives of involvement, communication, and relationships were analyzed to understand if demographic variables impacted parent perspectives. Research Question 3 included subquestions about educational level, race and ethnicity, and the number of years in special education. In addition to these variables, eligibility for free or reduced-price lunch, primary language, and the number of years attending an NPS were also analyzed. Due to the small sample size, when subgroups were created, they were relatively small. Results found during the analysis of subgroups should be interpreted with caution, and future research is necessary to verify the findings.

Research Question 3a: Is there a difference between perceptions of parent involvement among parents with different educational levels?

Parents were grouped into two categories to understand how parent level of education impacted parent perspectives. The categories included high school or school college and college degree or higher. Based on the groups created, parents' level of education, there were small 
differences in mean scores for communication and relationships; however, all three effect sizes were small.

Research Questions 3b: Is there a difference between perceptions of parent involvement among parents who self-identify in different race/ethnicity categories?

Parents were grouped into two categories to understand how parent race and ethnicity impacted parent perspectives. The two groups were White and people of color. Based on the groups created, there was a slight difference between the mean scores for communication. Using effect size, the actual difference between the mean scores of these two groups was high for communication and very small for involvement and relationships. More research should be conducted to determine the degree and type of impact race and ethnicity have on parent perspectives of communication at the NPS IEP meeting. Findings on the impact of race and ethnicity are not consistent with past research on parents of children receiving special education services (Correa, 1992; Kalyanpur, 1998; Kalyanpur et al., 2000; Kalyanpur \& Rao, 1991; Wong, 1989).

Research Questions 3c: Is there a difference between perceptions of parent involvement among parents whose children have been in special education longer than 5 years and those with children in special education less than 5 years?

Parents were grouped into three categories to understand how the number of years their students received special education services impacted parent perspectives. Groups included parents whose students had been receiving special education services for 4 or fewer years and those who received services for 5 or more years. Based on the groups created, there were slight differences in means for all three areas. Effect size suggests a medium difference for communication and a very small difference for involvement and communication. 


\section{Additional Demographic Findings}

The demographic information collected in this study provided a small view of the families and students attending NPSs in Southern California. The demographic information collected tells us the type of student or family most likely to be placed within an NPS. Relevant demographic data collected during this study include the guardian's role, gender, primary language, race and ethnicity, the highest level of education, students age, qualification for free or reduced-price lunch, special education eligibility, years in special education, and years attending an NPS. The following demographic data may be important in future research to describe the population of students and families who attend NPSs in California.

Most guardians identified themselves as parents; however, grandparents, stepparents, adoptive parents, and foster parents made up $23.8 \%$ of the sample. Guardians identified their race and ethnicity, and $54.7 \%$ reported being part of a minority group (i.e., Hispanic, Latino or Spanish origin; Black or African American; American Indian or Alaska Native; Asian), with 33.3\% identifying as Hispanic, Latino, or Spanish origin. Some guardians indicated their highest degree was a college-level degree; however, $54.7 \%$ of parents selected one of the following: (a) some high school, (b) high school diploma or equivalent, and (c) attended some college. Sixtysix percent of participants reported their students qualified for free or reduced-price lunch, suggesting families were of low socioeconomic status. Lastly, autism spectrum disorder (61.9\%, $n=26$ ) was the most common eligibility for students attending NPSs in this study. The survey was only offered in English and Spanish, so the primary language data may not accurately represent the population.

The researcher found many students and families attending NPSs have multiple challenges impacting their students. These challenges may combine to create a situation in which students 
cannot be successful at a public school. All students in the sample had a disability and were in special education; however, many also no longer live with biological parents, are part of a minority group, are low-income, and have parents who have not received a college degree. More research should be conducted to understand better NPS student populations and the challenges their families face. There may be a link between the number of home challenges and their inability to succeed within a public school.

\section{Distance Learning Findings}

The COVID-19 global pandemic caused schools in California to shut down in the spring of 2020. Due to the shutdown, many aspects of the IEP meeting were altered so meetings could continue to be held and educators, families, and students were safe. Due to the changes to IEP meetings, the researcher added seven questions to the survey to gather data about parents' perceptions of involvement, communication, and relationships during IEP meetings during virtual learning. The findings related to these questions do not correspond to a research question but may increase knowledge about the differences between virtual and in-person IEP meetings. Based on participants' survey responses, their perspectives of involvement, communication, and relationships were rated highly despite the change to the IEP meeting. The communication rating

was the one area that was slightly lower during virtual IEP meetings. Participants' comments supported the findings in the survey. Interview participants reported challenges with communication during distance learning and virtual IEP meetings.

\section{Implications}

There are many implications for this survey's results. Individual NPSs may use the study results to help improve their programs, and school districts may benefit from understanding parents of students at NPSs; however, there are two big benefits from this study. The two main 
implications of this studies' results are the possibilities of future research and the clearer understanding of NPS populations.

\section{Training}

One important implication of the study is its use in future training. Results from this study can be used to develop training for educators at NPSs and public schools, along with parents and guardians of students in special education. Educator training could include the teaching of the most important strategies for facilitating a meeting and the use of simulations to practice the skills being taught. Training that would benefit parents includes training on special education law, parent rights, services, and the continuum of supports available in special education.

\section{Educator Training}

Survey and interview results clearly described the things guardians perceived as important when attending IEP meetings at NPSs. Parents reported the educators communicated with them regarding their student's needs, listened to and valued their input as parents, and understood the challenges families face at home. These needs align with past research from Fishman and Nickerson (2014) that found that direct communication from teachers is a significant predictor of parent involvement. Current training for educators outside of special education involves the use of meeting simulations so teachers can practice their communication skills and interact with parents played by actors (Dotger, 2009; Dotger et al., 2008, 2010). Additional resources include extensive lists of strategies to promote parent involvement (Brandon \& Brown, 2009; Hoover-Dempsey et al., 2005). It would be beneficial to develop training for educators that includes the most important strategies and allows educators a chance to practice those strategies using role-playing or meeting simulations. Many interview 
participants reported they had negative experiences during IEP meetings at public schools before their students attended an NPS. This type of training could be used for public school special education staff, district administrators, and NPS educators.

\section{Parent and Guardian Training}

Study results can be used to create parent training to help empower parents and provide knowledge about special education law and parent rights. Parent training has been found to positively impact parents' perspectives (Rio \& Burke, 2021). During interviews with guardians, the researcher asked questions about their special education knowledge and what they do if they have questions or do not understand something in an IEP meeting. None of the interview participants indicated they had been provided information of training by the public school or school district. Participants reported getting information from friends, parent groups, advocates, and agencies. Past research has shown that parents who participate in parent training programs become more knowledgeable of their legal rights and feel they have benefitted from the experience (Citil, 2020). Additionally, programs that focus on parent empowerment can lead to shared decision making and empower families (Morrow \& Malin, 2004; Murrary et al., 2016). Results from this study can be combined with past research on parent engagement and empowerment to help provide parents with training on special education law, parent rights, services, and the continuum of supports available in special education.

\section{Understanding the NPS Population}

Due to the lack of research conducted at NPS, the characteristics of the population of students and families are unknown. This study described a small sample of guardians; however, it is a start at describing NPS families and students. Future studies can increase the sample size to understand the demographics of students and families attending NPSs. The following 
information should be collected about the NPS population: home living status, race and ethnicity, family income, primary language, and parent level of education. Understanding if there is a specific profile of students that typically attends NPSs can help public schools identify students before they require the restricted educational environment of an NPS. If students with at-risk profiles can be identified early, academic and behavioral interventions may be implemented to avoid the need for more restrictive environments.

\section{Future Research}

There has been very little research conducted on NPSs, especially NPS parents' perspectives. Future research should focus on expanding the field's knowledge about NPS students and their parents to improve both public and NPSs' interactions with these families. Recommendations for future research were made in the areas of future lines of inquiry and methodology.

\section{Future Lines of Inquiry}

When considering future lines of inquiry, the researcher considered the results of the current study and how these results could be expanded. Due to the limited amount of research in NPSs, there are many areas of research that are not discussed within this section but would be encouraged for future research. Three possible areas for future inquire would include (a) resolution or use of conflict, (b) impact on parent perspectives, and (c) parents' early experiences.

\section{Resolution or Use of Conflict}

Conflict occurs in IEP meetings at public and NPSs. Throughout this study, many participants indicated they had experienced conflict during an IEP meeting at an NPS; however, this study was not expansive enough to focus on those conflicts. Conflict amount members of a 
group are not always negative. Understanding if there are types of conflicts during IEP meetings that are beneficial or inconsequential would help educators know when conflict management or additional conflict strategies would and would not be necessary. Additionally, educators could benefit from understanding when discussions and differing opinions are beneficial to the outcome of the IEP. Future research should focus on the types of conflict that arise during IEP meetings and how to use those conflicts to foster productive meetings.

\section{Impact on Parent Perspectives}

In this study, frequent communication was identified by survey and interview participants as having an impact on their ability to feel comfortable and communicate at the IEP meeting. Parents reported feeling like there were less surprised when they had frequent communication. Future research would benefit from exploring other actions that may help positively impact parent perspectives during IEP meetings. Suggestions include identifying if any of the following have an impact on parents' perspectives of involvement and communication: sending home the assessment report before the meeting, sending home a draft IEP before the meeting, seeking out parent advice or input before the IEP meeting, educator communication styles, and previous experiences with specific educators. Additional things that have not been listed may have an impact on parent communication and satisfaction of communication.

\section{Early Experiences}

Future research should examine how family's early educational experiences impact their perspectives of communication and satisfaction with communication. In most cases, students who are attending an NPS have attended a public school before their experience at the NPS. Individuals use expectations from previous learning to make sense of their current situations and take action (Dewey, 1986), suggesting that parents' past experiences can impact their future 
behavior and perspectives. Understanding how families experience IEP meetings before attending an NPS may help educators guide families through any communication challenges during future IEP meetings. Additionally, some families have students who transition from a public school to an NPS and in a few years can transition back to a public school. Both public and NPS have their benefits and challenges. Understanding those families' past experiences would be very beneficial to understanding how to improve on the practices at public and NPSs.

\section{Future Methodology}

The current study used a convergent mixed-method approach, using survey and interview data to answer research questions. Alternative methods would be to use structured observations, extensive interviews, or case studies. Additionally, making alterations to the population would benefit future research

\section{Structured Observations}

Using a structured observation to understand the complexities of IEP meetings at NPSs would allow researchers to directly observe involvement, communication, and relationships. This perspective could reduce the amount of personal bias that may come from a parent or educator answering survey or interview questions. This method could be strengthened by using multiple observers or combining multiple forms of inquiry, such as observations and interviews.

\section{Extensive Interviews}

Using interviews allowed the researcher to hear directly from guardians about their perspectives on IEP meetings at NPSs. The current study did short interviews with a few participants. Future research could do more extensive semistructured interviews with more people. Increasing the number of interview participants and the length of interviews would significantly increase the amount of data gathered about parent perspectives. Additionally, the 
current study would have benefited from conducting an initial interview, reviewing the interview data, and conducting a secondary interview based on additional questions developed after analyzing the initial interview data. During this study, there was information that was brought up during the last few interviews that inspired the researcher to want to ask the previous interview participants additional questions. Possible additional questions included: "where do you look." or "whom do you ask when you do not understand something during an IEP meeting," "how were conflicts resolved," "have you ever experienced a conflict that required mediation or formal process to resolve," and "what do you feel your role is during the IEP meeting." Asking these questions during the current study was not possible due to the study design and timeline but could be incorporated into future studies.

\section{Case Study}

During the development of this study, the researcher considered transitioning from a survey design to a case study. A case study design would involve treating NPSs as the cases and studying the organizations. The researcher could collect data using surveys, school records, legal cases, and interviews with multiple IEP team members. Using multiple sources of evidence is one of the characteristics of data collection for a case study (Yin, 2014). When using multiple data sources, the advantage is creating "converging lines of inquiry" (Yin, 2014, p. 120). The findings of a case study are stronger when they are based on multiple sources that converge to one finding.

\section{Population}

The intended population of the current survey was parents of students in NPSs in Southern California. The actual sample of the current study was small, and the generalization of the findings is low. Stakeholders of NPSs would benefit from additional research about NPS 
parent perspectives during IEP meetings in California. Future research should increase the sampling area and work closely with schools to gain parent participation. Developing a clear and effective recruitment process may greatly increase the sample. During the current study, guardians received the survey through their email; however, NPS staff warned the researcher that many families do not use their email often, and some do not use email at all. The COVID-19 global pandemic limited the researchers' options for survey dissemination, but future research would benefit from using paper surveys or having parents complete an online survey at the end of each IEP meeting. Using a paper survey would help support those parents who have limited technology access or who rarely respond to emails. The use of a paper survey or allowing parents to complete an electronic survey at the end of their IEP meeting would allow participants to have the events current in their heads so there would be no issues with inaccurate memory. Paper surveys would need to be input; however, they have the potential to increase guardians' ability to participate.

Another suggestion to increase participation would be to collaborate with an organization that has access to multiple NPSs. For example, some SELPAs in California contract with multiple NPS and may be able to work more directly with multiple NPSs to increase the response rate. Another possibility would be to collaborate with the county department of education. Any opportunity to increase the access to NPS parents would benefit the response rate and would change the types of analyses possible.

\section{Limitations}

Limitations exist in every study, and it is the researcher's job to minimize limitations to the best of their ability. During this study, the researcher attempted to minimize all foreseen limitations whenever possible. Despite the researcher's best efforts, the study had the following 
possible limitations: (a) lack of generalizability, (b) an inaccurate representation of the population, and (c) participants' inability to recall in-person meetings.

\section{Lack of Generalizability}

A limitation of the current study was the lack of generalizability. The data collected can be used to create training and inform future research; however, the results do not easily generalize to parents whose children attend NPSs in other parts of the state. The results do not generalize to parents whose children attend NPSs in other states because NPSs in other states are not operated in the same way as schools in California. The results represent perceptions of parents whose children attend NPSs in Los Angeles, San Diego, and Orange counties; however, due to the limited response rate, the results do not have strong validity or reliability.

\section{Accurate Representation of the Population}

The second limitation was the uncertainty the sample accurately represented the population. Participants may not represent the population because the sampling method was convenience sampling. Using convenience sampling, there was no way to ensure the sample represented the population. For this study, the results may be more positive toward NPSs because those are the parents with the strongest urge to complete the survey. NPSs did not select who received the survey; however, access to email, the internet, and a device with internet capability may have limited the sample. The researcher made every effort to collect data from a sample that would represent the Southern California NPS parent population.

\section{Language}

The study language options were an additional limitation. The study materials were only available in English and Spanish. These two languages were selected based on primary language data for Southern California. Using only English and Spanish limited the response rate because 
parents whose primary language was not one of these two languages were unable to access the materials.

\section{Conflict Questions}

Using the survey and interviews, the researcher collected data about whether parents had experienced conflict and asked parents to example the conflicts that they experienced.

Unfortunately, the survey and interview did not include any follow-up questions about the outcomes of those conflicts. For example, asking if the conflict experienced was easily resolved or if a more formal process was required to resolve the conflict, such as mediation or a due process filing. Having disagreements with team members could be a beneficial part of the IEP process. It would be helpful to understand the outcomes of the conflicts and parent perspectives of if each conflict was meaningful or productive.

\section{COVID-19 Global Pandemic}

The shutdowns due to the COVID-19 global pandemic allowed for the collection of new data about virtual learning; however, the shutdowns increased the challenges of the research study and created a limitation. Due to the shutdowns, some of the parents had not experienced an in-person meeting in over a year. Parents who hadn't experienced an in-person meeting in over a year, caused challenges because participants had difficulty recalling their last IEP meeting, which impacted their opinions of IEP meetings at NPSs. If a parent had a negative virtual meeting, it might have unconsciously impacted their responses for in-person meetings. This could have been the case for any participant who had a negative experience for their last IEP meeting, virtual or in-person. However, virtual meetings were a new experience for parents and educators, and educators needed time to learn and apply new techniques. The focus of this study was to understand in-person IEP meetings. The researcher made every attempt possible to 
provide participants with clear instructions so that it was easy to understand what type of meeting was being discussed.

\section{Conclusion and Call to Action}

Previous chapters discussed past literature, the research design, methods, and results. This chapter linked survey and interviews data with previous research and provided suggestions for future research. Study results were found to mostly align with past research on parent perspectives of IEP meetings at public schools, but the differing perspectives of parents whose students attend NPSs were added to the field. Limitations were listed, and suggestions for future research were made with the intent to further the field of special education and increase the efficiency and effectiveness of IEP meetings at NPSs. NPSs have a unique population of students who have been placed in these more restrictive programs due to needs that impact their ability to learn in a public school environment. The primary goal of the study was to provide data on parent perspectives of involvement and parent-educator relationships during IEP meetings at NPSs by answering the three research questions. Using the survey data, all three research questions were answered. The interview data was able to validate the survey results and provide reliability.

Parents of students who have attended an NPS have a unique view of the special education process because they have been able to experience special education and IEP meetings at public schools and NPSs. The field of special education should use these parents' unique perspectives to better understand the most effective ways to support students at nonpublic and public schools. Once these parents' perspectives are understood, the data can be used to improve IEP meetings and educational outcomes for students attending NPSs. 


\section{References}

Agran, M., \& Hughes, C. (2008). Asking student input: Students' opinions regarding their individualized education program involvement. Career Development for Exceptional Individuals, 31, 69-76. https://doi.org/10.1177/0885728808317657

Albert, W., Tullis, T., \& Tedesco, D. (2009). Beyond the usability lab: Conducting large-scale online user experience studies. Morgan Kaufmann.

Antony, C. J., \& Ogg, J. (2019). Parent involvement, approached to learning, and student achievement: Examining longitudinal medication. School Psychology, 34(4) 376-385. https://doi.org/10.1037/spq0000282

Aquilino, W. S. (1994). Interview mode effects in surveys of drug and alcohol use: A field experiment. Public Opinion Quarterly, 58(2), 210-240. https://doi.org/10.1086/269419

Babbie, E. R. (2004). The practice of social research (13th ed.). Wadsworth.

Behfar, K., Peterson, R., Mannix, E., \& Trochin, W. M. (2008). The critical role of conflict resolution in teams: Links between conflict type, conflict management strategies, and team outcomes. Journal of Applied Psychology, 93(1), 170-188. https://doi.org/10.1037/0021-9010.93.1.170

Birks, M., \& Mills, J. (2011). Grounded theory: A practical guide. SAGE Publications.

Bouffard, S. E., Weiss, A., \& DeDeo, C. A. (2008). Thinking big: A new framework for family involvement policy, practice, and research. The Evaluation Exchange 14(1-2), 2-7. https://archive.globalfrp.org/early-childhood-education/publications-resources/thinkingbig-a-new-framework-for-family-involvement-policy-practice-and-research

Bourque, L. B., \& Fielder, E. P. (2002). The survey kit: How to conduct self-administered and mail surveys (3rd ed.). SAGE Publications. 
Brofenbrenner, U. (1986). Ecology of the family as a context for human development: Research perspectives. Developmental Psychology, 22(6), 723-742. https://doi/10.1037/00121649.22 .6 .723

Burke, M. M., \& Sandman, L. (2015). In the voice of parents: Suggestions for the next IDEIA reauthorization. Research and Practice for Persons with Severe Disabilities, 40(1), 7185. https://doi.org/10.1177/1540796915585109

California Department of Education. (n.d.). Fingertip facts on education in California. https://www.cde.ca.gov/ds/ad/ceffingertipfacts.asp

California Department of Education. (n.d.). Special education enrollment by age and disability statewide report. Special Education Division. Data Quest. https://data1.cde.ca.gov/dataquest/SpecEd/SpecEd1.asp?cChoice=SpecEd1\&cYear=2018 $-19 \& c$ Level $=$ State $\&$ cTopic $=$ SpecEd\&myTimeFrame=S\&submit1=Submit\&ReptCycle $=$ December

California Department of Education. (2020a). Definition of a school. https://www.cde.ca.gov/ds/si/ds/dos.asp

California Department of Education. (2020b). Enrollment/number of schools by grade span \& type. CalEdFacts. https://www.cde.ca.gov/ds/sd/cb/cefenrollgradetype.asp

California Department of General Services. (2021, April 23). Data and caseload statistics reports to state legislature. https://www.dgs.ca.gov/OAH/Resources/PageContent/Office-of-Administrative-Hearings-Resources-List-Folder/OAH-Reports 
Castro, M., Exposito-Casas, E., Lopez-Martin, E., Lizasoain, L., Navarro-Asencio, E., \& Gaviria, J. L. (2015). Parental involvement on student academic achievement: A metaanalysis. Educational Research Review, 14, 33-46. https://doi.org/10.1016/j.edurev.2015.01.002

Cavendish, W., \& Conner, D. (2018). Towards authentic IEPs and transition plans: Students, parents, and teacher perspectives. Learning Disability Quarterly, 41(1), 32-43. https://doi.org/10.1177/0731948716684680

Chapman University. (2020a). Institutional Review Board (IRB). https://www.chapman.edu/research/integrity/irb/index.aspx Chapman University. (2020b). Policies and guidelines. https://www.chapman.edu/research/integrity/irb/policies.aspx

Cheatham, G. A., \& Lim-Mullins, S. (2018). Immigrants, bilingual parents of students with disabilities: Positive perspectives and supportive dialogue. Intervention in School and Clinics, 54(1) 40-46. https://doi.org/10.1177/1053451218762490

Cheatham, G. A., \& Ostrosky, M. M. (2011). Whose expertise? An analysis of advice giving in early childhood parent-teacher conferences. Journal of Research in Childhood Education, 25, 24-44. http://doi.org/10.1080/02568543.2011.533116

Chen, D., Chan, S., Brekken, L., \& Valverde, A. (2000). Conversations for three: Communicating through interpreters. Brookes.

Çitil, M. (2020). Informative parent training on parental advocacy and legal rights for families with children with special educational needs. International Journal of Psychology and Educational Studies, 7(3), 178-193. https://doi.org/10.17220/ijpes.2020.03.016 
Childre, A., \& Chambers, C. R. (2005). Family perceptions of student-centered planning and IEP meetings. Education and Training in Developmental Disabilities, 40, 217-233. http://www.dddcec.org/etmrddv/TOC/etddv40n3.htm

Colton, D., \& Covert, R. W. (2007). Designing and constructing instruments for social research and evaluation. John Wiley and Sons.

Cook, V. J. (Ed.). (2002). Portraits of the L2 user. Multilingual Matters. https://doi.org/10.21832/9781853595851

Coots, J. J. (1998). Family resources and parent participation in schooling activities for their children with developmental delays. Journal of Special Education, 31(4), 498-520. https://doi.org/10.1177/002246699803100406

Correa, V. (1992). Cultural accessibility of services for culturally diverse clients with disabilities and their families. Rural Special Education Quarterly, 11(2), 6-12. https://doi.org/10.1177\%2F875687059201100203

Correa-Torres, S., \& Zebehazy, K. T. (2014). Lessons learned from Hispanic mothers in the United States: Recommendations for personnel preparation and research in visual impairment. British Journal of Visual Impairment, 32(3), 191-199. https://doi.org/10.1177/0264619614539954

Coughlan, M., Cronin, P., \& Ryan, F. (2009). Survey research: Process and limitations. International Journal of Therapy \& Rehabilitation, 16(1), 9-15. https://doi.org/10.12968/ijtr.2009.16.1.37935

Couper, M. P. (2008). Designing effective web surveys. Cambridge University Press.

Couper, M. P., Baker, R., \& Mechling, J. (2011). Placement and design of navigation buttons in web surveys. Survey Practice, 4(1). https://doi.org/10.29115/SP-2011-0001 
Creswell, J. W., \& Creswell, J. D. (2018). Research design: Qualitative, quantitative, and mixed methods approaches (5th ed.). SAGE Publications.

Crosnoe, R., Erickson, K. G., \& Dornbusch, S. M. (2002). Protective functions of family relationships and school factors on the deviant behavior of adolescent boys and girls: Reducing the impact of risky friendships. Youth \& Society, 33(4), 515-544. https://doi.org/10.1177/0044118X02033004002

Dabkowski, D. M. (2004). Encouraging active parent participation in IEP meetings. Teaching Exceptional Children, 36(3), 34-39. https://doi.org/10.1177/004005990403600304

Dee, C. A. (1981). Student mobility from public to nonpublic schools: Parental attitudes and reasons [Doctoral dissertations, University of Southern California]. Dissertation Abstracts International ProQuest Information \& Learning. https://about.proquest.com/en/dissertations/

Dewey, J. (1896). The reflex arc concept in psychology. The Philosophical Review, 3, 357-370. https://doi.org/10.1037/h0070405

Dillman, D. A. (2007). Mail and internet surveys: The tailored design method (2nd ed.). John Wiley and Sons.

Dillman, D. A., \& Tarnai, J. (1991). Mode effects of cognitively designed recall questions: A comparison of answers to telephone and mail surveys. In P. N. Biemer, R. M. Corres, L. E. Lyberg, N. A. Mathiowets, \& S. Sudman (Eds.), Measurement errors in surveys, (pp. 367-393). John Wiley.

Dixon, J. (2012). Communicating (st)ageism: Exploring stereotypes of age and sexuality in the workplace. Research on Aging, 34(6), 654-669. https://doi.org/10.1177/0164027512450036 
Domina, T. (2005). Leveling the home advantage: Assessing the effectiveness of parental involvement in elementary schools. Sociology of Education, 78(3), 233-249. https://doi.org/10.1177/003804070507800303

Dotger, B. H. (2009). From a medicinal to educational context: Implementing a signature pedagogy for enhanced parent-teacher communication. Journal of Education for Teaching, 35(1), 93-94. https://doi.org/10.1080/02607470802587186

Dotger, S., Dotger, B. H., \& Tillotson, J. (2010). Examining how preservice science teachers navigate simulated parent-teacher conversations on evolution and intelligent design. Science Education, 94(3), 552-570. https://doi.org/10.1002/sce.20375

Dotger, B. H., Harris, S., \& Hansel, A. (2008). Emerging authenticity: The crafting of simulated parent-teacher candidate conferences. Teaching Education, 19(4), 337-349. https://doi.org/10.1080/10476210802438324

Doyle, M. (1996). Forward. In S. Kaner (Ed.), Facilitator's guide to participatory decisionmaking (1st ed., pp. xv-xx)._New Society.

Dunst, C. J., \& Dempsey, I. (2007). Family-professional partnerships and parenting competence, confidence, and enjoyment. International Journal of Disability, Development, and Education, 54(3), 305-318. https://doi.org/10.1080/10349120701488772

Education for All Handicapped Children Act. (1975). Public Law 94-142.

Egelson, P., Harman, P., \& Achilles, C. M. (1996). Does class size make a difference? Recent findings from state and district initiatives. South Eastern Regional Vision for Education. http://files.eric.ed.gov/fulltext/ED398644.pdf 
Elbaum, B., Blatz, E. T., \& Rodriguez, R. J. (2016). Parents' experiences as predictors of state accountability measures of schools' facilitation of parent involvement. Remedial and Special Education, 37(1), 15-27. https://doi.org/10.1177/0741932515581494

Epstein, J. L. (1987). Parent involvement: What research says to administrators. Education Urban Society, 19(2) 119-136. http://doi.org/10.1177/0013124587019002002

Epstein, J. L. (1992). School and family partnerships. In M. Aiken (Ed.), Encyclopedia of educational research (6th ed., pp. 1139-1151). Macmillan.

Epstein, J. L. (1996). Perspectives and previews on research and policy for school, family, and community partnerships. In A. Booth \& J. F. Dunn (Eds.), Family-school links: How do they affect educational outcomes? (pp. 209-246). Lawrence Erlbaum Associates.

Epstein, J. L. (2001a). School, family, and community partnerships: Caring for the children we share. In J. L. Epstein, M. G. Sanders, B. S. Simon, K. C. Salinas, N. R. Jansorn, \& F. L. Van Voorhis (Eds.), School, family and community partnerships: Your handbook for action (2nd ed., pp. 7-29). Corwin Press. http://www.corwin.com

Epstein, J. L. (2001b). School, family and community partnerships: Preparing educators and improving schools. Westview Press.

Epstein, J. L. (2005). Attainable goals? The spirit and letter of the No Child Left Behind Act on parental involvement. Sociology of Education, 78(2), 179-182. https://doi.org/10.1177/003804070507800207

Epstein, J. L., \& Sanders, M. G. (2006). Prospects for change: Preparing educators for school, family, and community partnerships. Peabody Journal of Education, 81(2), 81-120. https://doi.org/10.1207/S15327930pje8102_5 
Etscheidt, S., \& Knesting, K. (2007). A qualitative analysis of factors influencing the interpersonal dynamics of a pre-referral team. School Psychology Quarterly, 22(2), 264288. https://doi.org/10.1037/1045-3830.22.2.264

Evans, A., Elford, J., \& Wiggins, D. (2010). Using the internet for qualitative research in psychology. In C. Willig \& W. Stainton-Rogers (Eds.), The SAGE Handbookfor Qualitative Research (pp. 315-334). SAGE Publications.

Fan, X., \& Chen, M. (2001). Parental involvement and students' academic achievement: A metaanalysis. Educational Psychology Review, 13, 1-22. https://doi.org/10.1023/A:1009048817385

Fantuzzo, J. W., Tighe, E., \& Perry, M. (1999). Relationships between family involvement in Head Start and children's interactive peer play. NHSA Dialog: A Research-to-Practice Journal for the Early Intervention Field, 3, 60-67 https://doi.org/10.1207/s19309325nhsa0301_6

Ferrara, M. M., \& Ferrara, P. J. (2005). Parents as partners: Raising awareness as a teacher preparation program. The Clearing House, 79(2), 77-81. https://doi.org/10.3200/TCHS.79.2.77-82

Fish, W. W. (2006). Perceptions of parents of students with autism towards the IEP meeting: A case study of one family support group chapter. Education, 127(1), 56-68. http://www.projectinnovation.com/education

Fish, W. W. (2008). The IEP meeting: Perceptions of parents of students who receive special education services. Preventing School Failure, 53(1), 8-14. https://doi.org/10.3200/PSFL.53.1.8-14

Fowler, F. J. (2014). Survey research methods (5th ed.). SAGE Publications. 
Galletta, A. (2013). Mastering the semi-structured interview and beyond: From research design to analysis and publication. New York University Press.

Garbacz, S. A., Herman, K. C., Thompson, A. M., \& Reinke, W. M. (2017). Family engagement in education and intervention: Implementation and evaluation to maximize family, school, and student outcomes. Journal of School Psychology, 62, 1-10. https://doi.org/10.1016/j.jsp.2017.04.002

Garriott, P. P., Wandry, D., \& Snyder, L. (2000). Teachers as parents, parents as children: What's wrong with this picture? Preventing School Failure, 45(1), 37-43. https://doi.org/10.1080/10459880109599814

Gilovich, T., Keltner, D., \& Nisbett, R. E. (2006). Social psychology. W.W. Norton.

Goldstein, S., Strickland, B., Turnbull, A. P., \& Curry, L. (1980). An observational analysis of the IEP conference. Exceptional Children, 46(4), 278-286. https://doi.org/10.1177/001440298004600407

Granello, D. H., \& Wheaton, J. E. (2004). Online data collection: Strategies for research. Journal of Counseling and Development, 82(4), 387-393. https://doi.org/10.1002/j.15566678.2004.tb00325.x

Groves, R. M., Fowler, F. J., Couper, M. P., Lepkowski, J. M., Singer, E, \& Tourangeau, R. (2009). Survey methodology (2nd ed.). John Wiley \& Sons.

Groves, R. M., \& Peytcheva, E. (2008.) The impact of nonresponse rates on nonresponse bias: A meta-analysis. Public Opinion Quarterly 72(2), 2-31. https://doi.org/10.1093/poq/nfn011

Habel, O., \& Persitz, S. (2014). Parental involvement in the individual education program for Israeli students with disabilities. International Journal of Special Education, 19(3), 5868. http://www.internationaljournalofspecialeducation.com/ 
Hackman. J. R. (2011). Collaborative intelligence: Using teams to solve hard problems. BerrettKoehler Publishers.

Harry, B. (1992). Cultural diversity families and special education system: Communication and empowerment. Columbia University Press.

Hart, J. E., Cheatham, G. A., \& Jimenez-Silva, M. (2012). Facilitating quality language interpretation for diverse families of students with special needs. Preventing School Failure, 56(4), 207-213. https://doi.org/10.1080/1045988X.2011.645910

Hiatt, D. B. (2001). Parent involvement in American public schools: An historical perspective 1642-1994. The School Community Journal, 4(2), 27-38. https://www.adi.org/journal/fw94/HiattFall1994.pdf

Hoagwood, K. E., Cavaleri, M. A, Olin, S. S., Burns, B. J., Slaton, E., Gruttadaro, D., \& Hughes, R. (2010). Family support in children's mental health: A review and synthesis. Clinical Child and Family Psychology Review, 13, 1-45. https://doi.org/10.1007/s10567-0090060-5

Hodge, N., \& Runswick-Cole, K. (2008). Problematising parent-professional partnerships in education. Disability \& Society, 23(6), 637-647. https://doi.org/10.1080/09687590802328543

Hoover-Dempsey, K. V., Walker, J. M., Sandler, H. M., Whetsel, D., Green, C. L., Wilkins, A. S., \& Closson, K. (2005). Why do parents become involved? Research findings and implications. The Elementary School Journal, 106(2), 105-130. https://doi.org/10.1086/499194 
Houpt, J. J. (2010). Job satisfaction/dissatisfaction of nonpublic school administrators [Doctoral dissertation, Univserity of La Verne]. Dissertation Abstracts International Section A: Humanities and Social Sciences. ProQuest Information \& Learning. http://www.proquest.com/en-US/products/dissertations/individuals.shtml

Hughes, J. L., Camden, A. A., \& Yangchen, T. (2016). Rethinking and updating demographic questions: Guidance to improve descriptions of research samples. Journal of Psychological Research, 21(3), 138-151. https://doi.org/10.24839/2164-8204.JN21.3.138

Hwa-Froelich, D. A., \& Westby, C. E. (2003b). A Vietnamese head start interpreter: A case study. Communication Disorders Quarterly, 24, 86-98. https://doi.org/10.1177/15257401030240020501

Individuals with Disabilities Education Act Amendments of 1997, P.L.105-17, 20 U.S.C $§ 1400$ et seq. (1997).

Individual with Disabilities Education Improvement Act of 2004, H.R.1350, 108th Cong. (2004).

Jackson, S. L. (2012). Research methods and statistics: A critical thinking approach (4th ed.). Cengage.

Jeynes, W. (2005). A meta-analysis of the relation of parent involvement to urban elementary school student academic achievement. Urban Education, 40, 237-269. https://doi.org/10.1177/0042085905274540

Jeynes, W. (2007). The relationship between parental involvement and urban secondary school student achievement: A meta-analysis. Urban Education, 42(1), 82-110. https://doi.org/10.1177/0042085906293818 
Jeynes, W. (2010). The salience of the subtle aspects of parental involvement and encouraging that involvement: Implications for school-based programs. Teachers College Record, 112(3), 747-774. http://doi.org/10.1177/016146811011200311

Jeynes, W. (2012). A meta-analysis of the efficacy of different types of parental involvement programs for urban students. Urban Education, 47(4) 706-742. https://doi.org/10.1177/0042085912445643

Jung, A. W. (2011). Individualized education programs (IEPs) and barriers for parents from culturally and linguistically diverse backgrounds. Diversity and Special Education, 19(3), 21-25. http://www.caddogap.com/periodicals.shtml

Kalyanpur, M. (1998). The challenge of cultural blindness: Implications for family-focused service delivery. Journal of Child and Family Studies, 7(3), 317-332. https://doi.org/10.1023/A:1022993512028

Kalyanpur, M., Harry, B., \& Skrtic, T. (2000). Equity and advocacy expectations of culturally diverse families' participation in special education. International Journal of Disability, Development and Education, 47(2), 120-136. https://doi.org/10.1080/713671106

Kalyanpur, M., \& Rao, S. S. (1991). Empowering low-income black families of handicapped children. American Journal of Orthopsychiatry, 61(4), 523-532. https://doi.apa.org/doi/10.1037/h0079292

Keeter, S., Kennedy, C., Dimock, M., Best, J., \& Craighill, P. (2006). Gauging the impact of Growing nonresponse on estimates from a national RDD telephone survey. Public Opinion Quarterly, 70(5), 759-779. https://doi.org/10.1093/poq/nfl035 
Kim, E. M., Sheridan, S. M., Kwon, K., \& Koziol, N. (2013). Parent beliefs and children's social-behavioral functioning: The mediating role of parent-teacher relationships. Journal of School Psychology, 51(2), 175-185. https://doi.org/10.1016/j.jsp.2013.01.003

Klingner, J. K., \& Harry, B. (2006). The special education referral and decision-making process for English language learners: Child study team meetings and placement conferences. Teachers College Record, 108(11), 2247-2281. https://doi.org/10.1111/j.14679620.2006.00781.x

Kroll, T., \& Neri, M. (2009). Designs for mixed methods research. In S. Andrew \& E. J. Halcomb (Eds.), Mixed methods research for nursing and the health sciences (pp. 3149). John Wiley \& Sons. https://doi.org/10.1002/9781444316490

Leavy, P. (2017). Research design: Quantitative, qualitative, mixed methods, arts-based, and community-based participatory research approaches. The Guilford Press.

Lee, Y., \& Park, H. J. (2016). Becoming a parent of a child with special needs: Perspectives from Korean mothers living in the United States. International Journal of Disability, Development, and Education, 63(6), 593-607. https://doi.org/10.1080/1034912X.2016.1154139

Lo, L. (2008). Chinese families' level of participation and experiences in IEP meetings. Preventing School Failure, 53(1), 21-27. https://doi.org/10.3200/PSFL.53.1.21-27

Lovitt, T. C., \& Cushing, S. (1999). Parents of youth with disabilities: Their perceptions of school programs. Remedial and Special Education, 20(3), 134-142. https://doi.org/10.1177/074193259902000303 
MacLeod, K., Causton, N., Radel M., \& Radel, P. (2017). Rethinking the individual education plan process voices from the other side of the table. Disability \& Society, 32(2), 381-400. https://doi.org/10.1080/09687599.2017.1294048

MacQueen, K. M., McLellan-Lemal, E., Bartholow, K., \& Milstein, B. (2008). Team-based code-book development: Structural, process, and agreement. In G. Guest \& K. M. MacQueen (Eds.), Handbook for team-based qualitative research (pp. 119-35). AltaMira Press.

Marshall, C., \& Rossman, G. (2016). Designing qualitative research (6th ed.). SAGE Publications.

Martin, J. E., Huber Marshall, L., \& Sale, P. (2004). A 3-year study of middle, junior high, and high school IEP meetings. Exceptional Children, 70(3), 285-297. https://doi.org/10.1177/001440290407000302

Mason, C. Q., \& Goldman, S. E. (2017). Facilitated individualized education planning. Journal of Disability Policy Studies, 27(4), 212-222. https://doi.org/10.1177/1044207316660828

McChesney, C., Covey, S., \& Huling, J. (2012). The 4 disciplines of execution: Achieving your wildly important goals. Simon \& Schuster.

McKenna, H., Hasson, F., \& Keeney, S. (2006). Surveys. In K. Gerrish \& A. Lacey (Eds.), The research process in nursing (5th ed., pp. 216-226). Blackwell Publishing.

Mehan, H., Hertweck, A., \& Meihls J. L. (1987). Handicapping the handicapped: Decision making in students' educational careers. Stanford University Press. 
Meterko, M., Restuccia, J. D., Stolzmann, K., Mohr, D., Brennan, C., Glasgow, J., \& Kaboli, P. (2015). Response rated, nonresponse bias, and data quality: Results from a national survey of senior healthcare leaders. Public Opinion Quarterly, 79(1), 130-144. https://doi.org/10.1093/poq/nfu052

Miyamoto, W. K. (1990). Handbook for contracting with nonpublic schools for exceptional individuals: A guide for contracting between local educational agencies and nonpublic, nonsectarian schools and agencies for providing special education and related services to exceptional individuals. California State Department of Education.

Moody, C., Obear, K., Gasser, H., Cheah, S., \& Fechter, T. (2013, December 5). ACPA standards for demographic questions. ACPA. http://www.myacpa.org/sites/default/files/Proposal-Demographic- Questions-andResponses-2.pdf

More, C. M., Hart, J. E., \& Cheatham, G. A. (2013). Language interpretation for diverse families: Considerations for special education teachers. Intervention in School and Clinic, 49(2), 113-120. https://doi.org/10.1177/1053451212472229

Morrow, G., \& Malin, N. (2004). Parents and professionals working together: Turning the rhetoric into reality. Early Years, 24(2), 164-177. https://doi.org/10.1080/0957514032000733019

Mortier, K., Hunt, P., Desimpel, L., \& Van Hove, G. (2009). With parents at the table: Creating supports for children with disabilities in general education classrooms. European Journal of Special Needs Education, 24(4), 337-354. http://doi.org/10.1080/08856250903223021 
Mueller, T. G. (2009). IEP facilitation: A promising approach to resolving conflicts between families and schools. Teaching Exceptional Children, 41(3), 60-67. https://doi.org/10.1177/004005990904100307

Murray, M., Curran, E., \& Zellers, D. (2008). Building parent/professional partnerships: An innovative approach for teacher education. The Teacher Educator, 43(2), 87-108. https://doi.org/10.1080/08878730701838819

Murray, M. M., Handyside, L. M., Straka, L. A., \& Arton-Titus, T. V. (2013). Parent empowerment: Connecting with preservice special education teachers. School Community Journal, 23(1), 145-168. https://files.eric.ed.gov/fulltext/EJ1004336.pdf

Namey, E., Guest, G., Thairu, L., \& Johnson, L. (2008). Data reduction techniques for large qualitative data sets. In G. Guest \& K. M. MacQueen (Eds.), Handbook for team-based qualitative research (pp. 137-161). AltaMira Press.

Nardi, P. M. (2018). Doing survey research: A guide to quantitative methods (4th ed.). Routledge.

Ortega, L. (2014). Ways forward for a bi/multilingual turn in SLA. In S. May (Ed.), The multilingual turn: Implications for SLA, TESOL, and bilingual education (pp. 32-53). Routledge.

Parrish, T., Chen, G., \& Shaw H. (1998). Special education: Nonpublic school and nonpublic agency study. Final Report. American Institute for Research. Retrieved from https://files.eric.ed.gov/fulltext/ED440487.pdf

Patel, N., \& Stevens, S. (2010). Parent-teacher-student discrepancies in academic ability beliefs: Influences on parent involvement. School Community Journal, 20(2), 115-136. http://www.adi.org/journal 
Pew Research Center. (2016). Writing survey questions. https://www.pewresearch.org/ourmethods/u-s-surveys/writing-survey-questions/

Pushor, D., \& Murphy, B. (2004). Parent marginalization, marginalized parents: Creating a place for parents on the school landscape. Alberta Journal of Educational Research, 50(3), 221. http://www.education.ualberta.ca/educ/journals/ajer.html

Rand, C. M., Blumkin, A., Vincelli, P., Katsetos, V., \& Szilagyi, P. G. (2015). Parent preferences for communicating with their adolescent's provider using new technologies. Journal of Adolescent Health, 57(3), 299-304. https://doi.org/10.1016/j.jadohealth.2015.06.006

Rea, L. M., \& Parker, R. A. (2014). Designing and conducting survey research (4th ed.). JosseyBass.

Rios, K., \& Burke, M. M. (2021). The effectiveness of special education training programs for parents of children with disabilities: A systematic literature review. Exceptionality, 29(3), 215-231. https://doi.org/10.1080/09362835.2020.1850455

Rodriguez, J., Olin, S., Hoagwood, K., Shen, S., Burton, G., Radigan, M., \& Jensen, P. (2011). The development and evaluation of a parent empowerment program for family peer advocates. Journal of Child \& Family Studies, 20(4), 397-405. https://doi.org/10.1007/s10826-010-9405-4

Saldaña, J. (2021). The coding manual for qualitative researchers (4th ed.). SAGE Publications. Salembier, G., \& Furney, K. S. (1997). Facilitating participation: Parents' perceptions of their involvement in the IEP/transition planning process. Career Development for Exceptional Individuals, 20(1), 29-42. https://doi.org/10.1177/088572889702000103 
Semke, C. A., Garbacz, S. A., Kwon, K., Sheridan, S. M., \& Woods, K. E. (2010). Family involvement for children with disruptive behaviors: The role of parenting stress and motivational beliefs. Journal of School Psychology, 48(4), 293-312. https://doi.org/10.1016/j.jsp.2010.04.001

Shepard, K. S. (2015). A case study: The operation of nonpublic schools from the perspective of nonpublic school staff members [Doctoral dissertation, University of Phoenix].

Dissertation Abstracts International Section A: Humanities and Social Sciences. ProQuest Information \& Learning.

Simpson, R. L. (1996). Working with parents and families of exceptional children and youth: Techniques for successful conferencing and collaboration (3rd ed.). Pro-Ed.

Singleton, R. A., Jr., \& Straits, B. C. (2010). Approaches to social research (5th ed.). Oxford University Press.

Slade, N., Eisenhower, A., Carter, A. S., \& Blacher, J. (2018). Satisfaction with individualized education programs among parents of young children with ASD. Exceptional Children, 84(3), 242-260. https://doi.org/10.1177/0014402917742923

Spann, S. J., Kohler, F. W., \& Soenksen, D. (2003). Examining parents' involvement in and perceptions of special education services: An interview with families in a parent support group. Focus on Autism and Other Developmental Disabilities, 18(4), 228-237. https://doi.org/10.1177/10883576030180040401

Stanley, S. L. G. (2015). The advocacy efforts of African American mothers of children with disabilities in rural special education: Considerations for school professionals. Rural Special Education Quarterly, 34(4), 3-17. https://doi.org/10.1177/875687051503400402 
Stoner, J., Bock, S. J., Thompson, J., Angell, M., Heyl, B., \& Crowley, E. (2005). Welcome to our world: Parent perceptions of interactions between parents of young children with ASD and education professionals. Focus on Autism and Other Developmental Disabilities, 20(1), 39-51. https://doi.org/10.1177/10883576050200010401

Tesch, R. (1990). Qualitative research: Analysis types and software tools. Falmer Press.

Thomas, K. (1992). Conflict and negotiation processes in organizations. In M. Dunnette \& L. Hough (Eds.), Handbook of industrial and organizational psychology (Vol. 3, pp. 651717). Consulting Psychologists Press.

Tjosvold, D. (1991). The conflict-positive organization. Addison-Wesley

Tucker, V., \& Schwartz, I. (2013). Parents' perspectives of collaboration with school professionals: Barriers and facilitators to successful partnerships in planning for students with ASD. School Mental Health, 5(1), 3-14. https://doi.org/10.1007/s12310-012-9102-0

Turnbull, H. R., Shogren, K. A., \& Turnbull, A. P. (2011). Evolution of the parent movement: Past, present and future. In J. M. Kauffman \& D. P. Hallahan (Eds.), Handbook of special education (pp. 639-653). Routledge.

Turnbull, A. P., \& Turnbull, H. R. (1997). Families, professionals, and exceptionality: A special partnership (3rd ed.). Merrill/Prentice Hall.

Turnbull, A., Turnbull, R., Erwin, E., \& Soodak, L. (2006). Families, professionals and exceptionality: Positive outcomes through partnerships and trust (5th ed.). Prentice Hall.

Umbach, P. D. (2004). Web surveys: Best practice. New Directions for Institutional Research 121, 23-38. https://doi.org/10.1002/ir.98

Underwood, K. (2010). Involving and engaging parents of children with IEPs. Exceptionality Education International 20(1), 18-36. http://doi.org/10.5206/eei.v20i1.7655 
U.S. Census Bureau. (2010a, September 22). About educational attainment. https://www.census.gov/topics/education/educational-attainment.html

U.S. Census Bureau. (2013, February 28). 2010 Census race and Hispanic origin alternative questionnaire experiment. https://www.census.gov/2010census/pdf/2010_Census_ Race_HO_AQE.pdf

U.S. Census Bureau. (2018). Language spoken at home, 2018 American community survey 5year estimates. https://data.census.gov/cedsci/table?g=0400000US06\&tid=ACSST5Y2017.S1601\&q=S1 601

Urdan, T. C. (2017). Statistics in plain English. (4th ed.). Routledge.

Valle, J. W. (2011). Down the rabbit hole: A commentary about research on parents and special education. Learning Disabilities Quarterly, 34(3), 183-190. https://doi.org/10.1177/0731948711417555

Valle, J. W., \& Aponte, E. (2002). IDEIA and collaboration: A Bakhtinian perspective on parent and professional discourse. Journal of Learning Disabilities, 35(5), 469-479. https://doi.org/10.1177/00222194020350050701

Wagner, M., Newman, L., Cameto, R., Javitz, H., \& Valdes, K. (2012). A national picture of parent and youth participation in IEP and transition planning meetings. Journal of Disability Policy Studies, 23(3), 140-155. https://doi.org/10.1177/1044207311425384

Whitbread, K. M., Bruder, M. B., Fleming, G., \& Park, H. J. (2007). Collaboration in special education: Parent-professional training. Teaching Exceptional Children, 39(4), 6. https://doi.org/10.1177/004005990703900401 
Williams, T., Kirst, M., \& Haertel, E. (2005). Similar students, different results: Why do some schools do better? A large-scale survey of California elementary schools serving lowincome students. Initial report of findings. EdSource. https://files.eric.ed.gov/fulltext/ED491575.pdf

Willis, P. (2012). Talking sexuality online - technical, methodological and ethical considerations of online research with sexual minority youth. Qualitative Social Work, 11(2), 4-55. https://doi.org/10.1177/1473325011400488

Wong, M. H. (1989). Kohlberg's "just community” and the development of moral reasoning: A Chinese perspective. In J. Valsiner (Ed.), Child development in cultural context (pp. 87110). Hogrefe and Huber.

Yin, R. Y. (2014). Case study research: Design and methods. (5th ed.). SAGE Publications.

Yoshida, R. K., Fenton, K. S., Kaufman, A. L., \& Maxwell, J. P. (1978). Parent involvement in the special education pupil planning process: The school's perspective. Exceptional Children, 44(7), 531-534. https://doi.org/10.1177/001440297804400706

Zeitlin, V. M., \& Curcic, S. (2014). Parental voices on individualized education programs: “Oh, IEP meeting tomorrow? Rum tonight!” Disability and Society, 29(3), 373-387. https://doi.org/10.1080/09687599.2013.776493 


\section{Appendix A. Nonpublic School Recruitment Email Template}

Dear Administrator:

I am a school psychologist in North San Diego County and a doctorate student at Chapman University. As part of my dissertation, I am doing a survey on parent perceptions of IEP meetings at nonpublic schools. The survey asks parents about their experiences with involvement, communication, and relationships with educators. Upon completion of the study, all schools that participate will be provided with a summary of the results. Schools will be able to use de-identified survey results to help improve IEP facilitation and train staff.

I am contacting you to ask if your school or district would be interested in participating in this survey. School participation would involve sending a template email to all parents whose students attend your nonpublic schools. The email to parents will include a link to the survey. Informed consent will be collected at the start of the survey. The survey will take 15-20 minutes to complete. No identifiable information will be collected from parents, so their results will be confidential.

If you have any questions, please let me know. I would love to set up a few minutes to talk. 


\section{Appendix B. Facebook Group Post Template}

Hello! I am a Ph.D. student at Chapman University and a school psychologist! I am researching parent perspectives during IEP meetings at nonpublic schools.

Do you have a student currently attending or used to attend a nonpublic school (NPS) in California? Or do you know someone who has a student attending a nonpublic school in California? I could use your help! As a parent, your perspectives are critical to the success of IEP meetings. Below is the link to a 15-20 minute survey about your experiences during IEP meetings. Those who participate will be entered into a raffle to receive an Amazon gift card. If you have any questions, please email xxxxx@chapman.edu.

Please use the link below to complete the survey. 


\section{Appendix C. Interview Recruitment Email Template}

Good morning,

You are receiving this email because you participated in a survey that was sent out through your nonpublic school and indicated that you would be willing to participate in an interview. I would like to schedule an interview with you to discuss your experiences during IEP meetings at your nonpublic school. The results of the survey and interviews are part of my dissertation through Chapman University. I would greatly appreciate your participation.

The interview would be via zoom and last approximately 40-60 minutes. Participant confidentiality is very important, and your name and identifiable information will not be used. With your consent, the interview will be audio recorded.

I will be starting interviews the week of May 31. I am available throughout the day and can accommodate your schedule. Please let me know a good day and time between May 31-June 11.

Your perspectives are valuable information that can help improve IEP meetings at nonpublic schools. I hope to be able to share the experiences of parents with schools across southern California to increase awareness and create better training for district and nonpublic staff.

Thanks, Alex Huynen, M.A.Ed. (she, her, hers)

Ph.D. in Education Student

Emphasis in School Psychology

Chapman University

xxxxx@chapman.edu 


\section{Appendix D. Parent Perspectives Survey 2020-2021}

\section{Demographics}

Directions: The following section will be asking about your child's special education eligibility, history in special education, and demographic questions. Please answer the following questions based on your knowledge of your child.

0. Does your student attend a nonpublic school in California?

- (Nonpublic Schools (NPS) are private, nonsectarian, and certified by the state of California to provide special education services to students based on their Individualized Education Plan (IEP). These schools provide an environment to help students that are struggling academically, behaviorally, and socially. Services are funded by the student's local school district, and placement is determined by the student's IEP.)

\footnotetext{
$\bullet$
}

1. Is your child in special education?

\section{Student Information}

- Yes

- No-end survey

2. What county do you live in?

- Los Angeles County

- Orange County

- San Diego County

- Other, please specify:

3. What is your child's age?

- Drop Down: 2 years or younger, 3 years old, 4, 5, 6, 7, 8, 9, 10, 11, 12, 13, 14, 15, $16,17,18,19,20,21,22$, Older than 22 years old

4. Does your child qualify for free or reduced-price lunches at school? (Receiving free or reduced-price lunches means that lunch at school is provided to you for free or you pay less for it.)

- Yes

- No

- I do not know

5. Please choose the answer that best fits your role in raising your child.

- Parent

- Grandparent

- Stepparent

- Foster Parent

- Other, please specify:

6. What is your gender?

- Female

- Male

- Non-binary/Third Gender

- Prefer to self-describe 
- I prefer not to answer

7. Your race/ethnicity (Select all that apply to you).

- American Indian or Alaska Native (e.g., Navajo Nation, Blackfeet Tribe, Mayan, Aztec, Native Village of Barrow Inupiat Traditional Government, Nome Eskimo Community)

- Asian (e.g., Chinese, Filipino, Asian Indian, Vietnamese, Korean, Japanese)

- Black or African American (e.g., Jamaican, Haitian, Nigerian, Ethiopian, Somalian)

- Hispanic, Latino, or Spanish Origin (e.g., Mexican or Mexican American, Puerto Rican, Cuban, Salvadoran, Dominican, Columbian)

- Middle Eastern or North African (e.g., Lebanese, Iranian, Egyptian, Syrian, Moroccan, Algerian)

- Native Hawaiian or Other Pacific Islander (e.g., Native Hawaiian, Samoan, Chamorro, Tongan, Fijian, Marshallese)

- White (e.g., German, Irish, English, Italian, Polish, French)

- Some other race, ethnicity, or origin, please specify:

- I prefer not to answer

8. What is your primary language?

- English

- Spanish

- Vietnamese

- Chinese (Incl. Mandarin, Cantonese)

- Korean

- Tagalog (Incl. Filipino)

- Persian (Incl. Farsi, Dari)

- Arabic

- Japanese

- Other:

9. What best describes your highest level of education/degree?

- Some high school

- High school diploma or equivalent

- Vocational training

- Some college

- Associates degree (e.g., AA, AE, AFA, AS, ASN)

- Bachelor's degree (e.g., BA, BBA, BFA, BS)

- Some post undergrad work

- Master's degree (e.g., MS, MBA, MFA, MS, MSW)

- Doctoral degree (e.g., EdD, PhD)

- Other, please specify:

- I prefer not to answer.

10. Your child receives special education services based upon which of the following disability categories (Select all that apply)?

- Autism Spectrum Disorder
- Orthopedic Impairment

- Other Health Impairment 
- Deaf-Blindness

- Deafness

- Emotional Disturbance

- Hearing Impairment

- Intellectual Disability

- Multiple Disabilities
- Specific Learning Disability

- Speech or Language Impairment

- Traumatic Brain Injury

- Visual Impairment, including Blindness

- I am not sure

- I prefer not to answer

11. How many years has your child been receiving special education services?

- Less than 1 year

- 1 to 4 years

- 5 to 8 years

- 9 to 12 years

- 13 or more years

- I am not sure

12. How many years has your child been attending a nonpublic school (if your student attended more than one NPS, provide the total years for all nonpublic school placements)?

- Less than 1 year

- 1 to 2 years

- 3 to 4 years

- 5 to 6 years

- 6 to 7 years

- More than 8 years

13. How many IEP meetings have you attended at a nonpublic school (current school and any past nonpublic schools)?

- 1 or less

- 2 to 4

- 5 to 6

- 7 to 9

- 10 or more

14. When was your last IEP meeting?

- Within the last 30 days

- 1-3 months ago

- 4-6 months ago

- 7-9 months ago

- $10-12$ months ago

- Over a year ago

- I am not sure

15. How many IEP meetings have you attended in the last year for the student attending this NPS (Please include both virtual and in-person meetings)?

- None

- 1

- 2 
- 3

- 4

- 5 or more

- I am not sure

\section{Prior To Virtual Learning}

Explanation: The next section will ask questions about Involvement, Communication, ParentEducator Relationships, and Conflict. Please answer the questions in this part of the survey based on your experiences prior to the COVID-19 shutdown and virtual learning.

These questions will ask about your experiences and interactions with the nonpublic school staff and faculty. Some questions will also ask about your experiences with school district staff (e.g., home public-school district administrators, teachers, or school psychologists) who participate in your child's IEP meetings at the nonpublic school.

16. Have you attended an IEP meeting, in person, at a nonpublic school?

- Yes

- No - If "No," skip to Question 44

- I am not sure - If "I am not sure," skip to Question 44

\section{Involvement}

Directions: The following questions will ask about your involvement during IEP meetings in the past. Please answer the following questions based on your perspectives from the IEP meetings you have attended at your nonpublic school and prior to the COVID-19 school shut down.

17. My level of involvement in IEP meetings (select a rating from 1 to 4):
- 1
2
3
4
- Not Involved At All
Involved As Much As I Should Be

18. I feel nonpublic school staff attempt to involve me throughout IEP meetings.

\begin{tabular}{|c|c|c|c|}
\hline Strongly Agree & Agree & Disagree & Strongly Disagree \\
\hline
\end{tabular}

19. I feel school district staff attempt to involve me throughout IEP meetings held at the nonpublic school.

\begin{tabular}{|l|l|l|l|}
\hline Strongly Agree & Agree & Disagree & Strongly Disagree \\
\hline
\end{tabular}

20. I feel involved in the creation of the IEP document.

\begin{tabular}{|c|c|c|c|}
\hline Strongly Agree & Agree & Disagree & Strongly Disagree \\
\hline
\end{tabular}

21. I feel my understanding of my child is recognized during IEP meetings.

\begin{tabular}{|c|c|c|c|}
\hline Strongly Agree & Agree & Disagree & Strongly Disagree \\
\hline
\end{tabular}

22. I feel the IEP team supported my involvement through the use of my primary language. (This question will not appear if they answered English as their primary language)

\begin{tabular}{|c|c|c|c|}
\hline Strongly Agree & Agree & Disagree & Strongly Disagree \\
\hline
\end{tabular}


23. What does your child's educational/IEP team do to include you in the IEP meeting process (Select all that apply)?

- Asking for my input into the draft IEP prior to the meeting

- Sent me the draft report before the meeting

- Having me work on academics and/or behavior at home

- Planning and writing goals and objectives with me

- Including input from outside providers (e.g., private service providers)

- Including me in the assessment process

- Other:

24. The IEP team has collaborated with me by:

\begin{tabular}{|l|l|l|l|l|}
\hline & $\begin{array}{l}\text { Strongly } \\
\text { Agree }\end{array}$ & Agree & Disagree & $\begin{array}{l}\text { Strongly } \\
\text { Disagree }\end{array}$ \\
\hline Including me in the assessment process & & & & \\
\hline $\begin{array}{l}\text { Including my suggestions for goals and objectives for } \\
\text { the IEP }\end{array}$ & & & & \\
\hline $\begin{array}{l}\text { Including my suggestions for curriculum or } \\
\text { instructional approaches }\end{array}$ & & & & \\
\hline Asking for my input during the meeting & & & & \\
\hline
\end{tabular}

25. Has there been a time that you have NOT felt included in your child's IEP meeting?

- Yes

- No - Skip Question 26

26. What happened that made you feel like you were NOT included in your child's IEP meeting (select all that apply)?

- Goals and services were developed without my input

- My input was not taken seriously

- The IEP team did not ask if I had any questions

- The IEP team did not answer my questions

- The meeting felt rushed

- I was not given time to fully understand all of the information provided

- I was not given time to consider if I agreed with the IEP

- I was not called or consulted prior to the IEP meeting

- Other:

\section{Communication}

Directions: The following questions will ask about your communication with nonpublic school staff regarding your student. Please answer the following questions based all communication you have with the staff at your student's nonpublic school and prior to the COVID-19 school shut down.

27. Rate your nonpublic school staff level of communication (select a rating from 1 to 4 ).
- 1 2 3 4
- No Communication With Me As Much Communication As I Need 
28. How often do nonpublic school staff communicate with you regarding your child?

- Monthly

- Weekly

- Several Days Per Week

- Every Day

- As Needed

29. How satisfied are you with the level of communication provided by the nonpublic school?

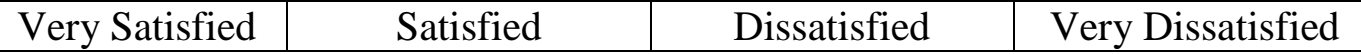

30. How does your nonpublic school staff communicate with you regarding your child (select all that apply)?

- Email

- Paper letters

- Phone calls

- Video calls (e.g., Zoom, Google Meets)

- Parent Communication Platform (e.g., Parentsquare, Remind, Aeries)

- Learning Platform (e.g., Google Classroom, Blackboard, Canvas)

- In person

- Other:

31. My nonpublic school staff communicates with me about the following, at least monthly (select all that apply)?

- Academic performance

- Attendance

- Health (medication, health plan, etc.)

- Goal progress

- Behavior

- Mental health

- Discipline

- Other:

\section{Parent-Educator Relationships}

Directions: The following questions will ask about your relationship with nonpublic school and district educators during IEP meetings. Please answer the following questions based on your perceptions from all past IEP meetings at your nonpublic school and prior to the COVID-19 school shut down.

32. Rate your relationship with nonpublic school staff, during IEP meetings (Select a rating from 1 to 4$)$.
1
2
3
4

- No relationship

Best Relationship Possible.

33. Educators provide a welcoming atmosphere for you during IEP meetings.

\begin{tabular}{|l|l|l|l|}
\hline Strongly Agree & Agree & Disagree & Strongly Disagree \\
\hline
\end{tabular}


34. I am treated respectfully by educators during IEP meetings.

\begin{tabular}{|c|c|c|c|}
\hline Strongly Agree & Agree & Disagree & Strongly Disagree \\
\hline
\end{tabular}

35. I am treated as an equal decision maker during IEP meetings.

\begin{tabular}{|c|c|c|c|}
\hline Strongly Agree & Agree & Disagree & Strongly Disagree \\
\hline
\end{tabular}

36. I am able to talk openly and freely with educators during IEP meetings.

\begin{tabular}{|c|c|c|c|}
\hline Strongly Agree & Agree & Disagree & Strongly Disagree \\
\hline
\end{tabular}

37. My input is valued by IEP team members during IEP meetings.

\begin{tabular}{|c|c|c|c|}
\hline Strongly Agree & Agree & Disagree & Strongly Disagree \\
\hline
\end{tabular}

38. Overall, IEP team members maintain positive relations with me during IEP meetings.

\begin{tabular}{|l|l|l|l|}
\hline Strongly Agree & Agree & Disagree & Strongly Disagree \\
\hline
\end{tabular}

39. Overall, I feel comfortable during IEP meetings.

\begin{tabular}{|c|c|c|c|}
\hline Strongly Agree & Agree & Disagree & Strongly Disagree \\
\hline
\end{tabular}

40. During IEP meetings, my overall relationship is positive toward ...

\begin{tabular}{|l|l|l|l|l|l|}
\hline & $\begin{array}{l}\text { Strongly } \\
\text { Disagree }\end{array}$ & Disagree & Agree & $\begin{array}{l}\text { Strongly } \\
\text { Agree }\end{array}$ & $\begin{array}{l}\text { Not } \\
\text { Applicable }\end{array}$ \\
\hline $\begin{array}{l}\text { Nonpublic School Para- } \\
\text { Professional or Aide }\end{array}$ & & & & & \\
\hline $\begin{array}{l}\text { Nonpublic School Administrator } \\
\text { (e.g., Principal, Program Specialist) }\end{array}$ & & & & & \\
\hline $\begin{array}{l}\text { Nonpublic School Special } \\
\text { Education Teacher }\end{array}$ & & & & & \\
\hline $\begin{array}{l}\text { Nonpublic School Service Provider } \\
\text { (Speech/Psych/OT/PT) }\end{array}$ & & & & & \\
\hline District Administrator & & & & & \\
\hline District Special Education Teacher & & & & & \\
\hline $\begin{array}{l}\text { District Service Provider } \\
\text { (Speech/Psych/OT/PT) }\end{array}$ & & & & & \\
\hline
\end{tabular}

\section{Conflict}

Directions: The following questions will ask about any conflict during IEP meetings at nonpublic schools. Please answer the following questions based on your perspectives from all IEP meetings you have attended at your nonpublic school and prior to the COVID-19 school shut down.

41. Have you ever experienced conflict during an IEP meeting?

- Yes

- No-skip questions 41,42 , and 43

42. Who was the conflict with during the IEP meeting (select all that apply)?

- Nonpublic school administrator

- Nonpublic school special education teacher 
- Nonpublic school staff

- Nonpublic school service provider (e.g., speech, OT, psych, PT)

- District administrator

- District special education teacher

- District service provider (e.g., Speech, OT, Psych, PT)

- Other, please specify:

43. What type(s) of conflict have you experienced with during the IEP meeting with nonpublic school staff (Select all that apply)?

- Disagreement over IEP content

- Disagreement over curriculum or instruction approach

- Disagreement over school placement

- Disagreement over eligibility

- Disagreement over services

- Disagreement over evaluation results

- Disagreement over discipline issues

- Personality or style conflicts

- Difficulty getting cooperation with outside services

- No conflict

- Other, please specify:

44. What type(s) of conflict have you experienced with district staff during the IEP meetings at nonpublic schools (Select all that apply)?

- Disagreement over IEP content

- Disagreement over curriculum or instruction approach

- Disagreement over placement decisions

- Disagreement over eligibility

- Disagreement over evaluation results

- Disagreement over discipline issues

- Personality or style conflicts

- Difficulty getting cooperation with outside services

- No conflict

- Other, please specify:

\section{During Virtual Learning}

Explanation: The next section will ask questions about your perspectives of IEP meetings at nonpublic schools. Please answer the questions in this part of the survey based on your IEP meeting experiences AFTER the COVID-19 shut down and DURING virtual learning.

45. Have you had an IEP meeting during virtual learning?

- Yes

- No-If No, skip to question 55

- I am not sure - If I am not sure, skip to question 55

46. My level of involvement in IEP meetings during distance learning (Select a rating from 1 to 4$)$.

- 1

2 
- Not Involved At All

Involved As Much As I Should Be

47. I have felt more involved at IEP meetings, at my student nonpublic school, during virtual learning, than I felt prior to to virtual learning.

\begin{tabular}{|l|l|l|l|}
\hline Strongly Agree & Agree & Disagree & Strongly Disagree \\
\hline
\end{tabular}

48. Rate your nonpublic school staff's level of communication, during IEP meetings during virtual learning (Select a rating from 1 to 4 ).
- 1
2
3
4
- No Communication with Me
As Much Communication As I Need

49. I have received more communication about my student's IEP at the nonpublic school, during virtual learning, than I received prior to virtual learning.

\begin{tabular}{|c|c|c|}
\hline Strongly Agree & Agree & \\
\hline
\end{tabular}

50. Rate your relationship with nonpublic school staff, during IEP meetings during virtual learning (Select a rating from 1 to 4 ).

1

2

- No relationship
3
4

Best Relationship Possible.

51. I feel IEP team members maintain positive relations with me during IEP meetings, during virtual learning.

\begin{tabular}{|l|l|l|l|}
\hline Strongly Agree & Agree & Disagree & Strongly Disagree \\
\hline
\end{tabular}

\section{Additional Questions}

Directions: The following questions will ask you to provide additional information about your experiences during IEP meetings at nonpublic schools. Please provide as much information as possible.

52. What can school districts or nonpublic schools do to improve the involvement of parents, parent-educator relationships, and communication during the IEP meeting?

\section{Interview Option}

Directions: After the completion of this study, the research may contact a few parents for additional information about their experiences at IEP meetings at nonpublic schools. Please complete the following section, indicating whether you would like to participate in further interviews about this topic.

53. If you would like to discuss this topic further by being interviewed by the researcher, please provide your preferred contact method below (Telephone, email)? Contact information will remain confidential and will be solely used to contact interview participants.

\section{Raffle Participation}


Thank you for completing the survey! If you would like to participate in the Amazon gift card raffle please use the link below to provide your email address. Three emails will be selected at random. Winners will receive a digital Amazon gift card for $\$ 15$.

https://forms.gle/5d6UNwsARcsPSj3t7 


\section{Appendix E. Interview Protocol}

\section{Involvement}

1. In your survey, you rated your level of involvement at a __ on a scale from one to four, one being Not Involved At All and four being Involved As Much As I Should Be.

a. Tell me why you select this rating?

b. Can you describe your involvement in the IEP process?

c. Can you describe your involvement in the IEP meeting itself?

d. Can you tell me how, if, at all, others such as teachers, administrators, service providers involve you in the meeting? (follow-up for more specific information on who and how).

e. Can you describe any other ways the team can involve you in the meeting?

2. You indicated that there had been times when you have not felt involved. Can you tell me why you felt you were not involved?

a. Can you describe instances where you felt involved?

b. Can you describe instances where you felt involved? Did the team members do anything to make you feel this way?

\section{Communication}

3. In your survey, you rated your nonpublic school's staffs level of communication at a on a scale from one to four, one being No Communication With Me and four being As Much Communication As I Need.

a. Can you tell me more about why you selected this rating?

b. Can you provide an example of things staff did or didn't do that made you feel this way?

c. Can you describe how the IEP team members could improve your ratings of level of communication?

\section{Parent Educator Relationships}

4. In your survey, you rated your relationship with nonpublic school staff at a __ on a scale from one to four, one being No Relationships and four being Best Relationship Possible

a. Can you tell me why you selected this rating?

b. Can you provide an example of things staff did or didn't do that made you feel this way?

c. Can you describe what would improve your relationship with nonpublic school staff?

d. Can you describe what would improve your relationship with school district staff?

e. Is there a difference between your relationships with nonpublic school staff and school district staff?

i. Can you describe the differences you have noticed?

\section{Conflict}

5. Can you describe any experiences you have had with conflict during IEP meetings at non-public schools?

a. Can you tell me about ways you think conflict could have been avoided? 


\section{Appendix F. Nonpublic School Site Approval}

[NONPUBLIC SCHOOL SITE'S LETTERHEAD]

[DATE]

Chapman University Institutional Review Board (CUIRB)

One University Drive

Orange, CA 92866

RE: Alex Huynen, M.A.Ed.

Amy Griffith, Ph.D.

Special Education Parent Perceptions of Involvement and Parent-Educator Relationships during IEP Meetings at Nonpublic Schools

To CUIRB:

This letter is to convey that I/we have reviewed the proposed research study being conducted by Alex Huynen, intended to investigate parent perspectives about IEP involvement and parenteducator relationships during the IEP meeting, while their student attends a nonpublic school at [INSERT NAME OF NONPUBLIC SCHOOL] and find Special Education Parent Perceptions of Involvement and Parent-Educator Relationships during IEP Meetings at Nonpublic Schools acceptable. I/we give permission for the above investigators to conduct research at this site. If you have any questions regarding site permission, please contact: [INSERT TELEPHONE NUMBER OR CONTACT INFORMATION].

Sincerely,

[INSERT AUTHORIZED AGENT'S NAME (E.G., SCHOOL PRINCIPAL, DIRECTOR, ETC.]

[INSERT TITLE] 


\section{Appendix G. Parent Survey Recruitment and Reminder Email}

\section{Parent Recruitment Email \\ Dear Parent/Guardian,}

I am a graduate student, and school psychologist conducting a research study on parent perceptions of IEP meetings at nonpublic schools and would like your input. Your input is important in understanding parent-school relationships with the goal of improving the IEP process. Those who participate will have the option to enter a raffle for one of three \$15 Amazon gift cards.

Participation involves completing a 15-20 minute survey about your perceptions of involvement and parent-school relationships during IEP meetings at nonpublic schools.

If you are interested, please use the link below to complete the survey. More information about the survey is provided using the link below. All information you provide will be confidential.

Your participation in this research is voluntary and not required. This research is being conducted by a student at Chapman University and is not directly connected to your school.

If you have any questions, please let me know.

Please use the link below to complete the survey.

[Link]

Alex Huynen, M.A.Ed.

xxxxx@chapman.edu

\section{Reminder Email}

Dear Parents,

This is a reminder that two weeks ago, we sent you a survey link via email. The survey will be available for you to complete until [date survey is no longer available]. If you have already completed the survey, we thank you for your time. If you have not completed the survey, we would greatly appreciate any input you could provide. Your input will help your student's schools and other nonpublic schools.

Remember, all those who participate are able to enter an Amazon gift card raffle.

If you have any questions, you may contact me at huynen@chapman.edu. [Link]

Thank you,

Alex Huynen, M.A.Ed.

xxxxx@chapman.edu 


\section{Appendix H. Survey Adult Informed Consent to Participate in}

\section{Research}

\section{Title of Study:}

Special Education Parent Perceptions of Involvement and Parent-Educator Relationships during IEP Meetings at Nonpublic Schools

\section{Members of the Research Team}

Student Researcher: Alex Huynen, M.A.Ed. $\quad$ Email: xxxxx@chapman.edu

Lead Researcher: Meghan Cosier

Email: xxxxx@chapman.edu

\section{Key Information}

You are being asked to take part in a research study. Research studies include only people who choose to take part. The details for the research study are provided below, and if you have any questions, a research team member will answer any questions you may have. You should take your time to decide whether or not you want to participate.

If you agree to participate in this study, the project will involve:

- Male and female parents of a child in special education who is currently attending a nonpublic school. Parents can be of any age over 18 years.

- Procedures will include a 20-minute online survey.

- There are some risks associated with this study that exceed what would typically be encountered in daily life. There is a risk of possible emotional and/or psychological distress because the surveys involve sensitive questions about your experiences during IEP meetings.

- You will be not be paid to participate in the study but will be able to participate in a raffle.

- You will be provided a copy of this consent form upon request. Please email the student researcher for a copy of the consent form.

\section{Invitation}

You are invited to take part in this research study. The information in this form is meant to help you decide whether or not to participate. If you have any questions, please email the student researcher.

\section{Why are you being asked to be in this research study?}

You are being asked to be in this study because you are a parent of a child currently attending a nonpublic school. This study is looking for parents of students who are in special education and are currently attending a nonpublic school. Parents should have attended at least two IEP meetings at a nonpublic school.

\section{What is the reason for doing this research study?}

Parents of children at a nonpublic school have a unique perspective of IEP meetings due to their student's educational placement. This research is designed to better understand parents' 
perspectives of parent involvement and the parent-educator relationship during IEP meetings.

\section{What will be done during this research study?}

You will be asked to complete one surveys using an internet-based questionnaire that ask questions about demographics and parent perspectives about their involvement, communication, relationship with educators, and conflict during IEP meetings. The survey will take 15-20 minutes to complete, and you may complete it from your home computer.

\section{How will my data be used?}

Your survey data will not be sent to researchers outside of Chapman University. Any personal information that could identify you will be removed before being shared with anyone outside the research team. If you provide contact information to participate in future interviews, your contact information will be removed and stored separately. Contact information will be used solely for contact purposes and will not be linked to survey data.

\section{What are the possible risks of being in this research study?}

As with any study involving the collection of data, there is the possibility of breach of confidentiality of data. This risk will be minimized within the collection process by making sure all data are de-identified. Other risks in this research include possible emotional and/or psychological distress because the surveys involve sensitive questions about your perspectives of involvement and the parent-educator relationship during IEP meetings.

It is possible that other rare side effects could occur that are not described in this consent form. It is also possible that you could have a side effect that has not occurred before.

\section{What are the possible benefits to you?}

You may receive intrinsic benefits by participating in this study. You may experience the enjoyment of helping contribute to the purpose of the study and helping to provide information to the field. However, you may not get any benefit from being in this research study.

\section{What are the possible benefits to other people?}

The benefits to science and/or society may include a better understanding of parent perspectives during IEP meetings at nonpublic schools. Educators may benefit from the information gathered. Data collected could help educators better understand parents' views during IEP meetings at nonpublic schools.

\section{What will participating in this research study cost you?}

There is no cost for you to be in this research study.

\section{Will you be compensated for being in this research study?}

Those who wish to be included in a raffle will have the option to provide their email address at the end of the survey. No purchase is necessary to participate in the raffle. Completion of the survey is not necessary to participate in the raffle. Participants do not have to provide their email addresses if they do not want to participate in the raffle. Raffle prizes will include three \$15 Amazon gift cards. No other compensation will be provided. 


\section{What should you do if you have a problem during this research study?}

Your welfare is the major concern of every member of the research team. If you have a problem as a direct result of being in this study, you should immediately contact one of the people listed at the beginning of this consent form.

\section{How will information about you be protected?}

Reasonable steps will be taken to protect your privacy and the confidentiality of your study data. The data will be stored electronically through a secure server and will only be seen by the research team during the study and for ten years after the study is complete.

The only people who will have access to your research records are the members of the research team, the Institutional Review Board (IRB), and any other person, agency, or sponsor as required by law. Information from this study may be published in scientific journals or presented at scientific meetings, but the data will be reported as a group or summarized data, and your identity will be kept strictly confidential.

\section{What are your rights as a research subject?}

You may ask any questions about this research and have those questions answered before agreeing to participate in the study or during the study.

For study-related questions, please contact the investigator(s) listed at the beginning of this form.

For questions concerning your rights or complaints about the research, contact the Institutional Review Board (IRB) at (714) 628-2833 or irb@ chapman.edu.

\section{What will happen if you decide not to be in this research study or decide to stop participating once you start?}

You can decide not to be in this research study, or you can stop being in this research study (e.g., "withdraw") at any time before, during, or after the research begins for any reason. Deciding not to be in this research study or deciding to withdraw will not affect your relationship with the investigator, with Chapman University, or with your nonpublic school. You will not lose any benefits to which you are entitled.

\section{Documentation of Informed Consent}

You are voluntarily deciding whether or not to be in this research study. Marking 'Yes' on this form means that (1) you have read and understood the consent form, (2) you understand the study, (3) you have had your questions answered, and (4) you have decided to be in the research study.
- Yes - I consent
- No - I do not consent 


\section{Appendix I. Interview Adult Informed Consent to Participant in}

\section{Research}

Title of Study:

Special Education Parent Perceptions of Involvement and Parent-Educator Relationships during IEP Meetings at Nonpublic Schools

Members of the Research Team

Student Researcher: Alex Huynen, M.A.Ed. $\quad$ Email: xxxxx@chapman.edu

Lead Researcher: Meghan Cosier $\quad$ Email: xxxxx@chapman.edu

\section{Key Information}

You are being asked to take part in a research study. Research studies include only people who choose to take part. A member of the research team will explain the study to you and will answer any questions you might have. You should take your time to decide whether or not you want to participate.

If you agree to participate in this study, the project will involve:

- Male and female parents of a child in special education who is currently attending a nonpublic school. Parents can be of any age over 18 years.

- Procedures will include one 30-45 minutes interview. The interview will be conducted over the phone or via video call. Audio of the interview will be recorded with your consent.

- There are some risks associated with this study that exceed what would typically be encountered in daily life. There is a risk of possible emotional and/or psychological distress because the interview involves sensitive questions about your experiences during IEP meetings.

- You will not be paid to participate in the study.

- You will be provided a copy of this consent form upon request. Please email the student researcher for a copy of the consent form.

\section{Invitation}

You are invited to take part in this research study. The information in this form is meant to help you decide whether or not to participate. If you have any questions, please ask.

\section{Why are you being asked to be in this research study?}

You are being asked to be in this study because you are a parent of a child currently attending a nonpublic school. This study is looking for parents of students who are in special education and are currently attending a nonpublic school. Parents should have attended at least two IEP meetings at a nonpublic school.

\section{What is the reason for doing this research study?}

Parents of children at a nonpublic school have a unique perspective of IEP meetings due to their student's educational placement. This research is designed to better understand parents' perspectives of parent involvement and the parent-educator relationship during IEP meetings. 
What will be done during this research study?

You will be asked to complete one 30-45 minute interview on the phone or through a video call. The semistructured interview will ask questions about parent perspectives about their involvement, communication, relationship with educators, and conflict during IEP meetings

How will my data be used?

Your interview data will not be sent to researchers outside of Chapman University. Pseudonyms will be used for all interview participants. Any additional identifiable information will be removed before being shared with anyone outside the research team.

What are the possible risks of being in this research study?

As with any study involving the collection of data, there is the possibility of breach of confidentiality of data. This risk will be minimized within the collection process by making sure all data are de-identified. Other risks in this research include possible emotional and/or psychological distress because the surveys involve sensitive questions about your perspectives of involvement and the parent-educator relationship during IEP meetings.

It is possible that other rare side effects could occur that are not described in this consent form. It is also possible that you could have a side effect that has not occurred before.

\section{What are the possible benefits to you?}

You may receive intrinsic benefits by participating in this study. You may experience the enjoyment of helping contribute to the purpose of the study and helping to provide information to the field. However, you may not get any benefit from being in this research study.

\section{What are the possible benefits to other people?}

The benefits to science and/or society may include a better understanding of parent perspectives during IEP meetings at nonpublic schools. Educators may benefit from the information gathered. Data collected could help educators better understand parents' views during IEP meetings at nonpublic schools.

What are the alternatives to being in this research study?

Instead of being in this research study you can choose not to participate.

\section{What will participating in this research study cost you?}

Other than the time set aside for the interview, there is no cost to you to be in this research study.

Will you be compensated for being in this research study?

You will not be compensated for your participation in this research study.

What should you do if you have a problem during this research study?

Your welfare is the major concern of every member of the research team. If you have a problem as a direct result of being in this study, you should immediately contact one of the people listed at the beginning of this consent form. 


\section{How will information about you be protected?}

Reasonable steps will be taken to protect your privacy and the confidentiality of your study data. The data will be stored electronically through a secure server and will only be seen by the research team during the study and for ten years after the study is complete.

The only people who will have access to your research records are the members of the research team, the Institutional Review Board (IRB), and any other person, agency, or sponsor as required by law. Information from this study may be published in scientific journals or presented at scientific meetings, but the data will be reported as a group or summarized data, and your identity will be kept strictly confidential. We cannot guarantee total privacy. Please note that all Chapman University employees are required to report any known or suspected abuse of children or minors to appropriate authorities.

\section{What are your rights as a research subject?}

You may ask any questions about this research and have those questions answered before agreeing to participate in the study or during the study.

For study related questions, please contact the investigator(s) listed at the beginning of this form.

For questions concerning your rights or complaints about the research, contact the Institutional Review Board (IRB) at (714) 628-2833 or irb@chapman.edu.

\section{What will happen if you decide not to be in this research study or decide to stop participating once you start?}

You can decide not to be in this research study, or you can stop being in this research study (e.g., "withdraw") at any time before, during, or after the research begins for any reason. Deciding not to be in this research study or deciding to withdraw will not affect your relationship with the investigator or with Chapman University [list others as applicable]. You will not lose any benefits to which you are entitled.

\section{Documentation of informed consent}

You are voluntarily deciding whether or not to be in this research study. Signing this form means that (a) you have read and understood this consent form, (b) you have had the consent form explained to you, (c) you have had your questions answered, and (d) you have decided to be in the research study. You will be given a copy of this consent form to keep.

\section{Printed Name of Participant or Legal Guardian}




\begin{tabular}{l} 
AUDIO RECORDING: \\
I have received an adequate description of the purpose and procedures for audio recording \\
sessions during the course of the proposed research. I give my consent to allow myself to be \\
audio recorded during participation in this study and for those records to be reviewed by persons \\
involved in the study, as well as for other professional purposes as described to me. \\
Yes, I agree to allow the research team to audio record my interview(s). \\
No, I do not wish to have my interview(s) audio recorded. \\
\hline Signature of Participant or Legal Guardian
\end{tabular}

\section{Investigator certification:}

My signature certifies that all elements of informed consent described on this consent form have been explained fully to the subject. In my judgment, the participant possesses the capacity to give informed consent to participate in this research and is voluntarily and knowingly giving informed consent to participate.

Signature of Person Obtaining Consent

Date 